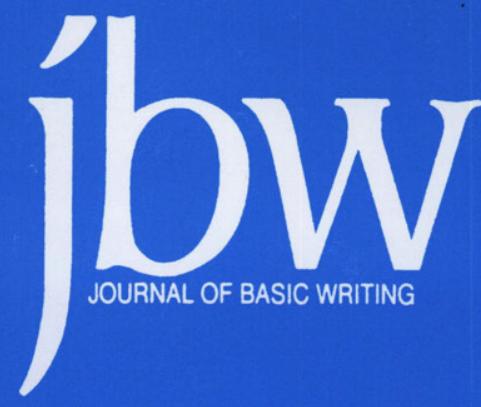

\title{
SPRING 2003
}

VOLUME 22 NUMBER 1

Serving Basic Writers: One Community College's Mission Statements Sallyanne H. Fitzgerald

Refocus through Involvement: (Re)Writing the Curricular Documents of the University of Minnesota-General College Basic Writing Program

Tom Reynolds and Patty Fillipi

Creating a Statement of Guidelines and Goals for Boise State University's Basic Writing Course:

Content and Development

Karen S. Uehling

A Developmental Perspective on the Relationship between Grammar and Text James Kenkel and Robert Yates

Nonacademic Professionals' Perception of Usage Errors Loretta S. Gray and Paula Heuser

Rethinking the Basic Writing Frontier: Native American Students' Challenge to Our Histories

Laura Gray-Rosendale, Loyola K. Bird, and Judith F. Bullock 

ISSN 0147-1635

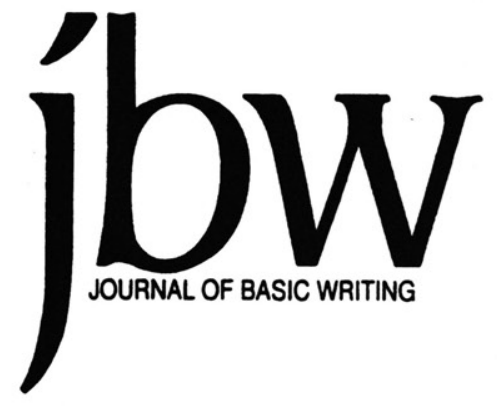

VOLUME 22 NUMBER 1 SPRING 2003

The Journal of Basic Writing publishes articles of theory, research, and teaching practices related to basic writing. Articles are refereed by members of the Editorial Board (see overleaf) and the Editors.

\title{
Bonne August and Rebecca Mlynarczyk
}

Editors

\section{Mikhail Gershovich and Rhona Cohen Editorial Assistants}

\section{Mary E. Carney, Subscriptions}

The Journal of Basic Writing is published twice a year, in the spring and fall. We welcome unsolicited manuscripts and ask authors to consult the detailed "Call for Articles" in this issue. Subscriptions for individuals are $\$ 15.00$ for one year and $\$ 28.00$ for two years; subscriptions for institutions are $\$ 20.00$ for one year and $\$ 38.00$ for two years. Foreign postage is $\$ 5.00$ extra per year. ADDRESS:

\author{
Journal of Basic Writing \\ City University of New York \\ 555 West 57 Street, Room 1601 \\ New York, NY 10019
}




\section{JOURNAL OF BASIC WRITING}

\section{EDITORIAL BOARD}

Linda Adler-Kassner

Eastern Michigan University

Chris M. Anson

North Carolina State University

David Bartholomae

University of Pittsburgh

Sarah Benesch

College of Staten Island, CUNY

Patricia Bizzell

College of the Holy Cross

Lynn Z. Bloom

University of Connecticut, Storrs

\section{Gay Brookes}

Borough of Manhattan Community

College,CUNY

Richard Courage

Westchester Community

College,SUNY

Martha Clark Cummings

The University of Aizu, Japan

Donald A. Daiker

Miami University

Suellynn Duffey

Georgia Southern University

Sarah Warshauer Freedman

University of California, Berkeley

Keith Gilyard

Pennsylvania State University

Gregory Glau

Arizona State University

Laura Gray-Rosendale

Northern Arizona University

Karen Greenberg

Hunter College, CUNY

Brenda Greene

Medgar Evers College, CUNY

Myra Kogen

Brooklyn College, CUNY

Patricia O. Laurence

City College, CUNY

Elaine O. Lees

Carlow Hill College
Andrea Lunsford

Stanford University

Jane Maher

Nassau Community College, SUNY

Susan Miller

University of Utah

Sandra Murphy

University of California, Davis

Deborah Mutnick

Long Island University

Nathaniel Norment, Jr.

Temple University

George Otte

Graduate Center, CUNY

Hope Parisi

Kingsborough Community College, CUNY

Elizabeth Rorschach

City College, CUNY

Charles I. Schuster

University of Wisconsin, Milwaukee

Tony Silva

Purdue University

Trudy Smoke

Hunter College, CUNY

Ruth Spack

Bentley College

Lynn Quitman Troyka

Queensborough Community

College, CUNY, ret.

Karen S. Uehling

Boise State University

Evelyn E. Webb

Mississippi State Board for

Community and Junior Colleges

Harvey Wiener

LaGuardia Community College,

CUNY, emeritus

Vivian Zamel

University of Massachusetts,

Boston 


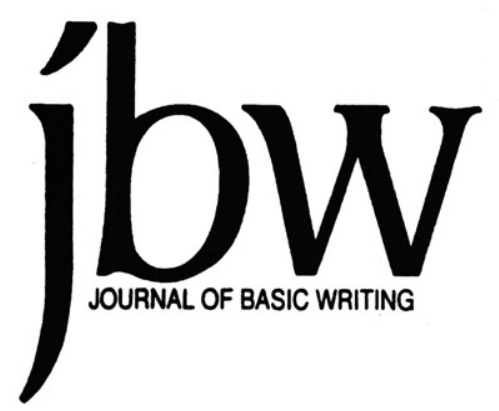

VOLUME 22

Developing Statements of Guidelines and Goals

for Basic Writing Programs: A Cluster -- Introduction

Serving Basic Writers:

One Community College's Mission Statements

Sallyanne H. Fitzgerald

Refocus through Involvement:

(Re)Writing the Curricular Documents of the University of Minnesota-General College Basic Writing Program

Tom Reynolds and Patty Fillipi

Creating a Statement of Guidelines and Goals for

Boise State University's Basic Writing Course:

Content and Development

Karen S. Uehling

A Developmental Perspective

on the Relationship between Grammar and Text

James Kenkel and Robert Yates

Nonacademic Professionals' Perception of Usage Errors

Rethinking the Basic Writing Frontier:

Native American Students' Challenge to Our Histories

Laura Gray-Rosendale, Loyola K. Bird, and Judith F. Bullock

News and Announcements 


\title{
CALL FOR ARTICLES
}

We welcome manuscripts of $10-20$ pages on topics related to basic and ESL writing, broadly interpreted. Manuscripts will be refereed anonymously. We require five copies of a manuscript and an abstract of about 100 words. To assure impartial review, give author information and a short biographical note for publication on the cover page only. Papers which are accepted will eventually have to supply camera-ready copy for all ancillary material (tables, charts, etc.). One copy of each manuscript not accepted for publication will be returned to the author, if we receive sufficient stamps (no meter strips) clipped to a self-addressed envelope. Submissions should follow current MLA guidelines. Manuscript submissions should be mailed to:

\author{
Professors Bonne August and Rebecca Mlynarczyk \\ Co-Editors, JBW \\ Department of English \\ Kingsborough Community College \\ 2001 Oriental Blvd. \\ Brooklyn, NY 11235
}

All manuscripts must focus clearly on basic writing and must add substantively to the existing literature. We seek manuscripts that are original, stimulating, wellgrounded in theory, and clearly related to practice. Work that reiterates what is known or work previously published will not be considered.

We invite authors to write about such matters as classroom practices in relation to basic-writing or second-language theory; cognitive and rhetorical theories and their relation to basic writing; social, psychological, and cultural implications of literacy; discourse theory, grammar, spelling, and error analysis; linguistics; computers and new technologies in basic writing; assessment and evaluation; writing center practices; teaching logs and the development of new methodologies; and cross-disciplinary studies combining basic writing with psychology, anthropology, journalism, and art. We publish observational studies as well as theoretical discussions on relationships between basic writing and reading, or the study of literature, or speech, or listening. The term "basic writer" is used with wide diversity today, sometimes referring to a student from a highly oral tradition with little experience in writing academic discourse, and sometimes referring to a student whose academic writing is fluent but otherwise deficient. To help readers therefore, authors should describe clearly the student population which they are discussing.

We particularly encourage a variety of manuscripts: speculative discussions which venture fresh interpretations; essays which draw heavily on student writing as supportive evidence for new observations; research reports, written in non-technical language, which offer observations previously unknown or unsubstantiated; and collaborative writings which provocatively debate more than one side of a central controversy. 


\section{EDITORS' COLUMN}

Modulation - the dynamic process through which theory shapes practice and practice refines theory-is a constant preoccupation in composition at every level from the global to the individual classroom. In The Testing Trap: How State Writing Assessments Control Learning (New York: Teachers College Press, 2002), George Hillocks carefully situates his critical study in the theories of writing implicit in these mandated assessments. Hillocks states: "The research and theory suggest that when teachers adopt a rhetorical stance, they also commit to a theory of knowledge and to the theory of teaching implied in its assumption." (21). Hillocks is explicitly following James Berlin, who in "Contemporary Composition: The Major Pedagogical Theories" (College English 44: 765-77), writes: "The test of one's competence as a composition instructor ... resides in being able to recognize and justify the version of the process being taught, complete with all its significance to the student."

Writing teachers rarely work in isolation; even in the absence of legislative mandates, we usually work in the context of an official "version of the process." The formal statements that writing programs compose and publish about themselves, therefore, are potentially powerful documents. This is true when the audience is external, but perhaps even more important when it is internal - when faculty define what is to be learned and how and why, to their students and to themselves. The cluster of articles that opens this issue, on Guidelines and Goals for Basic Writing programs, continues a discussion begun as a panel at the CCCC in Chicago in March of 2002. Sallyanne Fitgerald, Tom Reynolds and Patti Fillipi, and Karen Uehling describe the process of constructing, or reconstructing, such documents at their respective institutions - a California community college, an alternative college program of a mid-western state university, and a six-year western state university. In each piece the authors situate their work in multiple contexts - the mission statement governing their institution, the characteristics of the student population, and the theory influencing their pedagogy. The authors have appended samples of their documents.

The present moment seems to be a particularly critical time for this discussion about constructing collective versions of the process of teaching writing. The theory informing basic writing programs, although widely shared, is surely not uncontested. At the same time, documents elucidating goals and basic assumptions need to address site specific student populations and institutional characteristics and conditions. Many institutions are seeing changes in their traditional student populations, while something of a generation shift is occurring among the faculty. The three examples printed here reflect some 
of those issues and also reflect varying political stances.

The perspective narrows somewhat in two articles on "mechanics," specifically grammar and error. These are two of the particulars most problematic in attempts to explain composition theory to external audiences; however, they account for substantial disagreement within the profession, as well. In "A Developmental Perspective on the Relationship between Grammar and Text," James Kenkel and Robert Yates propose an approach to addressing specific constructions in student writing not as simple surface errors but as "innovative and purposeful attempts" by student writers to meet readers' needs for topic management, reference, or information-sequencing. The authors argue for assignments that generate these needs by requiring students to shift topics or focus, and they advocate explicit comparisons between the students' strategies and those used by mature writers.

Loretta S. Gray and Paula Heuser in "Nonacademic Professionals' Perception of Usage Errors" describe a research project that studies whether these perceptions have changed since Maxine Hairston's well-known 1981 study. Gray and Heuser find their readers more tolerant than Hairston's; nevertheless, as in Hairston's study, the errors most troubling to nonacademic readers, and therefore most stigmatizing, were those reflecting features of dialect. Now, as then, the implications remain troublesome: to what extent is it necessary or desirable for students to be able to produce "Edited American English," and if it is deemed necessary or desirable, how is this learning best accomplished?

In the final article in this issue, "Rethinking the Basic Writing Frontier: Native American Students' Challenge to Our Histories," Laura Gray-Rosendale, Loyola K. Bird, and Judith F. Bullock argue on behalf of a particular group of basic writing students. In addition to a vivid, multi-faceted account of what native American students bring to basic writing and to the university and how they respond to what they find there, the authors issue a powerful critique of the standard narratives the "authorized versions" - of basic writing as a field.

Finally, a flurry of hails and farewells is in order. Rebecca Mlynarczyk joins JBWas co-editor with this issue. Having taught basic and ESL writing at the City University of New York since 1974, Rebecca is strongly committed to developmental education as a way of providing opportunities to students whose previous education has not prepared them to succeed in college. Professor of English at Kingsborough Community College, she not only teaches basic reading and writing but also works as a program administrator in these fields. Her research interests include the journal writing of ESL students, teacher research, teachers' professional development, and learning community programs.

With this issue, too, the Editorial Board reflects a number of out- 
standing additions, as well as the retirement of some very active members. We express deep gratitude to those who are retiring, whose commitment to the field is equaled only by their thoughtful and generous responses to authors. We welcome the new members with a sense of excitement.

Several new members of the Board bring expertise in English as a Second Language. ESL and BW often overlap or exist in complementary relationships. $J B W$ has long acknowledged this fact in its Call for Articles, which invites submissions that address ESL perspectives on basic writing. As we announced in a prior issue, College ESL, in a sense a "sister" journal (like $J B W$ emanating from and supported by the City University of New York), is about to publish its final issue. JBW will provide a venue for some of the work that might have seen print there. We see this as a logical extension rather than a change in emphasis for $J B W$. As Gray-Rosendale, Bird, and Bullock remind us, the modulations of basic writing must continue. $J B W$, which has been the site of so much of the theory and history of the field, will modulate with it.

-- Bonne August and Rebecca Mynarczyk 


\section{DEVELOPING STATEMENTS OF GUIDELINES AND GOALS FOR BASIC WRITING PROGRAMS: A CLUSTER}

\section{Introduction}

Statements of guidelines and goals are critical documents in the academy. They articulate formally what faculty think is essential in programs and courses and make public the objectives and reasoning behind educational plans. Such documents have various uses. They represent programs to administrators, provide a basis for training teachers, and inform students and the wider public about the nature of programs. To create a statement of guidelines and goals, faculty must engage in considered thinking and discussion and reach consensus.

Statements of guidelines and goals can confer legitimacy on basic writing by providing self-definition. Such statements both describe what happens in classrooms and prescribe what should happen. Writers of these statements confront the interesting task of identifying what differentiates basic writing from freshman composition and what is common to both courses. Constructing a statement of guidelines and goals is a challenging rhetorical task because such statements address multiple audiences and are often composed and revised by several groups; further, such statements must articulate with other courses in the first-year writing sequence and writing program definitional statements, as well as institutional mission statements.

The cluster of three articles that follows originally formed a panel, "Mission Statements and Basic Writing" presented at the Conference of College Composition and Communication convention in Chicago, Illinois, March 2002, and chaired by Karen Uehling. Designed so that readers may compare the effects of local conditions, this cluster of articles will examine statements of guidelines and goals from three diverse institutions: Chabot College, a public community college in northern California; Boise State University, a six-year western urban state university, and the University of Minnesota-General College, an alternate college program of a Midwestern urban university. Each author helped to construct the statement on his or her campus. The statement documents are included with each article, and each author describes and explains the documents as well as the process of creation. We hope to open up a dialogue on this critical process.

-- Karen S. Uehling 


\section{Sallyanne H. Fitzgerald}

\section{SERVING BASIC WRITERS: ONE COMMUNITY COLLEGE'S MISSION STATEMENTS}

ABSTRACT: Various factors combined to move a California community college towards creating a mission statement for all their English courses and within that context, one for their basic writing courses. The context for the creation of the mission statement includes a commitment to basic writing as a legal mandate, but its final version is unique to the particular context of this college.

The legal guidelines governing the mission and much of what happens in the 108 California Community Colleges are delineated in Title V, part of the legal code of the state. That code explicitly mentions instruction in basic skills as one aspect of the mission of community colleges. The web site of the California Community College Chancellor's Office further illuminates the mission of the state's community colleges: "Primary missions of the Colleges are to offer academic and vocational education at the lower division level for both younger and older students, including those persons returning to school. Another primary mission is to advance Califomia's economic growth and global competitiveness through education, training, and services that contribute to continuous work force improvement. Essential and important functions of the Colleges include: remedial instruction for those in need of it and in conjunction with the school districts, instruction in English as a second language, adult noncredit instruction, and support services which help students succeed at the postsecondary level. Community Services is designated as an authorized function."

Since their mission is set by the legal mandate in Title V, the mis-

Sally Fitzgerald has been involved in teaching and researching basic writing since she began her higher education career at the University of Missouri-Saint Louis as a basic writing teacher. She received her doctorate from UM-St. Louis with a dissertation on basic writers and one-to-one conferences with teachers. She has published two basic writing textbooks and numerous articles. Most recently, she was the associate editor of a collection of essays concerning mainstreaming basic writers. She has served as the co-chair of the Conference on Basic Writing and chaired three national basic writing conferences. Formerly Dean of the Language Arts and Humanities Division of Chabot College, she is now Vice President of Instruction at Napa Valley College, a California community college. She is the California representative to the Two-Year College English Association of NCTE. 
sion statements adopted by the colleges vary little from campus to campus. Moreover, because Title $\mathrm{V}$ requires California community colleges to provide basic skills for students and the Chancellor's Office mentions remedial education, English teachers at Chabot College, like those at the other California community colleges, accept the validity of offering basic writing. The most recent version of the mission statement of Chabot College reflects this congruence: "Chabot College is a comprehensive community college that provides quality educational opportunities to all individuals who seek to enhance their knowledge and to improve their skills. The College offers both traditional and non-traditional methods of learning and student support services and activities that foster student success and enrichment. The College provides resources and programs that help students develop a sense of civic and social responsibility and commitment to life-long learning."

To accomplish this mission, the College provides the following academic programs:

- Technical and career-vocational education programs

- Transfer education programs to four-year universities

- General Education

- Basic Skills instruction

- English as a Second Language programs

- Community and Continuing Education programs

Although Californians accept the need, based on the community college mission, to offer basic writing courses, programs reflect differing opinions about how to offer basic writing and what should be included in a basic writing course. Indeed, across the state, basic writing courses range from word or sentence level courses to those requiring students to write full-length, documented, argumentative essays. The courses at Chabot College aim towards this latter goal.

Chabot College, a medium-sized, California community college with over 15,000 students, usually finds about $70 \%$ of its students have placed into one or more basic writing courses. Located in the San Francisco Bay area, Chabot is representative of the diversity of many California community colleges, with about $32 \%$ of the students being white and $56 \%$ being female in 2002-2003. Almost all students work full or part time, and the median age is 22 , younger than the median age in most California community colleges. Students transfer from Chabot to the University of California campuses, the California State University campuses, and many local, private four-year colleges.

In this context and to fulfill the mission of the college with regard to basic skills instruction, during the early 1990s, Chabot College English faculty created a basic writing, two-course sequence that pre- 
ceded freshman composition. To further delineate the mission of the college to provide basic skills instruction, the faculty developed a mission statement for all English courses and, within that broader mission, a statement for the basic writing sequence.

When I arrived at Chabot College in January 1993, I discovered that four things had happened simultaneously in order to create conditions that resulted in a basic writing mission statement:

- Institutional research had revealed that the basic reading and basic writing centers were not preparing students for success in transfer level courses.

- The college had been awarded a Title III grant which required integrating the basic reading and writing centers into one center.

- The college calendar was moving from quarters to semesters, and so all courses were being re-written for the new configuration.

- Long-term faculty members who had been involved in the original curriculum were retiring and newly trained faculty were replacing them.

During the first decades of the college, the faculty at Chabot had created two centers, the Reading Center and the Writing Center, implementing what were regarded at the time as very innovative strategies. The approach consisted of "courses" based on a mastery-learning model. Depending upon their needs, students might take both the reading and the writing center courses, or they might take only reading or only writing. For reading, students tested into a series of basic reading courses based on a reading placement exam, initially the Nelson-Denny and then the Descriptive Test of Language Skills. In the Reading Center, students completed seven workbooks, moving from word attack skills in Workbook A to critical reading skills in Workbook G. When they finished the programmed materials, they earned credit for the courses. In the Writing Center, students created essays based on standard prompts with the assistance of a teacher. Because the students did not necessarily work with the same teacher on each essay, the teachers read each piece of writing looking for the following specific traits: an introduction with a thesis; body paragraphs with topic sentences developed with brief clarification and "specific, anecdotal examples"; and sentences with few "grammar" errors.

The courses were intended to prepare students for freshman composition; however, the centers appeared subtly to compete with one another, and so there was no formal collaboration between the two. Although the rhetorical modes introduced in the writing prompts might 
be similar to some readings, no attempt was made to help students think about the connections between reading and writing. Although in freshman composition, students were expected to be able both to read freshman level texts and to compose freshman compositions, the reading in the Reading Center did not directly relate to the writing produced in the Writing Center. Critical thinking was taught in a quarter course that followed the first and second quarters of freshman composition, and such a course was not required for transfer unless students were continuing at institutions that specifically required it. Even the research paper was a separate course that students only took for transfer to a few institutions.

Most faculty were not surprised when the institutional research indicated students were not succeeding in courses following the basic reading and writing courses and, thus, they were very open to a Title III grant to support innovation in all basic skills curricula. The first year of the Title III grant called for the development of a computerized writing lab, but the only staff member funded by the grant was a new computer technician for the lab. The instructional assistants (IAs) and the adjunct teachers who staffed the Reading Center and the Writing Center were going to find there was no work for them unless they became involved in the new computer lab. The faculty were reluctant to let technology dictate what should happen in the new center, and so they began to investigate what other community colleges were doing with computers. Two faculty members went to San Francisco State University to take a class, Teaching with Computers, and they taught workshops for English faculty, almost all of whom attended, on how to use the new equipment. The IAs became involved in the discussions and attended the computer workshops. Almost everyone became excited about the possibilities of the changes that Title III was making possible.

In the midst of investigating the possibilities for change provided by the use of computers and examining the lack of success in the existing basic writing sequence, the faculty also began re-writing curriculum to make quarter courses into semester ones. Faced with these complex and pressing issues, the English faculty decided to do more than just change the length of courses. Instead, they embarked on a sixmonth project to research basic writing and reading pedagogy. They began to meet weekly to discuss what they were learning, what they valued, and what they thought would work for Chabot students. Long philosophical discussions happened. Some rather heated arguments flared. In the end, the English faculty came together to draft two statements. Cindy Hicks, an English faculty member who advised on this article, explained what happened as the result of the work done in order to draft the mission statements: "The process of rewriting the curriculum created a feeling of support, mutual respect --even when 
we disagreed - and friendship among us. Makes for a very wonderful learning and work environment!"

A concrete result of the collaboration was a mission statement or statement of philosophy for all English courses, called the Throughline. A second, related, outcome was the Articulated Assumptions that serves as a statement of mission or philosophy for all basic writing courses. Because the legally mandated mission of the college is so broad, these more specific, content related statements may appear to be program goals rather than a mission statement, but such criticism ignores the mandated college mission where the only flexibility resides in the more clearly articulated mission as it is attached to a specific philosophy.

\section{Throughline for Chabot College English Subdivision}

English courses at all levels will:

1. Integrate reading, writing, critical thinking, speaking, and listening.

2. Address directly students' reading practices. Reading is critical to academic success, and we strive to include more reading, in terms of both range and depth, in our program.

3. Approach the teaching of writing by inviting students to write prose pieces of varying length and complexity. Writing is not taught in a progression from the sentence to the paragraph to the essay.

4. Emphasize critical thinking. Critical thinking is the creation of meaning. Critical thinking is not limited to concepts of formal logic but includes grouping items/seeing patterns, drawing inferences, evaluating for purpose, synthesis and argumentation, differentiating fact from opinion, asking questions, evaluating for standards of fairness and accuracy, and making judgments. Critical thinking is broad-based, including sensing, feeling and imagining.

5. Create settings which include speaking, listening and responding that foster the building of community and forge links to critical reading and writing. Teaching those skills sometimes needs to be explicit and directed. Activities may include student presentations (solo and group/panel); small- and large-group discussions in which students speak to each other and not only to the instructor; student/teacher conferences; interviews in the class or community. We also encourage listening skills that involve note taking and feedback/response.

6. Include full-length works, defined as any work that sustains themes, 
including a book of short essays by a single author. We suggest that the work(s) be integrated into the course thematically. On the pre-1A level, we recommend that non-fiction be used; that if fiction or autobiographical works are assigned, they be analyzed for issues and themes connected to other readings in the course rather than for literary aspects; that a combination of book-length works and short essays be used to provide a variety of models; and that students be asked for both personal and analytical responses.

7. Increase students' familiarity with and knowledge of the academic culture, themselves as learners, and the relationship of the two. Some ideas include: collaborative teaching and learning, using materials reflecting successful college experiences, acknowledging and validating the students' experiences while introducing them to academic culture and values, modeling academic values, and demystifying the institution.

Within the context of this broader English mission, the basic writing mission spells out the elements expected in those courses.

\section{Articulated Assumptions}

- The hierarchal model of English where skills proceed from words to sentences to paragraphs to essay structure is not favored in this division.

- The whole language approach, involving reading, writing, speaking and listening, is the desired approach for English courses.

- Students who improve their reading tend to improve their writing and vice-versa.

- Preparatory English students often lack student skills.

- We should offer preparatory English students the same kind of reading and writing experiences we offer English 52A/1A students.

- Readers should read for ideas and process units of meaning rather than focus on word-by-word reading.

- An active reading style is vital to improving reading comprehension.

- Some form of study reading method, such as SQ3R, should continue to be taught in these courses.

- Reading and writing will improve as students become aware of structure, especially the [consistent] movement of English from general to specific [or specific to general]. 
- Student essays should largely, if not always, be based upon a response to something the students have read.

- We do not generally favor students' expository essays being exclusively personal reflection.

- Students should be encouraged to write and revise preliminary drafts of substantial written work.

- Students improve their writing when peer groups engage in focused discussions.

- Students should provide self-evaluation of their written works.

- Many students who currently don't pass preparatory courses need more time reading, reasoning, writing critically and/or improving "studenting skills."

- Book-length works, fiction or non-fiction, should be included at all levels of our curriculum, including the preparatory level.

- Students completing 101B should be able to summarize, analyze, evaluate, and respond academically to what they read.

Beyond the Title III grant, the findings from institutional research, and the change in the calendar, a fourth factor made possible the creation of mission statements: faculty retired who had created the original curriculum, and newly trained faculty were hired. Since the college's early days with mastery learning and separate reading and writing centers, the world of composition theory had changed from being focused on product to focusing on process, but the curriculum had been slow to follow. Process theory in both reading and writing had flourished in the 1970s supported by the same theory in psychology, so those faculty who attended graduate school in the 1980s received training in it. In addition, the connection between reading and writing had begun to be explored in those graduate programs and by innovative faculty. Finally, the UC and CSU campuses began demanding that courses they accepted for transfer in the early 1990s have an explicit goal of critical thinking. The newly trained faculty were familiar with the idea of explicitly training students to think critically, and their recent training in theory contributed greatly to the English Department's discussions about pedagogy and to the rewriting of the Chabot English curriculum.

From these four factors came a basic writing curriculum that mirrors the demands of the transferable freshman composition courses. The faculty created a two-course sequence of basic writing where students write essays from the very beginning of the courses and concentrate on using text to support an argument. They begin with summaries and research based on the reader chosen by the teacher in the first 
course, and by the end of the second one, they are using both primary and secondary sources to develop extended arguments. They read full-length non-fiction texts in each class as well as a reader that concentrates on non-fiction. All of the writing assignments are tied to readings. Students learn about grammar in the context of their own writing and discuss topics in small and large groups in order to reinforce the connections among all the language arts --reading, writing, speaking, listening, and thinking. These connections are also made explicit in the peer tutoring available in the Writing and Reading Across the Curriculum Center, now staffed by the original IAs as well as some instructors and student assistants. The computers are still available and are used both by classes and individuals, but they serve the curriculum and are not an end in themselves. No longer are there reading and writing center programs leading to freshman composition. Instead, the services in the very successful Writing and Reading Across the Curriculum Center are voluntary, intended to support students' efforts in all their classes across the campus.

Chabot College has come a long way from the early days of separate reading and writing centers with mastery learning to basic writing courses and a Writing and Reading Center that reinforce the connections among the language arts and prepare students successfully for other courses. Semester in and semester out, instructors from all disciplines report that $85-90 \%$ of the students who use a WRAC Center service succeed in their classes. In addition, students now perform as well as or better on the junior level writing exam than those who are native to the local CSU. Chabot faculty have accomplished a lot in just a decade guided by the basic writing mission in the context of the larger English mission, which in turn is related to the college mission and the mission of all California community colleges. 


\section{Tom Reynolds and Patty Fillipi}

\section{REFOCUS THROUGH}

INVOLVEMENT: (RE)WRITING

THE CURRICULAR

DOCUMENTS OF THE

UNIVERSITY OF MINNESOTA-

GENERAL COLLEGE BASIC WRITING PROGRAM

Curricular Document authored by Lisa Albrecht, Patrick Bruch, Terence Collins, Patty Fillipi, Debra Hartley, Christine Howell, Amy Lee, Robin Murie, Tom Reynolds, Geoffrey Sirc

ABSTRACT: This essay recounts the process of writing guiding curricular documents for the University of Minnesota - General College's basic writing program. The first part of the essay describes how this was a community-building process that involved a wide group of instructors and others connected to the program. The second part includes the opening statement, as well as the goals and principles of the program, from the document.

In her College English article, "More than a Feeling: Disappointment and WPA Work," Laura R. Micciche writes about the emotion of "disappointment" and the considerable role it plays, or can play, in the jobs of Writing Program Administrators. Her piece ends with recommendations for developing a deeper knowledge of and engagement with the processes of work in order to make WPA disappointment an occasion for change and better working conditions (453).

Although our story of writing, or really re-writing, the curricular documents of the University of Minnesota General College writing program did not begin in great disappointment, we, the instructors, embraced Micciche's ideas about how to go forward in a writing program. In short, the process of writing the documents helped our program, located in a developmental education college within the university, learn a great deal about itself as it re-evaluated and embraced common guiding ideas and practices. Our goal was not only to produce an

Tom Reynolds is an assistant professor of writing and co-director of the writing program at the University of Minnesota-General College. Patty Fillipi is a teaching specialist in the University of Minnesota-General College writing program. 
updated document, but just as important, to involve instructors and others associated with the program in that process. We were, in a sense, trying to use this process of wide involvement in order to forestall the kind of disappointment that results, as Micciche points out, in loneliness and isolation.

Initiation of the process of writing our curricular documents began with the hiring of three new program co-directors. As they got to know each other and had long talks about where they would like the program to go, they knew that they needed to learn where the program had been. One of the co-directors had some of that historical knowledge in a first-hand way, having worked in the program as a graduate student. But much of what was already in place had a deeper history that extended beyond what could be supplied through memories of those still present in the program. Luckily, our Head of Academic Affairs, Terry Collins, remembered that documents explaining and detailing the curriculum existed...somewhere. These documents were located in an old file cabinet and became a way to focus discussion.

As useful as these documents were, the directors also knew that bringing about change institutionally was a complicated matter. For starters, we work in a program made up of somewhere between fifteen and twenty teachers with varying levels of teaching experience and education. Bringing about change would need to involve and recognize the different work realities of these teachers. More than simply a matter of changing the wording in the old documents, we recognized that changes would affect the material lives of all the teachers in the program and, potentially, each teacher differently. A programmatic change that held implications for professors' work lives, for example, may well have seriously different implications for the jobs of the teaching specialists with double the course load or for graduate students just learning to teach for the first time. Apart from immediate programmatic concerns, we also needed to know what institutional brakes would be applied for any changes we wanted to implement.

All this was made more complicated by the fact that the balance of teachers had shifted so that numbers were now weighted more heavily toward full-time teaching specialists, most of whom had been hired in the past two or three years. They were well-experienced teachers, now on multiple year contracts, with a lot to add to any discussion of basic writing instruction. As the directors began to see the process of discussing the curriculum of the writing program as an opportunity to actively shape, or re-shape, the program, they sought to involve more constituent groups in a formal process of re-writing the existing documents. Given that we would all be teaching the same students under the developmental education mission of our college, inclusion of regular teachers of all ranks also seemed the right thing to do. We agreed 
that we should not be acting as independent agents when we could learn so much from each other in helping our students succeed.

Over the course of a year, a series of weekly meetings were held with the head of academic affairs, two teaching specialists, two tenured members of the writing faculty, the head of our ESL program, the Writing Center Director, and the program co-directors. Documents that were drafted initially by the program directors were read, discussed, and revised in committee. Additional revisions and sections written by other committee members became part of the merged document as the year progressed. The strengths of attempting a re-examination of the program and our classes with such a wide group quickly became apparent as we began to discuss best approaches to teaching our students.

One strength of working in committee was that we began to see our teaching as taking place within a wider College and University structure. Our job was, we saw more clearly, to prepare students as writers who would work in a number of different locations, including residence halls, writing centers, and variously equipped computer classrooms, and with an increasingly diverse set of audiences within the University. Working as a group also forced us to interpret and work within our College's primary mission of preparing “...students for transfer to schools and colleges of the University and other higher education institutions." The College's mission also states that the College "provides an environment for a diverse population of students, faculty, and staff and seeks to encourage multicultural perspectives in its activities" (General College Mission). How would our approaches in the writing program, both as teachers and as teachers working in a group, contribute to this effort? What kinds of principles would encourage us to be innovative teachers with our various perspectives informing our work but also bring us together as a "program" with a coherent approach? These kinds of considerations led us to proceed cautiously and with a great deal of listening to one another.

Even more important than the strengthening of the document's scope and purpose, however, were the strengths programmatically that came about as the result of acting as co-writers. At some points, this was a matter of making basic decisions about the structure and purpose of the document. Would it be primarily for teachers? Yes, we decided, but we also wanted it to be accessible to students and others who might view it on the web. Readability became a common concern, and at times, a source of humor, in our meetings. Sections would have to be intelligible to a fairly wide audience, but we still wanted it to reflect ideas that were not easily translated out of professional jargon. Terms such as "process pedagogy," for example, were spun out and explained in later drafts. As we worked together, we also came to know each other as readers/writers and as professionals with varying 
concerns and commitments. At times, we learned that approaches or concepts that we thought we had understood before were actually understood differently by different instructors. Some issues were resolved with inventive wording; others remain under discussion for the next round of revisions. Overall, we agreed much more than we disagreed, but we needed to talk about these issues in order to bring to light some of the buried assumptions in the program. And we were reminded, as writers who teach, of how difficult the process of collaboration can be - a valuable lesson for us to share as we planned for the program.

For non-tenure track teachers whose past jobs demanded that teaching follow either unstated or already set curricula and teaching philosophy, involvement in the process of constructing institutional policy has resulted in approaching tasks such as orientation for new instructors, syllabus/assignment writing, and job evaluation with a richer knowledge and commitment. For newer teachers, in particular, policies that used to be discussed and guessed at in hallways and offices can now be studied and used when planning the scope and sequence of assignments. Involving newer teachers in this process of redefining the program's curriculum and goals has helped to smooth development of individual teaching philosophies and in carrying out the more particular tasks of forming course objectives and student/ teacher expectations. Teacher development happens within particular programs with whatever help those programs can provide, including such documents as our curricular goals and guidelines. Ours is also a living document, we agreed, one to which new ideas and fresh revisions will be made as teachers construct their own understandings and teaching practices based on it and hold new conversations around it.

From the point of view of the program co-directors, the benefits of writing together as a committee strengthened our program in the kinds of ties it created among our teachers. As we teach our students, literacy is about the use of words to form relationships with other people. Writing does matter, we hope to show them. For us, the teachers, this act of writing together enacted what we hope to teach students: we discussed, argued, agreed, disagreed, and in so doing, formed working relationships that were more respectful of each other in the end. Part of the "literacy work" on which we place a great deal of value in the document also extends, we hope, to our own work efforts.

Of course this was not a perfect process. We recognized that some held more power in the group than others to effect change. Some had more time than others to do the drafting, with reward structures in place for carrying out that work. Negotiations that involved real acknowledgement of the possibilities and limitations of each of our positions in the process were ongoing. The process itself, we had to 
remember, was initiated more from above than below, even if it was intended to be inclusive. And of course, there were disappointments. Individual visions did not always make it into the final document. As we go forward, however, with our disagreements, we do so as participants on the level of policy, confident that our arguments will continue to be heard.

What follows are the two opening sections of our document an introductory statement of our program philosophy, "Toward a Deepened Notion of Access," and "Guidelines and Goals for GC Writing Courses." The entire document can be viewed online at <http:// www.gen.umn.edu/programs/writing/htm>

\section{Toward a Deepened Notion of Access: The Writing Pro- gram at the University of Minnesota General College}

The writing courses at the General College grow directly out of the mission of the College - to enable promising students excluded by the mainstream admission criteria of the University of Minnesota to gain access to the University and to contribute to its community of intellectual excellence. As is suggested by the College's explicit commitment to research and teaching within a multicultural paradigm, today's GC teachers continue the college's legacy of defining higher education around broadening and deepening access to knowledge and power. As teachers, we understand that assumptions about good writing are culturally grounded and deeply involved in legitimating certain interests and values. As we describe below, rather than avoiding talk about how valued forms of writing give definition to access, our curriculum embraces the challenge of enabling access while deepening the meanings of access through the guiding philosophy of our courses as "apprenticeships in multicultural literacy work."

The idea that our courses are apprenticeships in literacy work brings together the insights of process theories of learning writing with social theories of knowledge and power and teachers' experiences of what works. From process theory we learn that for purposes of teaching, "writing" is not so much a correct version of words on a page, but all of the overlapping practices of working alone and with others to get words and ideas down on paper and then reflect on them, perhaps share them, rethink them, revise them, try them out on audiences, assess the communication and so forth. Writing, then, is not something that one has, it is something that people do. As persons with extensive experience in the process of engaging and communicating ideas through writing, our teachers help students practice and reflect on the conventions of academic prose.

These insights of the process approach to writing instruction are 
inflected within the writing curriculum by the contemporary critical theories that link knowledge and practice to power. Historically, the concept that "knowledge is power" was widely understood as a one way street-any individual can get knowledge and automatically exercise the power of the better argument. Today, critical social theory has complicated the way we understand this relationship so that dominant knowledge is seen as a way that currently dominant worldviews exercise power over individuals and groups. The practices, like literacy, through which dominant knowledge is approximated, invested in, resisted, or negotiated are then sites of conflict. Applying this critical insight to the writing classroom, "literacy work" substantively extends process theories of writing by concentrating attention on the work writing does for people - the social functions the processes of writing serve. As we understand it, literacy work locates power in the specific ways that people take up conventions, in our ability to think critically about the contexts (institutional, social, material, rhetorical) we inhabit, and how those contexts both enable and inhibit textual possibilities. As fellow apprentices in critically navigating the possibilities of work, teachers continuously learn to reflect on our contexts and the work we do within them, conforming, reforming and deforming them, through our reading and writing. In other words, literacy work challenges either/or approaches that see writing as either totally dominating or completely liberating.

In the largest sense, our courses continue the historic striving for the democratic promise that has always been central to literacy education - to make available to all (or, to help all participate in creating) the communicative resources for enacting individual and social group equality. This means that we conceive of our classes as important sites for questioning current inequalities brought about, in part, by literacy practices, even as we study and demystify the commonly accepted forms that are used by those in power. As experienced apprentices in literacy work, we know that reading and writing are processes through which the most fundamental and powerful experiences and insights can be sharpened and shared in ways that change the world and keep it changing. We place this intensification of feeling, thought, and experience at the core of our classroom activities, always striving to create opportunities for ourselves and students to participate in literacy work that awakens and inspires us all.

Taken together, these insights from process theory and critical theory provide a framework for our teaching. Over the two semester sequence of writing course work, General College students write formal papers and a variety of other genres, going through the writing process from invention to completion many times in response to many different prompts and contexts. Through this practice students develop into more experienced writers, deepening their knowledge and sophis- 
tication about intellectual inquiry as it is conducted within the university setting. We recognize student work as serious and valuable, and as such, part of the social relations of power that extend through the university. Thus, student reading and writing are respected and studied as the complex texts that they are.

The writing sequence of the General College implements theoretical, technological, and pedagogical insights from basic writing to support the preparation of GC students to be successful and active participants in the degree granting colleges of the University. Outlined below are some of the goals for the writing courses at GC and specific objectives for students' learning:

\section{Guidelines and Goals for GC Writing Courses}

Through the two course writing sequence, General College students fulfill the freshman writing requirement. The primary goal of the sequence is to help students develop reading and writing practices that will serve their needs as they progress through the university. For us, rather than forcing conformity to a standardized norm, this goal requires inviting students to use the diverse skills, backgrounds, and experiences they bring to their writing courses as resources for interpreting and participating in academic literacies. Many students have been taught to see school writing as a rote exercise in a "correctness" foreign to anything they care about (other than a grade). Our goal of having students consciously create for themselves academic literacy strategies and practices that matter to them is, accordingly, a challenge. We respond to this challenge by seeking to nurture apprentice-type relationships among people (students and teachers, students and students) involved in the common project of knowledge creation and self-expression through various kinds of academic literacy work. We begin with six desired outcomes of the writing sequence.

1. Students will practice strategies for invention, drafting, revising, editing, and proofreading and will gain experience working in multiple scenarios of writing.

2. Students will develop confidence in the production of elaborated texts in response to a variety of prompts. They will produce focused, extended pieces of writing, consider various audiences, and effectively incorporate evidence or examples from outside sources and from experience.

3. Students will study the way texts work and the work texts 
do. In other words, students will pay attention not only to content, but to rhetorical context (to whom is it written? With what goal in mind?). This entails identifying the writer's rhetorical strategies or choices (how does the writer attempt to reach that audience in particular? Establish authority? What kind of language does writer choose to enhance effective communication?), and assessing the text's effectiveness (does the writing communicate successfully within the identified rhetorical context?). By reading texts (their own and others') as writers, students will grapple in their own writing with the ways that texts negotiate self-expression and social relations.

4. Students will develop a strong sense of their own process, including knowing where and how to seek feedback and assistance with their writing. For this reason, the course emphasizes the collaborative aspects of reading and writing, asking students to work with their peers and their teacher in conceiving, composing, revising and editing.

5. Students will gain experience in how writing, like learning itself, is an ongoing and shared endeavor, involving experience, reflection, discipline, discovery and participation. In other words, the course will emphasize not merely the practical, but the emotional/affective, ethical and cultural/traditional aspects of writing and learning.

6. Students will study and practice effective use of outside materials in writing, including the evaluation and assessment of sources for credibility, bias, and timeliness. Courses will also focus on rhetorical concerns, such as exploring the use of different kinds of sources in a range of writing situations, to enhance credibility, highlight particular views, affiliate individual writers with larger groups, and to explore and substantiate claims. Effective use of research includes, of course, exposure to formal systems of citation and proficiency in one.

7. Students will gain experience with using various technologies to enhance their writing and research processes.

These goals for our students underscore both our first and second semester required writing courses. It is worth noting that, although variety from section to section is expected and desirable as each teacher works to her or his strengths and responds to specific classroom dynamics, there are particular shared perspectives that inform our work as a Writing Program. Just 
as we have expectations for our students in these courses, we have expectations of one another as teachers of these courses. These expectations are informed by the following principles, drawn from research in Composition Studies.

\section{Principles:}

1. Student performance is directly related to teachers' expectations. Developmental studies show that, when teachers assume their students to be primarily characterized by a lack or a deficit (as writers or as students), they lower their expectations and don't foster a learning environment where students can develop to their utmost potential.

2. Focused, extensive practice is key to a writer's development.

3. Deep understanding of and competence in various literacies, including academic writing, depends on engagement with literacy as a social practice.

\section{Expectations of Writing Instruction in General College}

1. Teachers understand and affirm each student's basic linguistic competence, see all students as capable of progress and achievement, and encourage students to set and meet high expectations for their learning.

2. Teachers make student writing the central feature of each course. The courses help students to develop and extend their abilities to write, and enrich their thinking about writing and the kinds of work it does.

3. Teachers present writing, reading, teaching, and learning as processes that are never neutral. Rather, reading and writing are practices through which teachers and learners make choices about whether to reinforce, resist, revise, or record a particular cultural or academic conversation and the attendant relations of power.

\section{Works Cited}

General College Mission Statement. 30 Jan. 2003. 14 Feb. 2003. $<$ http://www.gen.umn.edu/gc/images/mission.pdfs.

Micciche, Laura R. "More than a Feeling: Disappointment and WPA Work." College English 64.4 (March 2002): 432-458. 
Karen S. Uehling

\section{CREATING A STATEMENT OF GUIDELINES AND GOALS FOR BOISE STATE UNIVERSITY'S BASIC WRITING COURSE: CONTENT AND DEVELOPMENT}

ABSTRACT: This essay describes a statement of guidelines and goals developed for Boise State University's (BSU) basic writing course. The essay includes an account of local conditions at $B S U$, a copy of the statement itself with commentary on its seven competencies, a description of how the document was developed through a collaborative process, and the effects of that development.

My institution, Boise State University, created a statement of guidelines and goals for our basic writing course in 2000-2001. ${ }^{1}$ To develop our statement, we wrestled with the relationship between basic writing and our two required first year composition courses. Ultimately, we envisioned a course that prepares students for English 101 in several ways. We hope students will be prepared "because they have begun to develop confidence in their reading and writing abilities, learn the conventions and expectations of university classrooms, [and] develop an awareness of the activities in writing classrooms and the terms used to talk about writing" (Boise State University). Like other documents of this kind, our curricular statement was developed in response to local conditions.

Boise State University (BSU) in Boise, Idaho, is a six-year urban, commuter institution of 17,000 part- and full-time students with an average age of about twenty-seven. BSU also fulfills a community college function through a vocational technical program that offers twoyear degrees and certificate programs. The Idaho State Board of Education, in its mission statement for the institution, describes Boise State University as "a comprehensive, urban university serving a diverse

Karen S. Uehling is an Associate Professor of English at Boise State University where she has taught basic writing and other writing courses since 1981. She is the author/editor of two basic writing textbooks: Starting Out or Starting Over (1993) and Vision and Revision (1994). She served as the second Chair of the Conference on Basic Writing (CBW). Recently she published a history of $C B W$ in a monograph edited by Dana Britt Lundell and Jeanne L. Higbee (University of Minnesota: 2002) and helped create an online archive on the CBW website. 
population...." Further, the mission statement calls for the university to "maintain basic strengths in the liberal arts and sciences, which provide the core curriculum or general education portion of the curriculum." Our basic writing course is within the English Department and thus within the College of Arts and Sciences; the college mission statement reads, in part: "In teaching, the College of Arts and Sciences offers a core curriculum that prepares undergraduate students for future lives and careers by developing their communication, numerical, and analytical skills, enhancing their creative abilities, fostering in them a greater awareness of human values and needs, and encouraging in them a lifelong appreciation of learning for its own sake." It was within these contexts that we worked to produce our statement of guidelines and goals for basic writing.

Numbered English 90, our basic writing class is a one-semester, non-credit course, the equivalent of three credits. ${ }^{2}$ Passing the course permits students to enroll in English 101. Our institution places students in basic writing based on test scores. Beginning fall term 2000, the Idaho State Board of Education raised the scores necessary for admission to first year composition, and consequently doubled the number of students in basic writing. In addition to those students who are required to take basic writing, some, primarily older, returning students, choose to take the course as a review.

Since the test scores were raised, the quality of writing has improved in the class, and the students now fall in two groups - those typical of students who enrolled previous to the change in test scores who have clear surface level writing problems and those who can write relatively correct prose, but whose texts seems vacant, vague, and disorganized. The current group of students in our basic writing course might be characterized as upper-level basic/lower-level freshman composition students.

\section{Our Statement of Guidelines and Goals for Basic Writing}

Our statement of guidelines and goals for basic writing (see Appendix A) contains several headings: an introduction, and sections called "Transforming Attitudes," "Making the Transition to the University" (which includes "Relationship to English 101"), "Demonstrations, Examples, and Models," "Consistent Goals and Methods," "Language Study," "Minimum Requirements," "Specifics," "Competencies," and "Suggestions for Teachers."

The framework for this document derived from curricular documents already developed by Boise State faculty for the two required first year writing courses at our institution, English 101 and 102. New features that the basic writing faculty added were "Relationship to 
English 101" and "Suggestions for Teachers."

The heart of this document is the seven competencies for basic writing because the competencies are tied to portfolio assessment and thus significantly influence what goes on in class. I will explain our thinking about and approaches to each competency in turn.

\section{The Competencies}

\section{They have confidence in themselves as writers and readers within a college environment.}

Students need confidence to access the skills they have. Many do not trust their own instincts about language. Students also need confidence to develop new skills, try out new processes and approaches, allow themselves to make mistakes, and learn. Some have had bad experiences with English in high school; for older students, negative feelings may have festered for years, and often students don't give themselves credit for having any language skills. Some students are "generation 1.5" learners who have used two languages or dialects since birth, and they may distrust standard English. Some students dropped out of high school and obtained GEDs and believe there is a vast world of education they missed in high school. Most hold a university in awe-they do not see themselves as peers of other students or capable learners.

2. They can engage in a multi-faceted process of writing, that includes invention, development, organization, feedback, revision, and editing/proofreading.

In our course we introduce and practice various methods of invention - free writing, brainstorming, clustering, listing, and other processes. We develop papers step-by-step over time. Students may draft five papers and later revise three in the last third of the course. We teach editing/proofreading as a separate step generally at the end of writing. Revised and edited papers become part of a portfolio due at the end of the course. The English 90 portfolio is fifteen pages, in line with twenty pages for English 101 and twenty-five for English 102: thus each course steps up five pages in portfolio length.

3. They are willing to use multiple strategies to view, revise, and edit their evolving written texts over time, moving from writer- to reader-based prose.

Students observe pieces of writing evolving and changing over time. Often the instructor demonstrates this process with her own 
drafts, by handing out raw invention materials, then a rough draft; next, after soliciting student feedback, a revised draft. Student assistants also model the invention and response processes with drafts of papers on later projects. And students see their own and their peers' papers shifting and developing as they focus and revise. Eventually students come to view the same text differently as they get reader response and reread a paper later in the term that had earlier seemed "finished." We want them to experiment with changing a text that they thought was completed; this is a key transition to English 101 and critical for English 102.

\section{They can produce writing that has a beginning, middle, and end developed with relevant details and examples.}

For this competency, we draw attention to how writers open and close pieces, such as the use of anecdote or dialogue as an opening strategy or returning to the beginning idea as a closing strategy. We point out how titles are not random or merely topic announcements but have some integral connection to the text. We review some essential organizational strategies, like chronology, categorization, and final emphasis. We push students to find these structures in readings and imitate them. Of course, we stress concrete details and specific examples and ask for figures, names, species, colors, ages, dates, and dollars and cents.

\section{They can produce writing in a format appropriate to its purpose.}

By "format," we mean these kinds of features: typed, double spaced, 1" margins; standard, 12-point font; left justified; paragraphs indented .5"; all important words of title capitalized, and title not all capitals, bold, underlined, in quotes, in italics, or in a larger typeface. "Format" in this competence also includes basic academic conventions like referring to the author by his or her last name, not first name; checking that the name is accurate and not in a similar or rough form; capitalizing the name; and spelling it right.

We also work on identifying and labeling work, and the basics of responding to a question: answering the question asked with adequate length and carrying out the number and kinds of tasks for which the question asks. We emphasize the need to answer questions using complete sentences and to make responses self-contained, so that the reader who does not have the question handy can still understand the response. We examine when and how to insert a quotation and the word choice needed to talk about quotations. 


\section{They can read actively and critically and engage in a dialogue with a text.}

Students read essays that connect directly to the kinds of essays they are writing; they also read the textbook, their own and others' drafts, and in many sections, a complete challenging nonfiction book. The textbook used most recently was Reading Critically, Writing Well, edited by Rise B. Axelrod and Charles R. Cooper, which is especially effective at connecting reading and writing assignments. Typical fulllength books that we might assign are Lives on the Boundary, by Mike Rose, or Bootstraps, by Victor Villanueva, both literacy narratives that focus on the transition to college. Students write reading log responses to such works, answering specific questions. We ask for a variety of responses, beginning with if they liked the reading or not and why and proceeding through such investigative processes as speculation about the title, use of sensory description and specific development, imitation of powerful lines, the meaning of the text, and connection with other texts. Some of us ask students to write midterm and final exam essays based on questions from the nonfiction book.

\section{They can edit their work for mechanical errors to the extent that, while perhaps not "perfect," surface features of the language do not interfere with communication.}

English 90 is the primary class we offer that includes some direct language work, as a review. We teach a minimal grammar; I favor Rei Noguchi's "writer's grammar." I show a video of a colleague coaching a student as she edits her paper for fragments and run-ons using this writer's grammar. We talk about proofreading as a different kind of reading from reading for meaning. We ask students to engage in selfstudy of problem areas and thus make them responsible for their errors; and we offer tips and hints for editing. And, all of this, we hope, is in an atmosphere of language play. Reading a challenging nonfiction book is also critical because a text that forces a reader to stop, look, and think about language helps develop awareness of language and the kind of seeing required for effective editing.

So that is the heart of our document. The final section of our statement is called "Suggestions for Teaching." Each competency connects with and is supported by the teaching suggestions. I will consider one example, our first competency: 1 . They have confidence in themselves as writers and readers within a college environment.

The teaching suggestion Making the Transition to the University supports confidence in that we introduce students to campus resources for academic services and support through guest speakers from groups 
like the Writing Center and student success and support programs; and we offer information on where and how to learn to type or learn basic word processing skills. We also build student confidence by reviewing and re-enforcing basic study skills. At one time Boise State University had a learning community program that linked basic writing students through grouped courses, including basic writing, study skills, and core courses, and we still try to support study skills in the basic writing class.

Consistent Goals and Methods is a teaching suggestion that also supports confidence; we offer an overview of the course at the beginning, and we make course goals and methods clear throughout. We repeat reading, writing, discussion, and feedback activities in a predictable format. And we present extended assignments in a step-bystep sequence.

\section{Developing the Statement of Guidelines and Goals}

The key to the development of the statement of guidelines and goals was a collaborative process, what Bruce Ballenger, our Director of Writing, characterizes as a "focus group." The group was initially created to increase the number of trained faculty prepared to teach basic writing. The group consisted of six adjunct faculty, chosen for their talent and experience teaching freshman composition, and me; I was asked to mentor these instructors during the first term they taught basic writing, fall 2000. An important feature of this training was administrative support. The adjunct faculty received an honorarium for participating in the training and collaborative work, and I received a course release for undertaking the mentor's role. ${ }^{3}$ As part of the training and mentoring, I wanted to engage the group in a substantive contribution to the basic writing endeavor on our campus, and producing the statement of guidelines and goals seemed timely and important $t^{4}$; and, for once we had the time to engage in serious reflection on our work as basic writing teachers.

We spent several of our weekly mentoring meetings working on the statement. We began by listing everything we did in basic writing, especially what we thought was critical or unique to the course. Next I categorized this list and gave it back to the group for discussion. At the same time, I had posted a request on the Conference on Basic Writing Listserv (CBW-L) asking for sample guidelines, goals, and mission statements, and I gave these samples to the group as well. Although our group did not directly consider the formal mission statements of the university and college when we initially drafted our statement, clearly it would be preferable to do so; however, the course we describe does support those mission statements. After all, we are directly engaged each day with the students the mission statement describes, an "urban 
university serving a diverse population," and we work to develop students' core communication skills in reading and writing.

Based on the group's feedback to my list of basic writing activities, I drafted the first full statement for group review and consensus. When we had a draft we could agree on, I sought response from two tenured colleagues who also teach the course. The revised document was then presented to the chair and Writing Committee.

The next term, spring 2001, the adjunct faculty and I met with the Writing Committee a few times and together we revised the document further. In the summer, the Writing Program carried out a preliminary assessment of basic writing portfolios based on the proposed competencies. Our students did well in this pilot assessment, revealing that the statement of guidelines and goals appeared appropriate. Further, there was informal evidence that students who took English 90 often did better in English 101 than those who did not take it. In October of 2001, the Writing Committee brought the statement of guidelines and goals to an English Department meeting where it was ratified and then the document was posted on the Writing Program website.

The collaborative nature of this process produced several benefits. Obviously, the faculty group, using a collective brainstorming method, generated more good ideas than could have been articulated by any one person. The initial focus group process also gave the instructors ownership of the document because they helped created it. The instructors thus "bought" into the process and the resulting course. The follow-up with other tenured instructors and the Writing Committee, which included the Director of Writing, strengthened the document, especially by aligning it more closely with our existing statements. When the statement was brought to the department, this development process gave it legitimacy; there was little discussion before approval because it had already been tested and revised. The creation of the statement of guidelines and goals brought visibility to our basic writing course; I feel the department better understands basic writing now and takes it more seriously as a course.

The development of the English 90 Statement of Mission and Minimum Requirements has also affected other first-year writing courses. The Writing Committee and Writing Program administrators liked the features the basic writing faculty added to the template of the document, which were "Relationship to English 101" and "Suggestions for Teachers," and there are plans to add similar sections, developed collaboratively, to the English 101 and 102 documents. Also the writing program plans eventually to develop statements of guidelines and goals for our other first year courses, honors composition and our English as a Second Language (ESL) sequence.

One of the most interesting aspects of creating our statement of guidelines and goals was trying to articulate how basic writing differs 
from English 101 and how it is the same. Ultimately, we framed our thinking in these terms: previewing, practicing, working on language, explaining writing courses, and developing confidence. We preview some of the academic work of English 101 and of the university as a whole. We practice reading and writing. We are the primary class that includes some language instruction. We explain what goes on in a college writing course and why. This information is especially important for students who have been out of school for a while. Adult learning theory suggests that learners need to know why they are being asked to do something and how it fits into the big picture of the course or the field of study (Knowles 174). This means we have to justify our goals and methods of instruction, for instance, why we ask for early free writing or peer response in feedback groups or editing as primarily the last step. We hope that we develop confidence through all of these activities.

Our English 101 course is now taught largely by teaching assistants who use a modified expressivist and reading process approach with free writing, conferencing, and group work. We hope our basic writing students will be ready to thrive in an atmosphere of this kind, especially where TAs may not be adept at articulating exactly why these teaching strategies are effective. Our students will be able to trust this process.

\section{Notes}

1. Although titled a Statement of Mission and Minimum Requirements, our document is not a traditionally conceived mission statement, that is, a concise statement of a group's mission and identity. Rather, our basic writing statement is a document of several pages that details course rationale and describes and explains curriculum; thus I refer to this statement as a statement of "guidelines and goals."

2. I think the course should carry elective credits, and, as a step in that direction, in fall 2002 I piloted a dual enrollment combined basic writing/freshman composition course, which met for six hours per week and offered the noncredit equivalent of three credits for English 90 and three regular credits for English 101; the course was successful enough that it will be offered again in fall 2003.

3. Recently, all tenured faculty in writing, including the Director and Assistant Director of Writing, participated in some of the basic writing training so that they will eventually be prepared to teach basic writing. This clear administrative support for basic writing strengthens the sense of commitment and community of those who teach basic writing and increases the visibility of the course to other faculty and cam- 
pus administrators.

4. The group of faculty who helped draft the initial statement included Julie Ewing, Jill Heney, Joy Kidwell, Siskanna Naynaha, Kate Pritchard, Marian Thomas, and Karen Uehling.

\section{Works Cited}

Axelrod, Rise B., and Charles R. Cooper, eds. Reading Critically, Writing Well: A Reader and Guide. $6^{\text {th }}$ ed. NY: Bedford/St. Martin's, 2002.

Boise State University. English 90: Statement of Mission and Minimum Requirements. Boise, ID: last revised 12 Nov. 2001. 19 Feb. 2003 $<$ http://english.boisestate.edu/writing/Mission.090.htm>.

Knowles, Malcolm S. The Adult Learner: A Neglected Species. 3rd ed. Houston: Gulf, 1984.

Noguchi, Rei. Grammar and the Teaching of Writing: Limits and Possibilities. Urbana, IL: NCTE, 1991.

Rose, Mike. Lives on the Boundary: The Struggles and Achievements of America's Underprepared. NY: Penguin, 1990.

Uehling, Karen S. "Mission Statement for Boise State University's Basic Writing Course: Content and Development." Paper presented at the Conference on College Composition and Communication. Chicago, March 2002.

Villanueva, Victor, Jr. Bootstraps: From an American Academic of Color. Urbana, IL: NCTE, 1993. 


\section{APPENDIX A}

\section{English 90 \\ Boise State University}

\section{Statement of Mission and Minimum Requirements}

Fall 2001

\section{Introduction}

One of the strengths and challenges of Boise State University is the rich diversity of its students, and ENGL 90 students are often some of the most diverse students on campus. They may be adults, returning to college after many years; they may work full or part-time as they attend school; they may be speakers of more than one language or dialect. ENGL 90, an introduction to college writing, is required if a placement test or writing sample demonstrates need, and it also provides review for those who wish further preparation before taking ENGL 101. ENGL 90 offers students extra time to work on their writing with attention to fluency, development, organization, revision, and editing/proofreading. ENGL 90 counts as the equivalent of 3 credits, though the credits do not count toward graduation.

\section{Transforming Attitudes}

Students in ENGL 90 are usually just entering the university and can often be distinguished by their lack of confidence. Yet to thrive in college, students must become confident as readers and writers and as members of the academic community. ENGL 90 is a course that builds both confidence and skill. We believe that students' experiences with language and language use in the course should be positive, and that this will provide the basis for the development of writing skills. As a consequence, ENGL 90 focuses, like ENGL 101, in part on the affective dimension of writing and thinking processes; that is, the course hopes to encourage students to believe that reading and writing are meaning-making activities that are relevant to their lives, within school and without.

\section{Making the Transition to the University}

ENGL 90 serves as a bridge between the community and the university. Instructors should assist students with this transition into the world of studenthood. Essential topics include active, critical reading; an introduction to the culture of the academy and to basic terms of academic analysis; review of study skills; and an introduction to campus resources for academic support. 
ENGL 090 students will be prepared to enter ENGL 101 because they have begun to

- develop confidence in their reading and writing abilities

- learn the conventions and expectations of university classrooms

- develop an awareness of the activities in writing classrooms and the terms used to talk about writing

\section{Demonstrations, Examples, and Models}

Students may have not seen writing develop over time and may be unfamiliar with the processes writers engage in to produce writing. Thus, students will observe how writing is produced.

\section{Consistent Goals and Methods}

We believe ENGL 90 students thrive in an atmosphere that is predictable. Clear goals, repeated routines, and "scaffolded" assignments are likely to create an atmosphere that builds student confidence and provides the basis for the development of writing skills.

\section{Language Study}

ENGL 90 is one of the few courses in which editing and proofreading skills are taught; however, such skills are only one part of ENGL 90, which is clearly a writing course. Language skills should be taught largely within the context of the student's own writing.

\section{Minimum Requirements}

\section{Specifics}

Students in writing classes should continuously produce written work. This includes evaluated work, such as formal assignments and subsequent revisions, as well as informal and non-evaluated work, such as journal entries, in-class writing exercises, rough drafts, and peer responses. ENGL 90 students will produce, on average, the equivalent of 3 to 3.5 double-spaced and typed pages - about 1000 words - a week. The equivalent of 15 pages of double-spaced and typed writing will be the basis for assessing students' final grades in the course.

Students will write several informal responses to reading materials using a variety of strategies for active, critical reading.

Students will begin to learn the terms, processes, and conventions of academic writing necessary for success in ENGL 101 and other university classrooms.

Students will meet all the attendance and class participation requirements and submit required assignments on deadline. 


\section{Competencies}

Students will demonstrate that:

1. they have confidence in themselves $\mathrm{c}_{\mathrm{s}} \mathrm{w}$ writers and readers within a college environment.

2. they can engage in a multi-faceted process of writing, that includes invention, development, organization, feedback, revision, and editing/proofreading.

3. they are willing to use multiple strategies to view, revise, and edit their evolving written texts over time, moving from writer- to reader-based prose.

4. they can produce writing that has a beginning, middle, and end developed with relevant details and examples.

5. they can produce writing in a format appropriate to its purpose.

6. they can read actively and critically and engage in a dialogue with a text.

7. they can edit their work for mechanical errors to the extent that, while perhaps not "perfect," surface features of the language do not interfere with communication.

\section{Suggestions for Teachers}

Making the Transition to the University. Demonstrate how to view a text not as a "flat landscape" but as a rich, living piece of discourse; have students practice engaging in a dialogue with the author. Preview some of the terms, processes, and conventions of academic writing. Review and re-enforce basic study skills. Introduce students to campus resources for academic services and support.

Demonstrations, Examples, and Models. Conduct demonstrations of writing in progress, both step-by-step examples of major assignments and examples of informal assignments. Several examples will provide a range for students rather than a single model to follow. Student interns can provide additional supporting demonstrations.

Consistent Goals and Methods. Present an overview of the course at the beginning of the term, carefully explaining course goals and methods 
of instruction. Repeat and practice reading, writing, discussion, and feedback procedures in a predictable format. Present extended assignments in a step-by-step, staged, and sequenced manner.

Language Study. Foster a playful, inquisitive attitude toward language and its richness, encouraging students to take an investigative approach to language phenomena. Practice individual error analysis, and teach editing and proofreading as a special task that requires its own particular ways of seeing and responding to text. Offer students practical tricks and hints for editing their own work rather than an exhaustive review of grammar. 


\section{James Kenkel and Robert Yates}

\section{A DEVELOPMENTAL PERSPECTIVE ON THE RELATIONSHIP BETWEEN GRAMMAR AND TEXT}

ABSTRACT: This article presents a developmental perspective on text construction, understood as managing information within and across sentence boundaries. The article claims that the systematicity in non-standard constructions in basic writers' texts reflects student awareness of three obligatory areas of information management in texts: topic management, reference tracking, and maintenance of given-new information chains. A taxonomy is presented that describes these obligations, shows how developing writers innovate to meet them, and compares these constructions to those of mature writers. The categories in the taxonomy are not traditional but instead describe textual functions relating to information management. Because these non-standard constructions are principled, explicit instruction is necessary to help students perceive that such constructions are not appropriate for academic writing.

As university professors who teach undergraduate writing and the "Introduction to Grammar" course required of pre-service English teachers, we have had an ongoing concern about the kind of knowledge teachers need to have about grammar and about how that knowledge should inform classroom teaching. As linguists, we have long recognized the shortcomings of traditional grammar. Of course, we know that this concern is not new. From the 1920s through the early 1960s, linguists repeatedly called for English teachers to abandon traditional descriptions in favor of more linguistic ones. The linguistic critique emphasized that descriptions of English offered by traditional grammar have significant shortcomings: its terminology is confusing,

In the last ten years, James Kenkel and Robert Yates have collaborated on a number of papers focused on two main concerns: the relationship of grammatical knowledge to native and nonnative speaker developing writing; and the knowledge of language needed by teachers of basic writing to native and non-native speakers of English. James Kenkel is a professor of English and Coordinator of Writing at Eastern Kentucky University. His current research focuses on the principles of text construction shared by native and non-native speaker developing writers. He teaches courses in linguistics, pedagogical grammar, second language acquisition, and the global spread of English. Robert Yates is a professor of English TESL at Central Missouri State University. His current research includes teacher response to developing writing. His main teaching responsibility is in an MA TESL program, and he teaches courses in linguistics, grammar, second language acquisition, and teaching reading and writing to non-native speakers of English.

(c) Joumal of Basic Writing, Vot. 22, No. 1, 2003 
and more important, its definitions do not reflect what native speakers of the language actually know.

In the last twenty years, there have been renewed attempts to reform English grammar teaching using insights from linguistics. Robert DeBeaugrande and Rei Noguchi have offered new ideas about the relation between the tacit grammatical knowledge possessed by all native speakers and the use of standard English. This work definitely represents a step forward in the teaching of grammar. However, we need to do more than show students that they can apply heuristics derived from their tacit knowledge of grammar to resolve some common sentence-level issues.

We need a developmental perspective focusing on the principles of language and text underlying student use of non-standard constructions. This kind of developmental perspective is important for pedagogy because the best teaching practices begin with what students know and proceed to what they need to know. For such a pedagogy, the perspective of traditional grammar is insufficient. Although sentencelevel descriptions are very important, teachers need a perspective on grammar which can extend beyond the sentence and which reflects learner understandings. In this article, we propose such a perspective for understanding some of the most complex non-standard sentences students write.

\section{Shortcomings of Traditional Grammar}

Many of the rules and descriptions of traditional grammar fail to describe adequately the facts of written English, even at the most general level. For example, Christine Hult and Thomas Huckin in The New Century Handbook describe the subject of the sentence as ". . . a noun, a pronoun, or a noun phrase (a noun plus its modifiers) that identifies what the sentence is about. Usually it precedes the main verb" (510). Although this definition would allow the identification of many grammatical subjects, it would fail in ordinary cases such as:

1. It is raining.

2. It is true that many people lost money in the stock market.

3. There are many people in the park today.

4. To eat a high fat diet is foolish.

Not only does this definition fail to identify many ordinary cases of sentence subjects, it is also impenetrable to students unschooled in traditional grammar. This problem is made clear by Patrick Hartwell, who describes many of the definitions and descriptions of traditional grammar as COIK, "clear only if known"(119). For instance, to even 
begin making use of this inadequate definition, a student would have to be able to identify nouns, pronouns, noun phrases, modifiers, verbs, and main verbs. Unfortunately for the student, traditional definitions of each of these categories also fail to capture many ordinary cases. As Hartwell makes clear, traditional definitions are useful only to those who have already overcome their vague formulations. It is no wonder that traditional grammar frustrates many students.

\section{Reform Efforts in the Teaching of Grammar}

As early as 1927, American structuralist linguist Charles C. Fries, in an attempt to reform English language teaching in the schools, critiqued traditional grammar teaching, observing that such pedagogy ignored advances in linguistics that had occurred during the preceding 100 years. His critique recognized the inadequacy of many traditional descriptions. With his influential 1952 book, The Structure of English, Fries again called for reform in the schools. Throughout the 1950s, a number of structuralist linguists answered Fries' call, but their efforts were ultimately rejected by English teachers because linguists were not able to demonstrate that student awareness of more accurate sentence-level descriptions would lead to improved writing skills. Robert Connors and Geneva Smitherman provide reviews of this debate as it occurred in the pages of College English and College Composition and Communication during the 1950s and 1960s.

In the last twenty years, reform efforts have been taken up again, most notably by Robert DeBeaugrande and Rei Noguchi. These linguists suggest means for overcoming the opaque or COIK nature of many traditional definitions for sentence-level grammar. Instead of criterial definitions for such concepts as "sentence" and "main verb," they propose operational ones. For example, typical traditional definitions define "sentence" as a group of words containing a subject and a predicate and expressing a complete thought. All of these criteria are problematic for naive native speakers of English seeking to identify sentences, which is a necessary step as students try to edit their texts for fragments and run-ons. DeBeaugrande and Noguchi resolve this problem by defining a sentence as any string of words that can be changed into a yes-no or a tag question. Generally speaking, formation of yes-no questions involves taking the first auxiliary verb and moving it just to the left of the subject (e.g., "Mary can speak French" becomes "Can Mary speak French?"). Formation of tag questions involves reversing the positive/negative polarity of the sentence, adding to the end of the sentence a copy of the first auxiliary as well as a copy of the subject but in its appropriate pronoun form (e.g.,"Mary 
can speak French, can't she?"). Yes-no questions and tag questions are only possible from full sentences. Such operations avoid the vague criteria of traditional grammar by asking students to manipulate sentences in ordinary ways. For sentences containing a dependent clause, the same strategy can be used to distinguish the verb in the dependent clause from the main verb. In this case, it is only the auxiliary verb of the main clause which is moved for making such questions. In other words, the operations proposed by DeBeaugrande and Noguchi allow students to use their tacit knowledge of sentence grammar to identify sentence-level categories instead of trying to apply traditional definitions.

The approach taken by DeBeaugrande and Noguchi is important because it shows students how to use their own language knowledge to address sentence-level issues such as agreement or fragments. In addition, it offers a more student-centered approach to teaching grammar. In spite of these strengths, this work has not addressed a stubborn problem which confronts English teachers, namely, how to understand why students use many of the inappropriate sentence constructions they do in the first place.

Because we believe that the teaching of grammar in a writing class must be based on problems students have with constructing texts, teachers need insight into how sentence-level grammar contributes to managing information within and across sentence boundaries, a core element of text construction. In traditional grammar handbooks, there is little recognition of grammatical concerns extending beyond the sentence. Grammar handbooks typically have sections on so-called "mixed constructions," which Hult and Huckin define as a "sentence that starts out one way but finishes in another" (885). ${ }^{1}$ For example,

5. In the world created by movies and television makes fiction seem like reality. (658)

The discussion that follows this example offers appropriate revisions, but it is striking that no attempt-other than imputing lack of attention - is made to account for the student's textual intentions. To do so requires descriptions of grammatical categories whose scope extends beyond the sentence and which function to manage information within and across sentence boundaries. In addition, responding to such constructions requires a developmental pedagogy. It is implausible to assume that the student who wrote 5 believed that he or she had failed to communicate effectively. Instead, we should assume that the absence of revision reflects the student's belief that he or she was following principles of information management and communication. 


\section{Student Language from a Developmental Perspective}

We are not the first to argue that teachers must do more than be "astonished and baffled" by sentences such as 5 when they occur in students' writing. This very point was made by David Carkeet (682), who wrote one of the earliest papers in the literature calling for teachers to adopt a developmental perspective on such sentences. This literature is premised on the notion that even such non-target-like structures as mixed constructions are principled, although they may be used by beginning writers who have had little experience with the demands of academic writing. Mina Shaughnessy's Errors and Expectations is the foundation of much of this work and remains vital today. She observed not only that beginning writers learn by making mistakes but also that these mistakes are largely systematic (5). Shaughnessy urges teachers to understand the reasons behind student errors.

Carkeet, writing in the same year as Shaughnessy, speculates that writers of such sentences perceive them "as strings made up of discrete chunks having little or no relation to each other. Each chunk has integrity, but that integrity is lost when the chunk is viewed as part of a whole" (685). Carkeet speculates that the cognitive demands of the writing process, especially for students with little practice in "disciplined" writing, may cause such constructions (686). Ellen Barton et al., in their study of types of "awkward" sentences, offer a similar account of their source. They suggest that "awkward" sentences result from writer "mismanagement" of syntactic structures and related "idea" structures. When student writers produce these sentences, it is because they have difficulty fitting complex ideas into the corresponding more complex syntactic structures (95).

David Bartholomae, Eleanor Kutz, and Charles Coleman appeal to two fundamental concepts in the study of second language acquisition, error analysis and interlanguage, ${ }^{2}$ as the basis of a framework to understand non-standard constructions of native English speakers. Although error analysis looks for systematicity in the non-target-like forms that students use, at best it can only identify systematic differences between what a student does and the target language. An interlanguage perspective looks for the principles underlying students' non-target-like constructions. As Kutz notes, from an interlanguage perspective, the students' sentences are systematic, rule-governed, and predictable (392). As a consequence, there are no "errors" if we analyze student production from an interlanguage perspective. Especially important for the framework we propose, Kutz suggests that from an interlanguage perspective, students might "return" to earlier principles when they encounter discourse demands which cannot be adequately met by their present knowledge (393). All of this work is important 
because it shows the inadequacy of traditional categories for understanding what students do as developing writers.

From our perspective, Coleman's analysis of sentences like mixed constructions is the most important. Coleman considers two types of structures in the writing of speakers of African-American vernacular English (AAVE): "by strings" and topic-comment sentence structures. With regard to "by strings," Coleman notes that eliminating by would make the sentence grammatical.

6. By making English the official language would take away one's constitutional rights. One would not have freedom of speech, choice, writing or the press if this was to happen. (490)

Coleman observes that such strings appear to be marking either an agent-action or a causative relationship. Citing claims that prepositions in AAVE have different uses than in standard English, Coleman suggests that these "by-strings" may be a feature unique to AAVE. We are not certain that sentences like 6 occur only in the writing of speakers of AAVE. For example, Lynn Troyka uses a "by string" as identified by Coleman as an example of a mixed construction (326); Diana Hacker uses a "by string" as an example in an exercise on repairing mixed constructions (212); Andrea Lunsford and Robert Connors also have an example of a "by string" in a similar exercise (311). If "by strings" were only prevalent in the writing of speakers of a particular variety, we would not expect to see examples in so many handbooks. That these strings all begin with by is certainly interesting; however, it is unclear to us that "by strings" are much different than the second type of construction Coleman discusses: topic-comment structures.

In traditional terminology, the structures discussed in Coleman as topic-comment would be labeled run-on, or fused, sentences. In the following sentence discussed by Coleman, we have labeled the "topic" and "comment" parts of the string.

7. To work hard and become successful is great. [ [topic $_{\text {Letting it }}$ take away your time with your friends and families]

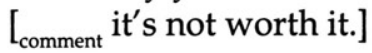

Coleman observes that the student who wrote 7 did not use punctuation to signal the topic-comment organization. He correctly notes that topic-comment constructions like 7 exist in other languages and suggests that this type of structure exists in AAVE.

We agree that 7 is a topic-comment construction but we believe that this construction does not reflect a particular non-standard variety of English. Instead, it is the extension into writing of a very frequent construction in the oral language of all English varieties. 
Douglas Biber et al. in The Longman Grammar of Written and Spoken English describe differences of spoken and written English. They observe that structures like 8, which they label "prefaces," are very common in spoken English.

\section{Sharon, she plays bingo on Sunday night. (957)}

They note prefaces serve to establish a topic in the discourse. We consider the structure in 7 to be a preface which uses the following it in the comment to repeat the topic. All of the other examples in Coleman can be analyzed the same way. Rather than attributing topic-comment structures to any particular variety of English, we believe they represent a developing stage in the writing of many students. In fact, this is exactly the kind of evidence needed to support Kutz's claim, cited above, that earlier forms are always available to a student. It is not surprising that when students need to announce a new topic and they lack (or lack confidence in using) the appropriate grammatical means in the written language, they return to earlier principles, especially those available in the oral language. Because prefaces are a feature of the spoken language, this structure is always available for introducing a new topic and for commenting upon it.

\section{A Framework for the Grammar-Text Interface of Developing Writers}

Coleman suggests examining these two kinds of structures, both of which can be classified as mixed constructions, from an interlanguage perspective. We agree, but believe that there is a wider range of nontarget-like structures produced by developing writers as they strive to manage the information in their texts. We propose three obligatory areas of information management in text: topic management, reference tracking, and maintenance of given-new information chains. ${ }^{3} \mathrm{We}$ believe that all writers know that they have these obligations to manage information in their texts. The systematicity that Shaughnessy observed is a reflection of the efforts of developing writers to realize their obligations. We propose a taxonomy to describe these obligations and show how developing writers try to meet them. The categories in the taxonomy do not have traditional labels but use labels based on textual functions relating to information management. It is important to note that textual functions do not have a one-to-one relationship with grammatical forms. Our observations on the kinds of constructions writers use to manage information are, therefore, suggestive and not complete. We cannot list all the possible constructions writers can use to realize these textual functions. 
Except where noted, all of the examples from developing writers come from first year students at comprehensive regional universities in Kentucky and Missouri. All students are native speakers of English. ${ }^{4}$ We have not edited these examples. For clarity, some phrases have been bolded.

I. Topic announcing structures

A. Presentationals

Mature writer: expletive there constructions

1 . There are many cuts expected in next year's budget.

Developing writer: fragments, imperatives, questions 1. In the writings of Erich Fromm, Solomon Asch, Shirley Jackson and Philip Zimabardo. Each of these people were professors at well known colleges or their experiments and studies have been to determine the reasons that human kind, obey and disobey.

2. The time of my life when I learned something, and which resulted in a change in which $I$ look upon life things. This would be the period of my life when I graduated from Elementary school to High school. (Bartholomae 255, citing the work of a developing writer)

3. In conclusion, start with the major things like the internet, and everyone else do their part, little by little the problem will start to vanish.

4. Personal freedom or personal safety, which should have more protection?

B. Prefaces

Mature writer: (only in the oral language)

Developing writer: topic followed by a co-referential pronoun or full noun phrase.

1 . Teenagers, especially, are almost for sure they are going to do it their mind is set on it.

2. In the case of Olmstead v. U.S. the investigators for this case were discovered to have broken the law in order to obtain critical information in the trial. (Beginning of paragraph)

3. In the case of wiretapping, I think the government has the full right to it. (Beginning of paragraph) 
C. Focus constructions (structures which present new information)

Mature writer: it-clefts

1. It is not surprising that the budget will be cut nextyear.

Developing writer: imperatives, rhetorical questions

1. I think that the government has all the control in order to catch some one if they are doing illegal stuff, and that includes tapping into someone's phone line. Think about it someone is going to do something, ...

2. School violence, will it ever stop?

D. Topic-comment constructions

Mature writer: sentences in which the relationship between the subject and predicate is grammatically linked

1. The fear that budgets would be cut is coming to pass.

Developing writer: mixed constructions

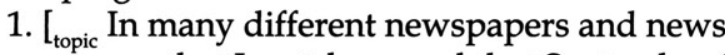
programs that I watch or read that September 11] [are ${ }_{\text {comment }}$ talking about how the Americans are not going to have safety and freedom at the same time].

II. Reference chains

A. Noun phrase displacement

Mature writer: traces (In the sentence below, which, whose antecedent is "technology stocks," is interpreted as the object of invest in. This position is marked by $\mathbf{t}$, which linguists call a pronominal trace. The subscripts mark the reference chain between antecedent and pronominals.)

1. Technology stocks ${ }_{i}$ which ${ }_{i}$ many invested in $\mathbf{t}_{i^{\prime}}$ have not rebounded.

Developing writer: repeated pronouns or full noun phrases.

1. [One of the young boys] was my crush, who I had liked him $_{i}$ since second grade.

2. For the teacher, he must refuse authority to stop the experiment. To not refuse it he must obey his experimenter and continue to inflict pain to his learner, which ${ }_{i}$ he can visually see [how painful the shocks have become $]_{i}$. 
B. Reference tracking

Mature writer: unambiguous reference to other words

Developing writer: inconsistent reference to other words

1. A person has to be of a certain status or certain rank to be included in the big part of society. In the upper-middle class a person has to show their wealth by having a big fancy home or a fancy car. If that person does not have either of the two they are not considered as apart of the upper-middle class. All of the people who do have the nice cars and the fancy homes do not consider that person of their rank so they discard them.

III. Information sequencing

A. Given-new information chains

Mature writer: constructions such as passive voice and pre-posing used to change word order for the purpose of maintaining appropriate given-new information chains.

1. Most of his proposals were accepted by the committee.

2. Most of his proposals the committee accepted. Developing writer: question-answer pairs, non-standard punctuation practices to mark boundaries within and between propositions.

1. A person has to prove themselves to the public for what reason? To be in a certain position in society or is it just to belong and be known. Being different is the best part of being a human. To be totally different from everybody else and know that there is no two people alike. Being a person selfmakes them different so what does it matter what they drive or how big there house is.

2. One of the biggest problems that my brother has. Is this complex about how he stands up on his pedestal and everybody is below him.

3. Street racing is like skateboarding on a bigger scale, those who don't participate in the "sport" will have to deal with those who do. There was no place for skateboarders to go in small towns, until the skateboarders talked to the city committee. Street racing is the same thing, nothing will happen until some one decides to face facts and the facts are that people love to be competitive. People love to 
do whatever it takes to get to the top, the problem is that people are starting to get dangerous and innocent people are getting hurt.

4. Some of the greatest thinkers in the history of mankind, were those that have went against authority and made their own decisions.

\section{Implications of the Framework for Analyzing Developing Writing}

The claim behind the proposed taxonomy is that although developing writers produce non-standard constructions, their textual "errors" are best understood as principled attempts to manage information and not clumsy attempts to construct a "standard" text. That developing writers are aware of their communicative obligation to manage information is often apparent in the constructions they use, many of which rarely, if ever, occur in standard texts. For example, mature writers rarely introduce topics using fragments or questions as presentationals. The use of prefaces, constructions which function to introduce topics in speech, demonstrates the developing writer's communicative awareness. Mature writers generally do not use rhetorical questions to shift focus. When they do so, their style is clearly marked. When developing writers use mixed constructions, never found in mature texts, they are responding to principles of how information is organized in text.

We claim that the non-standard constructions students use to manage information are innovative responses to textual demands. As such, they are evidence of students striving in purposeful ways to construct communicative texts. Rhetorical questions and non-standard punctuation practices are good examples. Faced with the task of introducing a new focus within the topic, the student can make use of a rhetorical question instead of using a cleft construction, which he or she may be unfamiliar with. The rhetorical question is a useful tool to introduce a focus without having to make it explicit because the answer to any question is focused information. In other words, students who use this construction for this purpose certainly know what they need to do. The issue which confronts their teachers is how best to guide them to more appropriate constructions.

The use of non-standard punctuation to indicate the boundaries within and between propositions is another case in point. The nonstandard punctuation usage of students, although not reflecting syntactic principles, is not random. Instead it serves to mark proposition boundaries or topic from comment within a proposition. Rather than 
demonstrating student carelessness, this kind of non-standard punctuation reveals innovative attempts to communicate as clearly as possible with the resources the student has.

\section{Pedagogical Implications}

We have argued that the non-standard constructions students use to manage information in their texts are innovative and principled attempts to manage information flow. Because student texts reflect student principles of information management, students have great difficulty in perceiving that such sentences are deviant from a mature-writing perspective. Read-aloud editing can help students notice many surface errors but is not as helpful in identifying errors in topic management, reference, or information sequencing. We believe that explicit instruction is necessary for students to perceive that the non-standard constructions they may use to manage information are not appropriate for academic writing.

We advocate a pedagogy that follows in a straightforward manner from our taxonomy of information management in texts. More generally, we urge teachers not to assign only personal narratives. Because the topic of personal narratives is the protagonist, they can be written with few, if any, topic changes. Assignments which oblige the student to shift topics or to shift focus within a topic facilitate greater awareness of the language needed to do so appropriately in academic writing. Of course, argumentative topics require such shifts, but so do more straightforward tasks such as descriptions. A description of a room, for instance, requires the writer to shift focus as he or she moves from one part of the description to another.

A developmental pedagogy of text construction should be based on an appreciation of principles underlying student writing. The taxonomy we propose suggests making explicit comparisons between student texts and mature texts. For example, a paragraph from a student paper which introduces topics inappropriately either through use of prefaces, fragments, or mixed constructions is compared to a text which introduces topics appropriately. Students realize that while topics are introduced in both texts, different grammatical structures are used in academic writing than in the student text. The key instructional point is that the principles of topic management be made explicit through the comparison between the grammar constructions of the student text and the mature writing text. Similar comparisons should be made in regard to reference tracking and information sequencing. When students can recognize that their constructions are inappropriate in an academic context, then the teaching of revision strategies can begin. 


\section{Conclusion}

We have argued in this article for teaching English grammar to developing writers from a principled student perspective, one which reflects students' keen awareness of principles of information management and communication. In 1985, Hartwell argued that teaching "school grammar" would not lead to improvement in writing skills because the categories of school grammar do not reflect what students tacitly know about the language and because there is no relation between learning these categories and writing. The efforts of structuralist linguists in the 1950s and 1960s to reform English language teaching also foundered on this point. While acknowledging that the work of DeBeaugrande and Noguchi is very important, we contend that effective grammar teaching in a writing class must be informed by a student perspective which sees non-standard constructions not as errors but as reflections of developmental principles which inform student text construction.

It is interesting that Hartwell argues against the explicit teaching of grammar, suggesting that most errors, including fragments, are best understood as performance errors - mistakes in punctuation (120). Moreover, citing Bartholomae, Hartwell claims that "by reading aloud, [most students] will correct in essence all errors of spelling, grammar, and, by intonation, punctuation, but usually without noticing that what they read departs from what they wrote" (121). While many surface errors can be self-corrected, we believe that the constructions we have discussed are not performance errors and are not easily self-corrected because they reflect underlying principles that developing writers have. It is striking that the one error that Bartholomae's student did not selfcorrect is a mixed construction (261-262). ${ }^{5}$ Because such constructions reflect underlying principles, we also disagree with Kutz's claim that these kinds of student errors will "disappear" as an effect of extensive reading and writing (395).

Innovative constructions reflect clear developmental principles of managing information in texts. We encourage grammar instruction in writing classes which draws students' attention to these innovations and demonstrates why these constructions are not effective from a mature writing perspective. Grammar instruction which is rooted in traditional categories and considers non-standard constructions as wrong rather than as purposeful and communicative will fail the student. We suspect it has already had that effect. All of the examples in our taxonomy were written by students who have had at least twelve years of formal education. However, instruction that looks positively at student innovations might succeed. Through our taxonomy, we suggest an outline of the pedagogical content needed to stay in step with student development. 
Our discussion of grammar and error is unusual, but traditional approaches do not help students with persistent errors of the type we describe. Traditional pedagogies start from the assumption that what students do is wrong. We advocate a pedagogy for teaching grammar that understands students' non-standard constructions as the student does - as both innovative and principled attempts to reconcile the writer's understanding and skill with reader need.

\section{Notes}

1. Similar discussions about mixed constructions can be found in Hacker (207-211), Lunsford and Connors (307-311), and Troyka (325326).

2. The term interlanguage was first proposed by Larry Selinker to describe the grammatical principles that second language students have about language learning. Despite the use of the prefix inter- an interlanguage must not be thought of as a grammar between the student's first language and the second language but as a principled grammatical system itself.

3. Mel'cuk notes that all three of these areas are necessary for developing a framework for what he calls communicative organization or information packaging.

4. All students whose words are cited have granted their consent. Consent forms are on file with the authors.

5. In the taxonomy (IA, Developing Writer 2), we have included an example of developing writing which Bartholomae presents as evidence that basic writers are not "immature." He claims that such structures are "intentional" and evidence that the student is "using writing as an occasion to learn" (254). Bartholomae does not offer an explanation of the principles underlying this construction.

\section{Works Cited}

Bartholomae, David. "The Study of Error." College Composition and Communication 31 (1980): 253-269.

Barton, Ellen, et al. "The Awkward Problem of Awkward Sentences." Written Communication 15 (1998): 69-98.

Biber, Douglas, et al. Longman Grammar of Spoken and Written English. Edinburgh Gate, UK: Pearson Education, 1999. 
Carkeet, David. “Understanding Syntactic Errors in Remedial Writing." College English 38 (1977): 682-686, 695.

Coleman, Charles F. "Our Students Write with Accents: Oral Paradigms for ESD Students." College Composition and Communication 48 (1997): 486-500.

Connors, Robert C. "Grammar in American College Composition: An Historical Overview." The Territory of Language. Ed. Donald A. McQuade. Carbondale, IL: Southern Illinois UP, 1986. 3-22.

DeBeaugrande, Robert. "Forward to the Basics." College Composition and Communication 35 (1984): 358-367.

Fries, Charles. C. (1927). "The Rules of Common School Grammars." Publications of the Modern Language Association 42 (1927): 221-237.

-- . The Structure of English. New York: Harcourt Brace \& World, 1952.

Hacker, Diana. The Bedford Handbook. 5th ed. Boston: Bedford Books, 1998.

Hartwell, Patrick. "Grammar, Grammars, and the Teaching of Grammar." College English 47 (1985): 105-127.

Hult, Christine A., and Thomas N. Huckin. The New Century Handbook. 2nd ed. New York: Longman, 2002.

Kutz, Eleanor. "Between Students' Language and Academic Discourse: Interlanguage as Middle Ground." College English 48 (1986): 385396.

Lunsford, Andrea, and Robert Connors. The St. Martin's Handbook. 3rd ed. New York: St. Martin's Press, 1995.

Mel'cuk, Igor. Communicative Organization in Natural Language: The Semantic-Communicative Structure of Sentences. Philadelphia: John Benjamins Publishing Company, 2001.

McQuade, Donald A., ed. The Territory of Language. Carbondale, IL: Southern Illinois UP, 1986.

Noguchi, Rei. Grammar and the Teaching of Writing. Urbana, IL: NCTE, 1991.

Selinker, Larry. "Interlanguage." International Review of Applied Linguistics 10 (1972): 209-231.

Shaugnessy, Mina P. Errors and Expectations. New York: Oxford UP, 1977.

Smitherman, Geneva. "CCCC's Role in the Struggle for Language Rights." College Composition and Communication 50 (1999): 349-376.

Troyka, Lynn Q. Simon \& Shuster Handbook for Writers. 3rd ed. Englewood Cliffs, NJ: Prentice Hall, 1993. 


\section{Loretta S. Gray and Paula Heuser}

\section{NONACADEMIC PROFESSIONALS' PERCEPTION OF USAGE ERRORS}

ABSTRACT: To test whether nonacademic professionals' attitudes towards usage errors have changed in twenty years, we conducted a small-scale survey similar to one conducted by Maxine Hairston in 1979. The results differ from those of the earlier study, indicating a trend for respondents to find errors less bothersome than the respondents did twenty years ago. However, the results support the claim made by Hairston and other researchers that many of the errors found most bothersome are dialect features. We conclude this report by discussing the implications as well as the limitations of our findings.

In 1981, College English published an article by Maxine Hairston entitled "Not All Errors Are Created Equal: Nonacademic Readers in the Professions Respond to Lapses in Usage." Since its publication, Hairston's research has appeared in other books, both academic and nonacademic. For example, Rei Noguchi discusses Hairston's results in Grammar and the Teaching of Writing, Constance Weaver refers to them in Teaching Grammar in Context, and Kathryn Riley and Frank Parker use them in a chapter-final exercise in English Grammar. Outside of the classroom, Douglas Cazort uses Hairston's findings as an organizing principle in his book for the usage-anxious writer, Under the Grammar Hammer. Because these results have been considered significant, we conducted a similar survey to see whether responses to the usage topics cited in Hairston's study, which relate to matters of grammar, spelling, diction, and punctuation, have changed in the past twenty years.

In both academic and popular forums, usage issues are still at the center of debates over the status of "Standard English" (Bex and Watts 5, Lippi-Green 53). Although much has been written since 1981 about language variation and language rights, writers of both popular and academic books continue to report entrenched, conservative attitudes toward usage. In The Language Instinct, Steven Pinker discusses the intolerance of "language mavens" (370-403), and in "The Consequences of Standardisation in Descriptive Linguistics," James Milroy warns

Loretta Gray teaches composition and applied linguistics at Central Washington University in Ellensburg, Washington. Paula Heuser teaches English at Fujairah Women's College in the United Arab Emirates.

DOI: 10.37514/JBW-J.2003.22.1.07 50 
against the capricious judgments of "language guardians," many with a limited knowledge of grammar or "a clear notion of what 'grammaticality' is" (21). Deborah Cameron advises against simply dismissing the views of language mavens and guardians, instead recommending that a full account be given of their language judgments as well as the beliefs and values that underlie them (xi).

We have undertaken this study with the hope that by learning more about the conventions of and attitudes toward language, we can refine our class discussions of language usage. Unless one takes a prescriptivist approach to language, teaching usage is difficult. On the one hand, we want to recognize and appreciate language variation. On the other, we want our students to be aware of the conventions that they may be expected to follow in school and in the workplace, as well as to be conscious of the character judgments often accompanying language bias.

\section{Hairston's Study}

Hairston introduces her research on usage by describing a quandary she encountered while writing a composition textbook. Although "content and organization" were her primary concerns, she worried that neglect of "surface features" would lead to complaints from professionals outside of academia. Hairston explains:

[I]f we take the attitude that helping students to generate content and organize it in a coherent pattern should be our major goal and that surface features are comparatively unimportant, we open ourselves to attack from that large group of nonacademic readers who are genuinely - even passionately - concerned about good English. They are the administrators and executives and business people who claim that we are not doing our job, that they hire high-school or college graduates who cannot write a readable report or compose a decent letter. They complain that their employees cannot spell or punctuate and that much of the writing they see by professionals is semi-literate. And they imply - or sometimes charge openly - that in their day English teachers were a different breed who had standards and saw to it that no one left their classrooms without being able to write. (794)

Thus, believing that surface conventions were indeed important and hoping to give appropriate advice to students headed for the nonacademic workplace, Hairston set out to determine whether common errors could be sequenced according to priority. Some mistakes might 
draw more attention than others, she posited. Her hypothesis was confirmed in a survey she conducted, the results of which suggested the title for her article: "Not All Errors Are Created Equal." She found that errors do bother nonacademic professionals, but not always the same errors and not always to the same degree.

Hairston surveyed 101 professionals, none of whom were English teachers, $85 \%$ of whom were acquaintances of hers. Her survey (see Appendix A) consisted of sixty-six sentences containing one error apiece. (She later removed one sentence because of a typing mistake.) She then asked nonacademic professionals to indicate their feelings about the sentences by choosing one of the following answers: "Does not bother me," "Bothers me a little," or "Bothers me a lot." There was also a final question asking respondents to identify "the most annoying feature of the writing" they encountered at work. Eighty-four surveys were returned, which she tabulated by hand, putting the sentences in categories according to the number of responses to each answer. She established six categories: Outrageous, Very Serious, Serious, Moderately Serious, Minor, or Unimportant. The results of the categorization are listed below. Hairston did not explain why she combined the last two categories, Minor and Unimportant, into one. She also failed to clarify whether she had ranked the items within each category.

\section{Outrageous}

Nonstandard past or past-participle verb form: brung, has went

Lack of subject-verb agreement (Type 1): ${ }^{1}$

we was

Double negative:

there has never been no one here

Object pronoun as subject:

Him and Richard were

\section{Very Serious}

Fragment:

In spite of administrative warnings.

Fused sentence:

He concentrated on his job he never took vacations.

Noncapitalization of proper noun:

texas instruments company

Misspelling:

would of 
Lack of subject-verb agreement (Type 2):

Enclosed in his personnel file is his discharge papers.

Comma between the verb and its complement:

Cox cannot predict, that street crime will diminish.

Nonparallelism:

impressed by her smooth manner, elegant clothes, and

being witty

Faulty adverb form:

treated his men bad

Misuse of transitive verbs:

If the regulating agency sets down on the job

Serious

Faulty predication (Type 1): ${ }^{2}$

The state's hiring policies intimidate the applications of ambitious people.

Dangling modifier:

Having argued all morning, a decision was finally reached.

Subject pronoun used as an object pronoun:

The army moved my husband and I.

Lack of commas to set off interrupters:

When the time came to pay the filing fee however the candidate withdrew.

Lack of commas in a series:

We direct our advertising to the young prosperous and sports-minded reader.

Tense switching:

The reporter paid attention to officers but ignores enlisted men.

Use of a plural determiner with a singular noun:

These kind of errors

Lack of pronoun ${ }^{3}$-antecedent agreement:

Everyone who attends will have to pay their own expenses.

Moderately Serious

Lack of possessive determiner before a gerund:

no objections to us leaving

Lack of comma to set off an absolute or a nonrestrictive appositive:

The President dismissed four cabinet members among them Joseph Califano. 
Inappropriate use of quotation marks:

"Take what you want and pay for it.

Lack of subjunctive mood:

If I was in charge

Object pronoun as predicate nominative:

That is her.

Lack of comma after an introductory clause:

Although the candidate is new to politics she has a

good chance of winning.

Faulty predication (Type 2):

The situation is when the patient ignores warning

Word usage:

symptoms.

The three men talked between themselves.

Comma splice:

Never reveal your weaknesses to others, they will ex ploit them.

\section{Minor or Unimportant}

Qualifier before a nongradable adjective:

the most unique city

Collocation mistake:

different than that of previous years

Lack of subject-verb agreement (Type 3):

The data supports

Use of colon after a linking verb:

Three causes of inflation are:

Omission of an apostrophe in a contraction:

Its wonderful.

Hairston's categorization is a valuable first attempt at gauging the impact of usage errors on professionals who are not academics. The following evaluation of her work, then, is done in the spirit of improvement. Our own study seeks, among other things, to broaden and strengthen some methodological aspects of Hairston's study conducted over twenty years ago.

One problem with Hairston's survey is that it lacks consistency in the number of sentences used for each category. The survey includes four examples of fragments but only two examples of dangling modifiers, two apostrophe errors but only one colon error, and so on. Hairston does not explain why she chose a specific number of sentences for each error category. Nor does she account for her choice of error category in the first place. For example, she does not say why she includes misuse of the colon but not misuse of the semicolon. In addition, she neglects 
to explain differences in error types: some errors, such as omitting final quotation marks, are likely the result of the writer's uneven proofreading, while others, such as using an object form as the subject predicate, probably result from a dialect or register preference. Accordingly, these errors may or may not be intentional.

Furthermore, the survey itself includes some distracting sentences. For instance, one sentence, which is supposed to be incorrect, is actually correct. The sentence Extra copies will be provided for whoever needs them was presumably testing for the use of whomever as object. However, the sentence is correct because whoever is the subject of needs. The entire clause whoever needs them is the object of the preposition for. Similarly, it is not clear that We direct our advertising to the young prosperous and sports-minded reader is necessarily comma deficient. According to Hairston, there should be commas because there is a series of adjectives. Although these adjectives do appear together, they are not necessarily coordinate. The "writer" (and perhaps some of Hairston's respondents) may be differentiating between young and old prosperous and sports-minded readers. Yet another sentence includes two possible errors. The error in Good policemen require three qualities: courage, tolerance, and dedicated could be faulty predication or lack of parallelism.

The tallying of the surveys in Hairston's study is also problematic. Out of 84 surveys returned, the number of responses recorded for each sentence ranged from 64 to 88 . If some people chose not to answer or answered with two responses, that deviation was not mentioned. Thus, the ranking of errors may not be reliable. In addition, the methodology used for ranking is not clearly described, resulting in inconsistencies and gaps in reporting. As the raw data are included in the report, however, we tried doing our own ranking. We used three different methods: (1) adding just the responses in the "bothers me a lot category," (2) adding all responses in the "bothers me a little" and "bothers me a lot" categories, (3) adding all responses in the "bothers me a little" and "bothers me a lot" categories but counting double for those responses in the "bothers me a lot" category. Unfortunately, we derived three different rankings, and inconsistencies and lapses were found in all three. For example, one sentence with noncapitalization of proper nouns (I was last employed by texas instruments company) clustered with other errors labeled very serious; however, another sentence with a noncapitalization error (A person who knows french and german will get along well in Switzerland) was ranked with other sentences labeled moderately serious. Along with inconsistencies such as this one, certain error types were not ranked; the possessive-signaling apostrophe and vague pronoun usage are two of those unmentioned. 


\section{Update of Survey}

In our attempt to update this study, we made some changes in the original survey. (This study's survey can be found in Appendix B.) First, we removed sentences in categories that included more than two examples. As well as taking sentences out, we added sentences. In categories that contained only one example, we added another. This change made it possible to examine the consistency of judgments. If the sentences were judged similarly, it would be safe to say that a given type of error was or was not bothersome. In addition, we included correct sentences in order to determine whether the professionals really identified mistakes or whether they were just marking an answer to save face. For the same purpose, we added a "No error" answer. Because we added quite a few sentences, we decided to remove those that contained errors we have rarely encountered so that the survey would not become too long. We also altered a few sentences that might be considered offensive to today's readers (e.g., Man is not the only user of tools, apes can also learn to manipulate them). Finally, we added sentences that reflected errors commonly found in student papers at our institution. Along with these changes in the content of the survey, we altered the format to include a blank under a sentence for those who wished to comment on the sentence.

\section{Surveying Procedures}

The survey was first piloted and then sent out to 420 nonacademic professionals from around the United States. This pool of prospective respondents included relatives, friends, acquaintances of friends, and professionals listed on Internet sources. Only 84 of the 420 surveys were returned, the same number of responses received for the original study. Most of the respondents in our study were from the West Coast, although 15 different states were represented. Of the 84 respondents, 51 were women and 33 were men. This study thus differs from Hairston's Texas-based, male-dominated study. The number of occupations represented in the two studies is similar, between 50 and 55; however, no teachers were included in our study. Hairston surveyed five non-English-teaching professors, three deans, and a superintendent.

\section{Results and Discussion}

The comparison reported in Table 1 shows the change in the num- 
ber of respondents marking sentences with usage errors as "bothers me a lot." For this comparison, we used only sentences from our study that were from the same error category as those in Hairston's; sentences from an error category not included in Hairston's study were dropped. We also matched the number of sentences falling into each category. Thus, if Hairston used only one test sentence, we chose the sentence from our study that most closely matched it syntactically. When an error category includes two sentences, numbers in parentheses placed below the category indicate the number of sentences out of the total number of sentences used in the comparison. So $1 / 2$ means that one of two sentences with the same error decreased by the amount indicated at the top of the column. The results of our survey show a trend for respondents to find errors less bothersome than the respondents did twenty years ago.

For most sentences, the percentage of "bothers me a lot" responses decreased, and the percentage of "bothers me a little" responses increased. In our study, nonacademic professionals identified a problem but were not as bothered by it. For 23 of the 39 sentences in the comparison, the number of responses in the "bothers me a lot" category dropped by $10 \%$ or more. For 6 sentences, the drop was $5 \%$ to $9 \%$. For 5 sentences, the number dropped $1 \%$ to $4 \%$ percent. That leaves 5 sentences that did not follow the trend. In total, these sentences represent 31 different error types.

Because Hairston prepared a ranking of her errors (from "outrageous" to "unimportant"), we decided to compare a ranking of our data against hers (see Table 2). However, given that her methodology for ranking was not clear, we returned to her data and ranked them according to the number of responses in the "bothers me a little" and the "bothers me a lot" categories, counting double for the responses in the "bothers me a lot" category to account for the intensity of the response.

Following this same method, we then ranked our own data. At first, we tried to rank them according to error category, but we found this procedure problematic because both sentences from one error category were rarely ranked together. In order to retain the intensity of responses to a particular sentence, we decided instead to rank only the fifteen most annoying sentences from each study and to include a description of the usage error in each.

Our list is similar to Hairston's. The most bothersome errors are still nonstandard verb forms, double negatives, object pronouns as subjects, and lack of subject-verb agreement. The lists do vary in some ways, however. For example, our list includes tense switching and misspelling, but Hairston's does not. And conversely, Hairston's list includes fragments and noncapitalization, but ours does not. The relatively low ranking of fragments differs from other studies as well (Leonard and Gilsdorf 145; Beason 41). 
Table 1. Decrease in "Bothers Me a Lot" Category

\begin{tabular}{|c|c|c|c|c|}
\hline $\begin{array}{l}\text { Decrease: } \\
20 \% \text { or more }\end{array}$ & \begin{tabular}{|l} 
Decrease: \\
$10 \%$ or more
\end{tabular} & $\begin{array}{l}\text { Decrease: } \\
5 \% \text { to } 9 \%\end{array}$ & \begin{tabular}{|l} 
Decrease: \\
$1 \%$ to $4 \%$
\end{tabular} & No decrease \\
\hline $\begin{array}{l}\text { Noncapitalizati- } \\
\text { on } \\
(1 / 2)\end{array}$ & $\begin{array}{l}\text { Nonstandard } \\
\text { past-participle } \\
\text { verb form }\end{array}$ & $\begin{array}{l}\text { Lack of subject- } \\
\text { verb agreement } \\
\text { Type } 1(1 / 2)\end{array}$ & Tense switching & $\begin{array}{l}\text { Contraction } \\
\text { apostrophe } \\
(2 / 2)\end{array}$ \\
\hline $\begin{array}{l}\text { Subject pronoun } \\
\text { used as object }\end{array}$ & Double negative & Fused sentence & $\begin{array}{l}\text { Lack of subject- } \\
\text { verb agreement } \\
\text { Type } 3\end{array}$ & $\begin{array}{l}\text { Lack of subject- } \\
\text { verb agreement } \\
\text { Type } 2\end{array}$ \\
\hline $\begin{array}{l}\text { Lack of } \\
\text { pronoun-antec- } \\
\text { edent } \\
\text { agreement } \\
(2 / 2)\end{array}$ & $\begin{array}{l}\text { Object pronoun } \\
\text { as subject }\end{array}$ & $\begin{array}{l}\text { Omission of } \\
\text { possessive } \\
\text { apostrophe }\end{array}$ & $\begin{array}{l}\text { Nonparallelism } \\
(1 / 2)\end{array}$ & Fragment $(1 / 2)$ \\
\hline $\begin{array}{l}\text { Dangling } \\
\text { modifier } \\
(2 / 2)\end{array}$ & Misspelling & $\begin{array}{l}\text { Lack of commas } \\
\text { in a series }\end{array}$ & $\begin{array}{l}\text { Lack of subject- } \\
\text { verb agreement } \\
\text { Type } 1(1 / 2)\end{array}$ & $\begin{array}{l}\text { Nonstandard } \\
\text { past verb form }\end{array}$ \\
\hline $\begin{array}{l}\text { Object pronoun } \\
\text { as predicate } \\
\text { nominative }\end{array}$ & $\begin{array}{l}\text { Misplaced } \\
\text { comma } \\
\text { (verb/complem- } \\
\text { ent) }\end{array}$ & $\begin{array}{l}\text { Lack of commas } \\
\text { around } \\
\text { interrupters } \\
(1 / 2)\end{array}$ & $\begin{array}{l}\text { Lack of commas } \\
\text { around } \\
\text { interrupters } \\
(1 / 2)\end{array}$ & \\
\hline $\begin{array}{l}\text { Lack of } \\
\text { possessive } \\
\text { determiner } \\
\text { before a gerund }\end{array}$ & $\begin{array}{l}\text { Faulty } \\
\text { predication } \\
\text { Type 1 }\end{array}$ & $\begin{array}{l}\text { Faulty adverb } \\
\text { form }\end{array}$ & & \\
\hline \multirow[t]{8}{*}{$\begin{array}{l}\text { Use of a plural } \\
\text { modifier with a } \\
\text { singular noun }\end{array}$} & $\begin{array}{l}\text { Lack of comma } \\
\text { to set off an } \\
\text { absolute }\end{array}$ & & & \\
\hline & $\begin{array}{l}\text { Nonparallelism } \\
(1 / 2)\end{array}$ & & & \\
\hline & Fragment (1/2) & & & \\
\hline & $\begin{array}{l}\text { Lack of } \\
\text { subjunctive } \\
\text { mood }\end{array}$ & & & \\
\hline & $\begin{array}{l}\text { Noncapitalizati- } \\
\text { on } \\
(1 / 2)\end{array}$ & & & \\
\hline & $\begin{array}{l}\text { Colon after } \\
\text { linking verb }\end{array}$ & & & \\
\hline & $\begin{array}{l}\text { Collocation } \\
\text { mistake }\end{array}$ & & & \\
\hline & $\begin{array}{l}\text { Qualifier before } \\
\text { a nongradable } \\
\text { adjective }\end{array}$ & & & \\
\hline
\end{tabular}


One expected yet disturbing finding of this study was that our survey takers were inconsistent, and sometimes incorrect, in their application of rules. As previously mentioned, we made sure we had two examples for each category of error. The differences in "bothers me a lot" responses to the two examples ranged from $0 \%$ to $38 \%$. This disparity could have been caused by having more than one problem in a sentence. However, in other cases, that reason does not hold. The sentences for subject-verb agreement (Type 2) are as follows:

Enclosed in his personnel file is his discharge papers and job references.

Included on the resume is the experience and education of the applicant.

Sixty percent of the respondents were bothered a lot by the first sentence; only $28 \%$ of these same respondents were bothered by the second sentence. We believe that many of the respondents were either viewing "experience and education" as one conceptual unit or applying a proximity rule to these sentences rather than the traditional handbook rule. Also noting inconsistencies among each of the fourteen participants in his study, Larry Beason explains the variation with both textual reasons (e.g., lexical or syntactic complexity) and extra-textual reasons (e.g., assumptions about the nature of language) (47).

By adding a "no error" category and correct sentences, we were also able to determine how well some of the rules were understood. In all but one of the error categories, there were a number of respondents who marked "no error" next to sentences that contained errors according to traditional handbook rules. Likewise, all the correct sentences were marked bothersome by some percentage of respondents. For example, next to $\mathrm{He}$ is one of the people who agree with the manager, $48 \%$ of the respondents marked "bothers me a little" and $37 \%$ of the respondents marked "bothers me a lot." Given such inconsistencies, English teachers may well ask, "What should we teach our students?" If students learn and apply the handbook rule, they may be considered poor writers. This finding, by the way, supports Marianne CelceMurcia and Diane Larsen-Freeman's suggestion that this agreement rule be revised to reflect current usage (66). 
Table 2. Comparison of Sentences with Errors (Most Bothersome to Least Bothersome)

\begin{tabular}{|c|c|}
\hline Hairston (1979, published in 1981) & Current (2000) \\
\hline $\begin{array}{l}\text { 1. When Mitchell moved, he brung his } \\
\text { secretary with him. } \\
\text { Nonstandard past verb form }\end{array}$ & $\begin{array}{l}\text { 1. When we was in the planning stages of } \\
\text { the project, we underestimated costs. } \\
\text { Subject-verb agreement (type 1) }\end{array}$ \\
\hline $\begin{array}{l}\text { 2. There has never been no one here like } \\
\text { that woman. } \\
\text { Double negative }\end{array}$ & $\begin{array}{l}\text { 2. When Mr. Mitchell moved, he brung } \\
\text { his golf clubs with him. } \\
\text { Nonstandard past verb form }\end{array}$ \\
\hline $\begin{array}{l}\text { 3. Him and Richards were the last ones } \\
\text { hired. } \\
\text { Object pronoun as subject }\end{array}$ & $\begin{array}{l}\text { 3. I can't get no one to do the job. } \\
\text { Double negative }\end{array}$ \\
\hline $\begin{array}{l}\text { 4. Calhoun has went after every prize in } \\
\text { the university. } \\
\text { Nonstandard past-participle verb form }\end{array}$ & $\begin{array}{l}\text { 4. The director should have went to the } \\
\text { training session. } \\
\text { Nonstandard past-participle verb form }\end{array}$ \\
\hline 5. Jones don't think it is acceptable. & $\begin{array}{l}\text { 5. Him and Richards were the last ones } \\
\text { hired. } \\
\text { Object pronoun as subject }\end{array}$ \\
\hline $\begin{array}{l}\text { 6. When we was in the planning stages of } \\
\text { the project, we underestimated costs. } \\
\text { Subject-verb agreement (Type 1) }\end{array}$ & $\begin{array}{l}\text { 6. There has never been no one here like } \\
\text { him. } \\
\text { Double negative }\end{array}$ \\
\hline $\begin{array}{l}\text { 7. State employees can't hardly expect a } \\
\text { raise this year. } \\
\text { Word usage }\end{array}$ & $\begin{array}{l}\text { 7. Mrs. Gray and her are working on the } \\
\text { project. } \\
\text { Object pronoun as subject }\end{array}$ \\
\hline 8. Senator javits comes from new york. & $\begin{array}{l}\text { 8. The client refused to pay the filing fee } \\
\text { and then cancels his court date. } \\
\text { Tense switching }\end{array}$ \\
\hline $\begin{array}{l}\text { 9. The company is prepared to raise } \\
\text { prices. In spite of administrative } \\
\text { warnings. } \\
\text { Fragment }\end{array}$ & $\begin{array}{l}\text { 9. Good police officers require three } \\
\text { qualities: courage, tolerance, and } \\
\text { dedicated. } \\
\text { Nonparallelism, Faulty predication }\end{array}$ \\
\hline 10. The lieutenant treated his men bad. & $\begin{array}{l}\text { 10. He concentrated on his job he never } \\
\text { took vacations. } \\
\text { Fused sentence }\end{array}$ \\
\hline $\begin{array}{l}\text { 11. Good policemen require three } \\
\text { qualities: courage, tolerance, and } \\
\text { dedicated. } \\
\text { Nonparallelism, Faulty predication }\end{array}$ & $\begin{array}{l}\text { 11. Mrs. Jones don't think it's acceptable. } \\
\text { Subject-verb agreement (Type 1) }\end{array}$ \\
\hline $\begin{array}{l}\text { 12. The army moved my husband and I } \\
\text { to California last year. } \\
\text { Subject pronoun as object }\end{array}$ & $\begin{array}{l}\text { 12. She went to the meeting she gave her } \\
\text { presentation. } \\
\text { Fused sentence }\end{array}$ \\
\hline $\begin{array}{l}\text { 13. Cox cannot predict, that street crime } \\
\text { will diminish. } \\
\text { Comma between verb and complement }\end{array}$ & $\begin{array}{l}\text { 13. She wishes the presentation would of } \\
\text { gone better. } \\
\text { Misspelling }\end{array}$ \\
\hline $\begin{array}{l}\text { 14. He concentrated on his job he never } \\
\text { took vacations. } \\
\text { Fused sentence }\end{array}$ & $\begin{array}{l}\text { 14. The manager treated his employees } \\
\text { bad. } \\
\text { Faulty adverb form }\end{array}$ \\
\hline $\begin{array}{l}\text { 15. I was last employed by texas } \\
\text { instruments company. } \\
\text { Noncapitalization of proper nouns }\end{array}$ & $\begin{array}{l}\text { 15. He went through a long battle a fight } \\
\text { against unscrupulous opponents. } \\
\text { Lack of comma to set off an appositive }\end{array}$ \\
\hline
\end{tabular}




\section{Conclusion}

The results of our study, and of all similar studies, are weakened by the impossibility of researchers knowing for sure which part of a sentence participants are judging. The results of this study also deserve qualification because the number of participants was small; thus, the percentages used in Table 1 might be deceiving. A $10 \%$ shift refers to only eight people. In addition, this study would be improved with better sentences. Like some of Hairston's sentences, some sentences in the current study included more than one possible error. Moreover, studies such as this one would benefit from surrounding the sentences with context. Decontextualized sentences, though they may be grammatically correct, often just sound strange.

Despite the survey's weaknesses, our study suggests that there has been a change in the ways nonacademic professionals view lapses in usage: they are not as bothered by many of the errors that were found irksome twenty years ago. Generally, fewer sentences fall into the "bothers me a lot" category. In his 1991 book, Noguchi predicted that the attitudes expressed in the Hairston study would change. This change seems to have occurred. However, Noguchi also claimed that if more females had participated in Hairston's study, "the degree of negative reactions for many of the nonstandard items would have, in all likelihood, increased rather than decreased" (27). This claim was based on sociolinguistic research from the 1970s showing that when perceiving language change as socially significant, women chose conservative rather than innovative forms. Hairston herself noted that women registered more responses in the "bothers me a lot" category (796). Noguchi's prediction, though, was not borne out in our overall findings; our female-dominated pool of respondents was less conservative, if we take conservatism to be related to intolerance of usage errors. Whether this finding contradicts earlier research or suggests that women today do not find these errors socially significant is not clear.

Our study does, however, suggest a dialect bias, also noted by Hairston, Noguchi, Weaver, and Rubba. Many of the high-stakes errors are common dialect features. But these features are only considered erroneous when they appear in contexts that require Edited American English. If double negatives and nonstandard pronoun forms appear on an application letter, the writer will be judged harshly. When these forms are used among speakers of the same dialect, they will go unremarked. Unfortunately, according to Johanna Rubba, students from lower socio-economic backgrounds will likely be perceived as making errors, instead of choices, and consequently be "punished more severely" for doing so.

As teachers, then, we need to encourage students to become aware 
of register and dialect differences. In order to do so, we may have to go beyond the minimalist grammar recommended by Noguchi and Weaver. Students may benefit from learning sentence parts other than the subject, verb, and modifier. For example, in order to choose correct pronouns for occasions requiring Edited American English, students will have to know the difference between subject and object. In addition, to select an appropriate adverb for a formal paper, they will have to know the difference between an adverb and an adjective. Learning certain rules of formal English may help students in various ways. For example, students who develop a large repertoire of metalinguistic skills may not only produce essays that are more "correct," but they may also develop a better understanding of the similarities and differences between the language of their homes and the language of other communities such as the university or the workplace.

We should be honest in letting students know of the inconsistency that exists in the nature and application of usage rules. Sometimes participants in our study found one instance of an error but not the second instance. Sometimes they hypercorrected; that is, they mistakenly found a structure erroneous because it resembled another erroneous structure. A common hypercorrection is to suppose that because object pronouns are incorrect in the position before the verb, they are also incorrect in positions following the verb. Additionally, there were some participants who misidentified an error (e.g., identifying a split infinitive when there was none). Such inconsistency implies a danger that subordinates are being judged unfairly. Thus, basic writing that follows the rules of formal English is not guaranteed high marks outside the classroom.

Although it is difficult to say what effect the results of this study may have, we hope that they reflect a trend toward tolerance and that this trend will continue. By "tolerance," we do not mean lowering standards to accept careless proofreading; rather, in tolerating usage that veers from a standard, we stress the need for teachers and students to recognize the arbitrariness of usage rules, the dialect prestige associated with the mastery of certain of these rules, and the misunderstanding and misapplication of many of these rules. Thus, we encourage the teaching of a comprehensive grammar curriculum, one that focuses both on the rules of English used for various professional purposes and on the rules that describe English used for other purposes. We advocate moving away from using the traditional dichotomies of correct/incorrect, right/wrong, grammatical/ungrammatical and instead moving toward discussing usage in terms of community conventions expectations of language usage and other behaviors that change as the defining features of the community change. Against this background, teachers and students, together, can examine language judgments their own and those of others - as well as the beliefs and values that 
support them.

\section{Notes}

Author's Note: An earlier version of this paper was presented at the 2000 ATEG Conference, Brooklyn Park, Minnesota. The authors would like to thank Rei Noguchi for his helpful comments.

1. Three types of subject-verb agreement were examined. The first type is based on the canonical subject-verb order. The second type is based on the inversion of the subject and the main verb. The third type is similar to the first in that the subject comes before the verb. It differs from the first in that the subject in Type 3 is used as a mass noun (like furniture) by many professional writers.

2. The first type of faulty predication involves nonlinking verbs. In Type 2, the main verb links the subject to an inappropriate clause.

3. In current descriptions of grammar, their is generally considered a determiner rather than a pronoun.

4. Prepared by NCTE's Assembly for the Teaching of English Grammar, Grammar Alive! A Guide for Teachers provides useful background information and activities addressing these goals.

\section{Works Cited}

Beason, Larry. "Ethos and Error: How Business People React to Errors." College Composition and Communication 53 (2001): 33-64.

Bex, Tony, and Richard J. Watts. Introduction. Standard English: The Widening Debate. Ed. Tony Bex and Richard J. Watts. London: Routledge, 1999. 1-10.

Cameron, Deborah. Verbal Hygiene. London: Routledge, 1995.

Cazort, Douglas. Under the Grammar Hammer. Los Angeles: Lowell House, 1997.

Celce-Murcia, Marianne, and Diane Larsen-Freeman. The Grammar Book: An ESL/EFL Teacher's Course. $2^{\text {nd }}$ ed. Boston: Heinle \& Heinle, 1999. Hairston, Maxine. "Not All Errors Are Created Equal: Nonacademic Readers in the Professions Respond to Lapses in Usage." College English 43 (1981): 794-806.

Haussamen, Brock, with Amy Benjamin, Martha Kolln, Rebecca Wheeler, and members of NCTE's Assembly for the Teaching of English Grammar. Grammar Alive! A Guide for Teachers. Urbana: National Council of Teachers of English, 2003. 
Leonard, Donald. J., and Jeanette W. Gilsdorf. "Language in Change: Academics' and Executives' Perceptions of Usage Errors." Journal of Business Communication 27 (1990): 137-58.

Lippi-Green, Rosina. English with an Accent. London: Routledge, 1997. Noguchi, Rei. Grammar and the Teaching of Writing. Urbana: National Council of Teachers of English, 1991.

Milroy, James. "The Consequences of Standardisation in Descriptive Linguistics." Standard English: The Widening Debate. Ed. Tony Bex and Richard J. Watts. London: Routledge, 1999, 16-39.

Pinker, Steven. The Language Instinct: How the Mind Creates Language. New York: Harper Collins, 1994.

Riley, Kathryn, and Frank Parker. English Grammar: Prescriptive, Descriptive, Generative, Performance. Boston: Allyn \& Bacon, 1998.

Rubba, Johanna. "Grammar and Social Class: Dialect Discrimination in Language Arts." Assembly for the Teaching of English Grammar Conference. North Hennepin Community College, Brooklyn Park. 15 July 2000.

Weaver, Constance. Teaching Grammar in Context. Portsmouth: Boynton/Cook, 1996. 


\section{APPENDIX A}

\section{Sentences in Hairston's Study}

1. Extra copies will be provided for whoever needs them.

2. Tact not anger is the best tactic in this case.

3. He concentrated on his job he never took vacations.

4. Wellington said, Trains will just cause the lower classes to move about needlessly.

5. The three men talked between themselves and decided not to fire the auditor.

6. Never reveal your weaknesses to others, they will exploit them.

7. Everyone who attends will have to pay their own expenses.

8. Murphy is the person we chose to represent us. (Results discarded.)

9. Coventry is the most unique city in England.

10. People are always impressed by her smooth manner, elegant clothes, and being witty.

11. Almost everyone dislikes her; they say she is careless and insolent.

12. The state's hiring policies intimidate the applications of ambitious people.

13. The small towns are dying. One of the problems being that young people are leaving.

14. Having argued all morning, a decision was finally reached.

15. If the regulating agency sets down on the job, everyone will suffer.

16. The situation is quite different than that of previous years.

17. A person who knows french and german will get along well in Switzerland.

18. It is late in his term and inflation is worse and no one has a solution.

19. Our companys record is exceptional.

20. The President dismissed four cabinet members among them Joseph Califano.

21. When Mitchell moved, he brung his secretary with him.

22. Three causes of inflation are: easy credit, costly oil, and consumer demand.

23. When a person moves every year, one cannot expect them to develop civic pride.

24. We direct our advertising to the young prosperous and sports- 
minded reader.

25. The worst situation is when the patient ignores warning symptoms.

26. The army moved my husband and I to California last year.

27. He went through a long battle. A fight against unscrupulous opponents.

28. The lieutenant treated his men bad.

29. Sanford inquired whether the loan was overdue?

30. When the time came to pay the filing fee however the candidate withdrew.

31. The data supports her hypothesis.

32. Those are the employees that were honored.

33. Visitors find it difficult to locate the plant, which affects business.

34. Him and Richards were the last ones hired.

35. There has never been no one here like that woman.

36. These kind of errors would soon bankrupt a company.

37. My favorite quotation is, "Take what you want and pay for it.

38. The reporter paid attention to officers but ignores enlisted men.

39. If I was in charge of that campaign, I would be worried about opinion polls.

40. If Clemens had picked up that option, his family would of been rich.

41. Its wonderful to have Graham back on the job.

42. Calhoun has went after every prize in the university.

43. Next year we expect to send a representative to China (if Peking allows it.

44. Cheap labor and low costs. These are two benefits enjoyed by Taiwan-based firms.

45. The difficult part is if the client refused to cooperate.

46. State employees can't hardly expect a raise this year.

47. The supervisor has no objections to us leaving.

48. Although the candidate is new to politics she has a good chance of winning.

49. A convicted felon no matter how good his record may not serve on a grand jury.

50. I was last employed by texas instruments company.

51. When leaving college, clothes suddenly become a major problem.

52. Enclosed in his personnel file is his discharge papers and job references.

53. The president or the vice-president are going to be at the opening ceremonies.

54. To me, every person is an individual, and they should be treated with respect.

55. Good policemen require three qualities: courage, tolerance, and dedicated. 
56. The interruption will not effect my work.

57. I have always hoped to work in that field, now I will have the opportunity.

58. Senator javits comes from new york.

59. I believe everyone of them are guilty.

60. That is her across the street.

61. Cox cannot predict, that street crime will diminish.

62. When we was in the planning stages of the project, we underestimated costs.

63. The union claims it's rights have been violated.

64. The company is prepared to raise prices. In spite of administrative warnings.

65. Jones don't think it is acceptable.

66. Man is not the only user of tools, apes can also learn to manipulate them. 


\section{APPENDIX B}

\section{Sentences in Current Study}

Note: An asterisk indicates a sentence used for the comparison reported in Table 1.

1. Extra copies will be provided for whoever needs them.

2. That is him in the front row.

*3. These kind of errors would soon bankrupt a company.

*4. When the time came to pay the filing fees however the candidate withdrew.

5. He lay down for a nap after the noon meeting.

6. The market shares have grown quick.

7. If I would have known about the party, I would have attended it.

*8. The director should have went to the training session.

9. He is one of the people who agree with the manager.

10. Mrs. Gray and her are working on the project.

11. These data support our decision.

12. The manager didn't like his talking on the phone to non-customers.

*13. A convicted felon no matter how good his record may not serve on a grand jury.

*14. The small towns are dying. One of the problems being that young people are leaving.

*15. Him and Richards were the last ones hired.

16. Most of the computers from the 1970's are no longer in use.

17. Given that our deadline is only three weeks away, we have decided to postpone our annual meeting, which usually takes place in March, so that we can complete the project and submit it to the committee.

*18. We are merging with microsoft.

19. The museum bought a valuable old marble statue.

*20. Mrs. Jones don't think it's acceptable.

*21. If Mr. Clemens had picked up that option, his family would of been rich.

22. She went to the meeting she gave her presentation.

23. Included on the resume is the experience and education of the applicant.

24. There will be job recruiting at the university this week.

25. The staff must choose, which intern to hire. 
*26. Cheap labor and low costs. These are two benefits enjoyed by Taiwan-based firms.

*27. People are always impressed by her smooth manner, elegant clothes, and being witty.

*28. There has never been no one here like him.

*29. The manager treated his employees bad.

30. Sit the computer on the table.

*31. Good police officers require three qualities: courage, tolerance, and dedicated.

*32. The state's hiring policies intimidate the applications of ambitious people.

*33. He concentrated on his job he never took vacations.

*34. Having argued all morning, a decision was finally reached.

35. We must decide which computer software to use for the design of the Web page.

*36. The company asked my husband and I to move to California.

*37. Enclosed in his personnel file is his discharge papers and job references.

*38. A person who knows french will get along well in Quebec.

39. She did, however, attend the meeting on time.

40. The marketing director was a skilled diligent imaginative employee.

41. They asked my husband and me out to dinner.

*42. The reporter paid attention to officers but ignores enlisted men.

43. These type of stocks are expensive.

*44. Our companys record is exceptional.

*45. Ms. Cox cannot predict, that street crime will diminish.

46. The work was theirs, so they were rewarded properly.

*47. The supervisor has no objections to us leaving.

*48. The President dismissed four cabinet members among them Joseph Califano.

49. Lets look over these details after lunch.

50. The manager went through the training program, classes that all managers have to attend.

*51. If I was in charge of that campaign, I would be worried about opinion polls.

52. She wishes the presentation would of gone better.

*53. That is her across the street.

54. I can't get no one to do the job.

55. Who did you appoint to the cabinet?

56. If I was you, I'd apply for that position.

*57. Everyone who attends will have to pay their own expenses.

58. The hostess didn't mind him networking.

59. The investment is their's to handle.

60. Those are they in the file. 
61. Who did you call?

*62. The union claims it's rights have been violated.

*63. Coventry is the most unique city in England.

64. Ones resume must have education and experience listed.

*65. To me, every person is an individual, and they should be treated with respect.

66. The file will be more complete when the form is added.

67. The perks of the job are: maternity leave, three week vacations, and a company car.

*68. The situation is quite different than that of previous years.

69. The papers and contract are laying on the table.

70. The marketing result was different than that of last month.

*71. The data supports her hypothesis.

72. Everybody has to do his or her own work according to the manager's requests.

73. The criteria for the job is to have a Ph.D.

74. The reason that the meeting didn't go well proved that they were not prepared.

*75. Three causes of inflation are: easy credit, costly oil, and consumer demand.

*76. We direct our advertising to the young prosperous and sportsminded reader.

*77. Its wonderful to have Mr. Graham back on the job.

78. If it were up to the owner and I, we'd buy the stocks.

79. There was much economic turmoil during the 1990's.

80. He went through a long battle a fight against unscrupulous opponents.

81. If I had known about the meeting, I would have had the proofs done on time.

*82. When Mr. Mitchell moved, he brung his golf clubs with him.

*83. When leaving college, clothes suddenly become a major problem.

84. If we would have had that information by the deadline, we would have included it in the brochure.

*85. When we was in the planning stages of the project, we underestimated costs.

86. The client refused to pay the filing fee and then cancels his court date.

87. The 1998 's volatile stock market rose more than it fell.

88. The supplies to bring for the seminar will be paper, a laptop computer, and graph sheets. 


\title{
Laura Gray-Rosendale, Loyola K. Bird, and Judith F. Bullock
}

\author{
RETHINKING THE BASIC \\ WRITING FRONTIER: \\ NATIVE AMERICAN \\ STUDENTS' CHALLENGE TO \\ OUR HISTORIES
}

ABSTRACT: The authors contend that Native American students have too often been marginalized in Basic Writing research. Asking why this may have been the case, they call attention to the discipline's unwitting allegiance to images of "territory," "mapping, " and "Western frontierism." They also note that since much early research on Basic Writing has emanated from East Coast institutions, Basic Writers of the Southwestern United States have perhaps understandably received far too little attention. Contending that this lack of research may potentially result in a further "othering" of Native American students, they note that we must work against 1) a somewhat narrow, even racist conception of who Basic Writers might be, 2) the continued invisibility of Native American students as well as our collective lack of knowledge about how the cultural functions of tribal life impact writing skills, and 3) the unspoken mythology in our scholarship that the Basic Writer is largely an urban phenomenon - the student who can be heroically rescued from violence, crime, and poverty rather than the student who risks losing tribal and cultural affiliations by coming from the reservation and assimilating to the university environment. In response, each of the authors speaks of her own experiences working with Native American Basic Writing students from Arizona, Utah, and New Mexico, making assertions about what can be learned from these experiences. The article concludes with tentative suggestions for future research concerning Native American students and Basic Writing.

This project is born of a shared interest and passion-working with Native American students who have, correctly or not, been institutionally classified as "Basic Writers." As our stories will disclose, we

Laura Gray-Rosendale is Associate Professor of English at Northern A rizona University. GrayRosendale's publications include Rethinking Basic Writing: Exploring Identity, Politics, and Community in Interaction; Alternative Rhetorics: Challenges to the Rhetorical Tradition with Sibylle Gruber; and Fractured Feminisms: Rhetoric, Context, and Contestation with Gil Harootunian. Her two books on popular culture and radicalism are forthcoming in 2004. Loyola K. Bird, who is Jicarilla Apache, is pursuing her Master's degree in Northern Arizona University's Rhetoric, Composition, and Professional Writing program. Bird has worked for the Department of Interior, Bureau of Indian Affairs, and is now writing a book-length autobiography that traces her experiences with language and culture. Judith F. Bullock is pursuing her Master's degree in Northern Arizona University's Rhetoric, Composition, and Professional Writing program. She has published numerous fiction and nonfiction works, one of which was recently nominated for the Pushcart Prize Best of Small Presses XXVIII. Her nonfiction book, Bury Me in Someone Else's Pajamas: Reclaiming Creativity, will be published by Echelon Press in 2003.

-6) Joumal of Basic Writing, Vol. 22, No. 1, 2003

DOI: $10.37514 / J B W-J .2003 .22 .1 .08$ 
come to this work with different histories, approaches, and backgrounds. Originally we met in a graduate course Laura taught titled "Basic Writing Theory and Practice" - a class that seeks to investigate the major historical shifts that have occurred within Basic Writing Studies. As we have surveyed the research in Basic Writing together, we have been disturbed to discover that the available scholarship has not been speaking clearly to the matters many of our students face. Laura first started to trace this absence while directing a Summer Bridge Program that involves many Native American students from various tribes across Arizona and New Mexico. How could she create a curriculum that helped to foster, preserve, and give voice to these students' cultural ties while also teaching them basic skills in reading and writing? Loyola noticed this lack when she started to study Basic Writing literature while simultaneously writing her own literacy autobiography. Loyola looked for glimmers of her own experiences as a Native American student studying English on the Jicarilla Apache reservation as well as within the Southwestern university system, finding none. Judith came upon this troubling phenomenon as an English tutor for Navajo (Diné) students who live in boarding schools within the Flagstaff, Arizona, community, schools far away from their families on the reservation. Judith could locate no research that investigated how we might bridge the gaps between Navajo students' grammar school, high school, and college writing experiences. This paper is our collaborative attempt to speak through this silence in Basic Writing scholarship, to join together our many conversations as well as our separate projects, ones that continue to converge with and overlap each other.

Together we weave our partial stories, stories still being written, ones even formed in the telling. We hope to convey concerns that have not been a central part of Basic Writing Studies and to advocate their importance. In so doing we do not propose to answer all of the questions associated with the concerns raised. However, we do wish to generate critical awareness that Basic Writers of the Southwest, particularly Native American students, remain the "silenced others" of our research. Briefly tracing some of the metaphoric allegiances that form the foundation of Basic Writing scholarship, we ponder why this may be the case. We propose a few possible responses and we put forward narratives that we hope may illuminate matters relevant to teaching and research about Native American Basic Writers. 


\section{THE LANGUAGE OF BASIC WRITING: UNDERSTANDING OUR INVESTMENTS}

\section{Of Territory, Mapping, and Otherness}

Basic Writing scholarship's historical and rhetorical investments may play some part in the lack of research concerning Native Americans and Basic Writing. First, we will observe some of the metaphoric allegiances of Basic Writing Studies, a discipline that has frequently employed descriptions of the frontier, unmapped territory, and the pedagogical West. Second, we will expose what we perceive could be partially an East Coast bias within the history of Basic Writing scholarship. This may be in some measure due to the fact that much initial Basic Writing research emerged from the Eastern United States as well as the fact that such issues related to Western populations have not been spoken about regularly enough. No matter the reasons, as a result, Native American students have heretofore not been considered among Basic Writing's "visible subjects."

Mina Shaughnessy's efforts to aid Basic Writers in the 1970s were critical, decisive, and politically compelling. Despite this, her metaphoric allegiances have perhaps contributed to the absence of Native American students in our scholarship. As many have contended for years, the articulation of the Basic Writer and Basic Writing as a new sub-discipline depended somewhat on an adherence to this work as part of a "new territory" (Adler-Kassner and Harrington; Fox "Basic"; Gay; Gunner; Harris; Horner; Horner and Lu; Hourigan; Laurence et al.; Lu; Mutnick; Stygall "Resisting"). We recall that Mina Shaughnessy's 1977 Errors and Expectations commences with this oftquoted passage, one rife with specific images of landscape. A number of scholars have maintained that this text echoes and even supports the values inherent in American expansionism:

Despite such advances, the territory I am calling basic writing (and that others might call remedial, or developmental writing) is still very much of a frontier, unmapped, except for a scattering of impressionistic articles and a few blazed trails that individual teachers propose through their texts. And like the settlers of other frontiers, the teachers who by choice or assignment are heading out to this pedagogical West are certain to be carrying many things they will not be needing, that will clog their journey as they get further on. So too will they discover the need of other things that they do not have and will need to fabricate by mother wit out of whatever is at hand. This book is intended to be a guide for that kind of teacher, 
and it is certain to have the shortcomings of other frontier maps, with doubtless a few rivers in the wrong place and some trails that end nowhere. (5 our italics)

While we would not contend that Shaughnessy's impulses were inherently colonizing, we do believe that Shaughnessy's particular terminological investment has inevitably played some part in Basic Writing Studies' legacy. In Regeneration Through Violence: The Mythology of the American Frontier and The Fatal Environment, critic Richard Slotkin indicates that the representation of the "frontier" and "free land" has largely been responsible for a distinctly American identity - one connected to individuality, autonomy, rugged masculinity, the principles of democracy (the economic parity that "free land" was thought to promise), and capitalism. Embodied in the archetype of the lone frontiersman, frequently dubbed an "Indian hunter," the myth of the frontier has been utilized to rationalize the excesses of American territorial expansion, the stealing of lands, as well as the forced re-education, assimilation, and murder of Native peoples (see H. Smith and Turner for elaboration). In order to support its excesses, frontier logic constructs a version of nature-or other forces (be they natural, social, or political) - as either blissfully pastoral or deeply threatening. As such, nature might "destroy a people's capacity for civilized sentiment and social forms" or "kill man's better nature" (Slotkin Regeneration 269). Native Americans came to stand in for this natural world in the myth of frontierism. This occurred most acutely in the captivity narrative's structure, with the notion that through interaction with the "Indians," the white man might "go native," becoming corrupt and uncivilized. According to Slotkin, the response to this fear and our linguistic allegiances to frontierism have led to all sorts of atrocities throughout history, key among these the segregation of Native peoples on reservation lands that creates enforced reliances upon colonizing cultures.

To contend that Shaughnessy herself was engaged in colonizing her students is far too simplistic, failing to account for the significant political viability of her efforts. All the same, we witness the disconcerting linguistic allegiance invoked in her language choices. Of course, Shaughnessy is not alone in her use of such terms. Rather these are very often among the few metaphors one might call upon while engaging in new research, undertaking new areas of study. As rhetorician Kenneth Burke proposes, however, all language use embodies a perspective rooted in history through which some dimensions of a situation are exposed while others are elided. As Burke maintains, "Even if any given terminology is a reflection of reality, by its very nature as a terminology it must be a selection of reality; and to this extent it must function also as a deflection of reality" (45). Burke terms this phenomenon a "terministic screen," a set of word choices, made for any num- 
ber of purposes, that strategically directs the attention to one set of ideas and concepts rather than another (50).

Shaughnessy's text has presented a specific terministic screen for Basic Writing Studies. The image of the Old West-complete with descriptions of pioneer teachers heading out to tame the academic wilderness while instilling the American values of individualism, autonomy, democracy, and capitalism - remains with us. We will point to a few rather random examples. This allegiance to metaphors that evoke issues of territory, mapping, inside/outside, and borders has been maintained even as our research has become infused by new theories in feminism, Marxism, poststructuralism, and postcoloniality theoretical approaches aimed at greater inclusion of historically marginalized student groups. While our adherence to frontier imagery is perhaps more subtle, it may still impact the language choices we feel are available to us. Tom Fox echoes and calls to mind Shaughnessy's metaphors in his excellent piece "Standards and Access." Fox writes:

I will begin with three quotations concerning "standards" in higher education. These points of view represent the cultural ground, the territory on which I will be trespassing. ... Many of these authors gained their property rights to this discourse by virtue of their association with the last two presidential administrations. We'll start with the lay of the land.... (37)

While Fox in no way elicits a connection between the Old West in need of mapping and the students in need of taming, his language is important to note. Images of "ground," "territory," "trespassing," and "lay of the land" have a powerful history in American colonization even while often detached from a direct correspondence to their original meanings. While such word choices are doubtlessly made largely for reasons of cadence, impact, and style, they additionally call to mind a disconcerting history. When such linguistic preferences are read within the context of Native American Basic Writers' absence from our literature, the potential implications become yet more troubling.

One might also argue that these allegiances to metaphoric investments in territory, mapping, westward expansion, as well as colonization have been carried out in the continued references within Basic Writing Studies to "insiders" and "outsiders." There are many examples of this to which we might point. In her essay "Linguistic Cultural Capital and Basic Writers," Charlotte Brammer, herself drawing upon such a terminology, reveals how Basic Writing teachers are led to create "the other." In answer to the question "Who are linguistic outsiders?" she responds, "many basic writing students are, to use Burke's term, not consubstantial with us. They speak and write a language that is different from ours" (17). Determining an "inside" and an "outside," an "us" 
and a "them," we necessarily risk continually remapping the "territory" - one composed of "margins" and "centers," a landscape of those who "have" and those who "have not."

In his important essay entitled "On Not Listening in Order to Hear: Collaborative Learning and the Rewards of Classroom Research" Kenneth A. Bruffee unwittingly reinforces this terminology. This leads him to describe Basic Writers, not as emerging academics, but in terms of a landscape that has been left as a byproduct of the frontier-as inner city dwellers, who live in crowded landscapes and who necessarily know only their own kind. Bruffee writes that - "our students have been acculturated to talk to and deal effectively only with people in their own crowd, their own neighborhood" (99). Likewise, while Mike Rose's groundbreaking Lives on the Boundary does not in any way advocate a frontier myth ideology, his title, like many of ours including ones that authors of this piece have invoked in the past, draws upon this terminology, implying that certain spaces are firmly within acceptable borders, identities secured, and others stand at the edges of known territories, marking the "abandoned underclass" (237).

The model of Basic Writing as land, as territory, as frontier - understood as the place where pioneers or crusaders contact "foreign beings and strange landscapes" - is something we all want to believe we have left behind. In many ways we have; our sensitivity to the specific identities and needs of Basic Writers has become ever greater. Yet the terminology we use that draws from this history remains a prevalent theme in Basic Writing, sustaining metaphors that still may depict Basic Writers as savages and aliens in a besieged land. This becomes doubly disconcerting when the language of Western frontierism in Basic Writing research fails to account for Native American Basic Writers, not unlike the ways in which white settlers on American frontiers failed to account for the cultural heritages, needs, and experiences of Native Americans.

\section{Mining Metaphors}

With so many metaphors of frontierism in Basic Writing it seems odd, and potentially quite problematic, that there is so little discussion of Native American peoples within Basic Writing scholarship. Fortunately, however, Rhetoric and Composition Studies, Education, and History contain critical work relevant to our discussion - research advanced by Thurman Lee Hester, Dell H. Hymes, M. Annette Jaimes, Winona LaDuke, Sidner J. Larson, Russell Means, Deborah Deutsch Smith, Margaret Connell Szasz, Gerald Vizenor, and Robert Warrior, among others. Likewise, Jessica Enoch's November 2002 College English piece "Resisting the Script of Indian Education: Zitkala Sa and the Carlisle Indian School" furnishes a critical addition, revealing some of 
the specific ways in which Native Americans have been historically written out of the larger discipline of Rhetoric and Composition Studies. Enoch calls for further scholarship that details the history of Native American pedagogies of resistance against assimilation programs and American schooling - a disruption of murder and ethnic cleansing that otherwise prevailed. Malea Powell's February 2002 "Rhetorics of Survivance: How American Indians Use Writing" also offers a significant counterpoint to traditional histories of rhetoric, urging us not only to reimagine the "possibilities for existence and ironic identity within native communities" but also to reunderstand "a scholarly relationship to writings by Indian peoples, one that hears the multiplicities in those writings and in the stories told about them" (401).

Perhaps the most sustained, crucial examination of Native American students in Rhetoric and Composition Studies, however, has been undertaken by Scott Lyons, whose tribal affiliation is Anishinaabe. In his dissertation project, "Rhetorical Sovereignty: American Indian Writing as Self-Determination," his article in College Composition and Communication entitled "Rhetorical Sovereignty: What Do American Indians Want from Writing?," his chapter "A Captivity Narrative: Indians, Mixedbloods, and "'White' Academe," and his forthcoming essay "The Left Side of the Circle: American Indians and Progressive Politics," Lyons has shifted the discussion about Native American students and writing in critical directions never before investigated in Rhetoric and Composition Studies. His focus, though, has not been on Native American Basic Writers specifically. Instead, this crucial work still remains the "unsaid" of Basic Writing Studies. As Lyons puts it, "Our [Native American] histories, philosophies, political struggles and cultures are too often obscured to such an extent that it doesn't even make sense to call them 'marginalized'" (138).

Basic Writing scholarship often depicts its students as people of color-African American or, perhaps less frequently, Latino-and habitually also characterizes them as urban, Eastern, and poor. While these groups may certainly be part of a profile for some Basic Writers at some institutions, this representation strikes us as problematic for a number of reasons. First, the absence of research on Basic Writing and Native American peoples depends upon a potentially racist polarization of black/white as well as a fundamentally racist conception of who Basic Writers might be. Keith Gilyard makes this phenomenon clear when he describes how time and again he witnessed colleagues walk past basketball courts in urban settings and comment upon the number of Basic Writing students there (see Foreword to GrayRosendale Rethinking).

Certainly, it is not race alone that designates one as a Basic Writer. In the case of Gilyard's colleagues, however, race and physicality were linked together. As such, our images of the Basic Writer as possessing 
physical prowess over and against intellectual might give dangerous ammunition to those who would write off Basic Writers as "other." Even in an important text such as "Politics and Proof in Basic Writing," Gail Stygall is led to describe Basic Writers as "boxers who are bleeding and winded but not yet ready to quit" (28). Once again the image of the Basic Writer is unwittingly linked to physicality, echoing the subtle notion of the Basic Writer as more primitive, less civilized, unschooled.

Second, the absence of Basic Writing research concerning Native American students may depend to a degree upon the relative invisibility of Native American students living in the West to many of the Easterners who produce Basic Writing research. When we speak about "defending access," as Tom Fox (Defending) calls upon us to do, time and again Native American students are not considered to be even part of the "margins" that ought to be brought toward the "center." Not only do our metaphors ignore the presence of Native American people living in that Western landscape, our scholarship rarely speaks of such students, a scant article or two representing the unusual exception. This indicates that perhaps Native American students as well as the landscapes that many of them inhabit can be mined for the metaphors they offer but yet not frequently allowed to function as part of our crucial conversations about Basic Writing teaching and scholarship.

Even within our most significant contemporary scholarship, Basic Writers are imagined as deculturated and properly reculturated, echoing the historical notion of Basic Writers as savages in need of civilizing. In an article entitled "Competing Epistemologies and Female Basic Writers," authors Paul Hunter, Nadine Pearce, Sue Lee, Shirley Goldsmith, Patricia Feldman, and Holly Weaver write, "the basic writers in our study appear to perceive, at some level, that they are being asked to abandon a familiar way of knowing ... in favor of an alien way of knowing" (74). In such cases, Basic Writing students are being asked to at least partially give up their Native voices - what in Diné culture is referred to as "bizaad" - in order to assimilate to academic standards.

Third, our metaphoric investments have left Native American Basic Writers outside of the discussion, preserving yet another myth. The identity of the Basic Writer is not only articulated in terms of people of color, usually residing in the Eastern United States, but also as a largely urban phenomenon-evoking the images of crowded housing and gang violence. Such an impression of the Basic Writer has upheld the notion that the movement of Basic Writers into the academy might be proper philanthropic work or even politically radical work, in either case a vaguely heroic act. Basic Writers, so the narrative goes, are rescued from the deadly streets and brought into safer, more encour- 
aging spaces. And, in some cases, the myth may hold a grain of truth. This same narrative of philanthropy or politicization, however, is not as easy to maintain with many Native American Basic Writers. We are not rescuing them from the perils of the urban jungle. Instead, we might tell ourselves, we are taking them away from a lack of resources, both academic and economic. However, on the flip side, we are clearly taking them away from their entire cultures, traditions, rituals, and family structures - oftentimes moving them from more rural to more urban locations. Likewise, we might comfort ourselves with the notion that by teaching Native American Basic Writers standard academic discourse we are aiding their enculturation and politicizing them. But, in such cases, it is abundantly clear that we could be imposing our own cultural politics upon them - the move to instill radicalism in the student being little more than a new form of colonialism. So, what of the United States Basic Writers who live in rural settings, have no access to phones, haul their own water, ${ }^{1}$ and the like? What of the Basic Writers who are constantly trying to negotiate clan and tribal responsibilities with their sense that they would like lives that allow them to move outside the reservations (oftentimes with the plan to return and aid their tribes)? These are perhaps the less racy images of the Basic Writer, the ones we do not see in our mainstream media or our scholarship. They do not lend themselves as easily to the rescue narratives and representations of the Basic Writing teacher as hero that we habitually keep in play.

At times Native American students are those for whom leaving the tribe to gain a college education can feel like a tremendous betrayal of one's culture and may be talked about as such by other members of one's clan. Who are we saving, and from what? In their cases, is the journey from "margin" to the "center" such a valuable journey after all? Despite their obvious lack of representation in our research, these students exist. We know them. We work with them. And, as Loyola points out poignantly later in this piece, sometimes we are them.

\section{LAURA'S STORY: TEACHING NATIVE AMERICAN BASIC WRITERS IN A SUMMER BRIDGE PROGRAM}

For many years I have directed a Summer Bridge Program at Northern Arizona University with the Multicultural Student Center. This program aims to provide extra liberal studies credit and writing experience to students from Arizona and New Mexico. There are 150 students in this program and I train eight graduate assistants to teach them and tutor them every year. The students in this program are either first generation college, racial or ethnic minorities, and/or in eco- 
nomic need - with many falling into all three categories. Some, though certainly not all, of these students are classifiable as Basic Writers. They are placed in tutorial sessions alongside our entry composition classes or forced to take lower level classes at Coconino Community College. Some come to us with tribal scholarships, others with state funding, and still others with monetary support from Northern Arizona University - and all of the students elect to be a part of the program. As a result, many of the students for whom I have been designing programs are in part Native American or Chicana/o. And many students are mixed-race, identifying themselves by pointing to three or more racial, ethnic, or tribal groups as well as three or more linguistic groups.

As I began working with these students a few things became very clear to me. While Native American students are often treated in terms of ESL issues, many of the students who come to the program do not speak or write their Native languages fluently, having been raised in a culture that values English over other languages. In the case of some Native American languages such as Navajo it is important to recognize that the language has been written down only recently. ${ }^{2}$ Not until college do many of these students come to learn their Native languages more fluently, after they are away from home and feel the pressing need to integrate their multiple selves. While certainly some Native American students struggle with ESL issues in their writing, we cannot ignore the fact that many universities, including my own, track students into these programs based upon tribal affiliation, whether they necessarily might benefit from being there or not. For some students this is an incredibly useful experience. They may gain critical skills while working in a supportive community composed of many other Native American students. For other students the classes are perhaps not challenging enough, and these students may understandably ask themselves why they are there. Why are such students often tracked into non-credit tutorial sessions and Basic Writing courses? It occurs in large part because of funding issues and because university studies show that in order to retain Native American students they need to feel as if they are part of a cohort, a community, as well as to have additional help. A Summer Bridge Program becomes one critical space in which this may be able to occur. But it can also become a place where Native American students come to feel that they do not have sufficient writing skills to succeed in college.

As I continue to design curricula for these students and teach in the program, I continue to be a student to these teachers, my students. The majority of the Native American students are Diné or Navajo since a great deal of the money supporting the program comes directly from various tribal scholarships. In this work I have noticed a number of things about Native American students that Basic Writing scholars and teachers need to take seriously and about which we all need to learn a 
good deal more. This past summer I taught a class in which the Native American students were the majority, with one African-American student and two Chicana students. The rest were Diné, some from the reservation, some from the Flagstaff community, and some from the suburbs of Phoenix. In the class I have designed, "Rhetoric in the Media," students learn how to perform rhetorical analyses and argumentation by reading advertisements, films, television shows, music videos, and websites critically. And, despite the fact that some students have no access to running water in their homes, they all have ready access to mainstream cultural images - in magazines, in newspapers, and in movies. They also often have access to televisual representations. This speaks to the pervasiveness of American popular culture and the ways it impacts even those cultural groups who might seek strategically to exclude it.

There were several key moments or snapshots of this class and other related experiences that I will recount here, moments during which I learned a great deal from my Native American students. I do not see these experiences as somehow wholly symbolic of Native American students in particular, let alone Diné students, though many of the students referred to their cultural positions as Native Americans impacting their choices, their thoughts, and their feelings. More importantly, I think, they reveal critical cultural differences about which administrators as well as Basic Writing instructors need to be aware as we begin teaching Native American students who have been designated as Basic Writers as well as conducting research about Basic Writing and Native American students.

Snapshot One: We have built a strong community as a class. Ribbing, joking, and banter have become part of the fabric of the classroom environment. Bright laughing eyes surround me. We are working on a section in the class that focuses on communities, neighborhoods, and our definitions of home. We have just finished reading John Barlow's "Cyberhood Versus Neighborhood." The essay poses the question, Does the virtual world, the on-line world, offer the same possibilities of "home" for us as do our physical homes? In order to get at our own thoughts about this question, I ask us all to present our definitions of "home." I imagine it an easy question, a question with which many students will identify. But I know so little about the kind of identification this question fosters, enables. Each student details her/ his experiences of home. One after the other cries softly as they speak painfully about leaving grandparents, siblings, and parents to come to this university far away from anything familiar, anything that feels remotely safe. Early on I try to intervene, to say no one need feel as if they have to answer the question. One after the other mentions how 
she or he wants to speak about home, how important it is, how even though we began the course with literacy autobiography assignments, there has been no place until now to do this as fully as they wanted to, needed to.

When people talk about what they most like to do-what home is-- one student remarks that home was climbing up on the roof of his family's house at night on the reservation. He would look out at the stars against the outlines and shapes of the shadowed desert. Another Dine student, one who lives in Phoenix and has never been back to the reservation, responds, "I do that too. That's home for me, too." Another student says that home is being able to walk between each of his family member's homes, to sit and laugh and cook together. It is simply about being there with his family community. When he cannot be there, home is far away and he feels strangely disconnected from himself, from everything he has known himself to be. Still other students talk about the silence, the peace of home. Home is not loud or crowded or angry. Home is about what really matters-home is what takes people away from things like frustration, anger, competition. Home is in part safety.

When I ask if some students do not consider their house to be their home, a few pipe up immediately. Some students speak out with other kinds of stories, stories that bring more tears from both those talking and those listening. Home is a place they have never been, or have rarely been. The house is where abuse occurs, drunken brawls, and yelling. But home can only be found on the mesa, in the woods, out in the mountains. Home is not the house. One student recalls her brother's alcoholism, how she does not know him anymore, how he nearly died in a car accident. These particular students understand how a virtual community might be a better, safer home than the house within which they live. Some of them already consider cyberspace a better home than their physical homes. But, they wonder about the landscapes that would be missing since many of them associate outdoor space, the environment-cacti, hoodoos, coyotes, rocks, red soil, and painted desert-with community and home.

Part of the Diné creation story indicates that First Woman designated the four mountains and four rivers to show the Diné where they should live-Diné Bikeyah or Navajo Country. Contemporary poet Laura Tohe writes in her poem "Within Dinétah, the People Remain Strong": "Carson tried to wrench us from the land. What was our crime? We wanted only to live within our sacred mountains. The land holds the memories of our people's whispers, cries, and blood." She adds, "We vowed we would never again be separated from the land." ${ }^{3}$ Identity, at every level, is at least partially linked to land. As Scott Lyons reminds us, teachers and researchers concerned with Native American issues should begin by "locating their work not on the 'frontier' 
but on Indian land, not as 'pioneers' but as settlers" ("Left" 126).

How could one create or at least simulate outdoor spaces in cyberspace, they wondered? Could you ever be some place other than there when you were there? Could you use cyberspace to connect to the land? What kind of environments were possible exactly? Would the links and networks such as those on www.ienearth.org, the Indigenous Environmental Network, be enough?

Snapshot Two: Many students talk about how it feels to move from high school into college classes. I imagine what the difficult transitions might be-unfamiliarity with the campus, lack of knowledge about which classes to take and how to register, homesickness. But, again, I do not know enough. Some speak about their English classes on the reservation, how they felt as if their teachers did not care about their welfare, taught classes as if they were asleep. "I never wrote a paper in high school" is something that students repeat over and over again to me, like a mantra. What I am asking them to do is entirely new - how do they even begin to approach such a process? Other students remark that they had wonderful teachers on the reservation, but that these people were not paid well, and that the best ones could not stay for long. Other teachers, some mention, are Navajo and were raised in the boarding school system themselves. Sometimes they perpetrate what they have learned in boarding schools upon their students, they tell me. My students all talk about how they never had to make claims of their own, state ideas of their own. It feels strange to do this. It does not seem in line with the position of humility they have adopted in other areas of their lives. Why would they want to call attention to themselves? When I ask the students to tell me about themselves as writers, many say they do not see themselves as writers. "Why would I call myself a writer? I am so terrible at it." Students have very low confidence. Even if they are not fluent in Navajo, they have heard stories about their own inabilities to learn English sufficiently well because they know Navajo or maybe because they are Navajo. Knowing Navajo, they come to think, is a liability. I hear it so many times I begin to wonder how my students manage to write anything - "I know I am a bad writer. I have heard people say that Natives are not good writers."

I think about the higher level administrators to whom I speak on a regular basis. I make cases for the viability of the program, for the students, to make sure we can keep doing this as any budgets deemed "extraneous" get slashed. I listen to the hand-wringing over Native American student retention. "Why do we lose them?" the low voice in the suit asks me, staring at me from behind the desk. Windows can be 
seen behind the suit, windows that look out onto the campus, pine trees bending in the wind. I smile as I watch two Native American students pass by. Here is a conversation about them in which they are given no part. No one asks them what they think. The suit sits behind a desk surrounded by shelves lined neatly with books. What answer do I give? The answer that is expected of me, the Professor, the Director of a Program? Or do I give the answer that I think is most accurate? I try out the latter to see how it will fly. "Maybe we lose them because they have real lives elsewhere. Maybe we lose them because they have to work three jobs to stay here and send money home to their families. Maybe we lose them because they do not feel at home here and we do not make them feel at home. Maybe we lose them because too often we tell them who they are without listening to them tell us about themselves." And the answer comes much as I expected it. The eyes look at me with suspicion. Not the easy answer. Not the instant cure. The suit wants the numbers to add up, the calculations to yield the solution. "Hmmm," as a finger traces a line down a page in a thick binder. Various figures are rattled off-how many students drop out when, how much money this costs the institution. And yet serving surrounding tribes is a critical part of the university's stated mission. What are we to do?

The writing difficulties with which we struggle include things that some people say typify Basic Writing - lack of complete sentences and problems with subject/verb agreement, logical progression of ideas, diction and tone, and word choice. At the same time, these students' writings contain many things that are not usually associated with Basic Writing - complex critiques of the operations of American culture, the American media, and the privileged discourses in mainstream American society. Reading our work aloud to each other and talking about grammar and style rules in the context of each others' papers seem to be very helpful as students gain some confidence. Still, what this course asks the students to do is embrace the idea that we should critique how mainstream American culture constructs us all. We can challenge the American government. We can challenge a United States that constructs Native Americans as "others." I watch them watching me out of the corners of their eyes. Can it be true that this woman, this woman who looks "white," is for real?

One Diné student comes to my office, making idle chit-chat. She jokes with me easily. She talks, saying she loves the class and pauses as she sits in the chair in my office and looks at my doctoral diploma.

"Rosendale?" she smiles at me sideways and laughs, "You are Chicana, right?" I laugh. "No," I say, knowing that now that I have faced the question head-on I may be perceived as just a stupid white chick, and perhaps rightly. I could mention the rural, impoverished town of 500 people in southern New Hampshire in which I grew up, 
the dusty dirt road that passed by our house and then the cemetery, the one room schoolhouse I went to as a kid, my Jewish blood. I don't. "Oh," she says. I look at her and smile. She fumbles for a moment and then says what she has been wanting to say. "I asked because, well, you just seem to understand us." And, I realize what a compliment this is. And, yet, I think to myself. No, I could not, would not claim to understand you, but I am learning more about you. You are teaching me. And, thank you for this. I learn from what you tell me, what you show me. I learn from you, but I do not claim to know you. And I have so much more to learn.

Snapshot Three: Other administrators and teachers in other university programs targeting Native American students tell me that their Navajo students are having trouble writing. Writing what? Writing how? Writing in rows. A straight line-trace an idea to its logical conclusion. The arguments spin, circular. Opened but never closed. "The Circle, correctly described by conventional wisdom as philosophically foundational to many if not all indigenous peoples across the globe, represents holism, regeneration, reaping what one sows, and the importance of listening to the past-which is, on this model, also the present, also the future: the Circle always comes around," Lyons reminds me ("Left" 135).

"Sure," I hear them say. "These students can give amazing speeches about political issues relevant to the reservation. But, there is no translation into the writing." The moans. The sighs. The furrowed brows. And now I see the rows.

"Why is it that they do not just make claims and support them?" come the frustrated voices." "Have they never been asked to do this before?" "No," I say. "Maybe they have not. And maybe it feels hard, counter-intuitive, even wrong to do this." Again, the suspicious looks. And I feel for a moment that I have crossed over some invisible line, moved from proper admin-speak to something altogether different. I do not stop. "After all," I pause, "they raise the critical question for us every day. We need to listen. They say 'Why do we have to do this?' Do we really always know how to answer that question? I know that I do not." Again the Hmmm. ... And we move on our ways.

I read my Diné students' papers and I realize that the demand for adherence to standard academic discourse (whatever that is) is a simplistic way of viewing the problem. The complex ideas about American culture and politics, the media and representation, offered by my students defy such an easy interpretation of their work. Some might say that my students are circular arguers. Too easy to try to push a circle into straight lines without tracing the circle first. The circle comes full circle-if you learn how to read it. And the key becomes that Native American students, all students, should have the chance to learn 
many modes of writing, many kinds of argumentative strategies - not just one, not just some amorphous standard.

One Diné woman, Marlenda Luther, describes herself in her Writer's Profile: “When people first see me they think 'She looks like the tough type.' You know the kind of person who is not so attached to their family. Well that's because they don't know me very well. That really bugs me because I am the family, homey person."

She decides that representations of female Native Americans in the mainstream media really bother her. She begins to ask herself why the media tells her who she should be, how she should look, what she should think, and what life as a Native American is like. "But, it's all mixed up," she says. She focuses on one cultural text in particular, the animated Disney film Pocahontas. Pocahontas was twelve or younger at the time, not the voluptuous woman presented in the film. John Smith is portrayed as dashing when he is known to have been a small man with a beard. Various historical characters disappear, others are rewritten, and still others fictionalized. "In this paper I will prove that Walt Disney's Pocahontas is derived from legends and stereotypes rather than anything like historical accuracy. The film does not portray Native Americans well, using derogatory terms and changing the images of the real character to better fit society's myths about Native Americans," she writes. She examines how stereotypes about femininity and race are intricately connected in this visual text. The lead woman, whiter and wearing more colorful garb. The women not in the lead role, darker treated in the film as backdrop for the "real action," more "other." She talks about how the film places Native Americans hiding in trees "like monkeys," Pocahontas watching John Smith from behind bushes - suggesting that Native Americans are - "uncivilized" and that they "do not know how to communicate with others."

The language used to describe Native Americans in the song lyrics for the film employs words such as "savages," "filthy little heathens," and "Injuns," Marlenda tells us. "It is as if Native Americans are depicted as having no sense of education, and no moral behavior. I mean, we, Native Americans weren't that stupid back then. We did have a good education, but other people did not see it because the language barrier made things different," she states. She talks about how it has to be that way for the film to be marketable to mainstream white America. Making money in a capitalist culture depends upon racist depictions of Native Americans, she says. The white man could not be seen to want the darker woman - it would undermine all that American mainstream culture depends upon, white as privileged. She makes note of the lack of historical accuracy in the film, discusses Pocahontas' age, and the way in which the film plays up her romance with Smith when historical fact suggests that perhaps no such romance really existed. She shows where and how the film makers inappropri- 
ately mix various Native American traditions without making any distinctions between very different, sometimes feuding, cultures. To her mind, "they mess with Native Americans' ancestry" by depicting false images and histories.

"Is it okay that I want to write about this?" she asks me after class is over. She has a full draft in her hand. She has a worried look on her face. "I mean, I do not have good things to say about this film." I smile. "You do not have to say good things. You need to say what you think." The fear seems to leave her face, at least for the moment. "Really?" "Really. You should say what you think and back it up by referring to the text," I say. "I can do that," she laughs with excitement. We say good-bye. The Native American students in my class already recognize that there are few to no representations of Native Americans in the mainstream media, that the ones that exist often depend upon myths of them as savages, as exotic squaws - the construction of an "other." In many cases they need not be taught the lenses of cultural studies and postcoloniality to understand such issues palpably. Having the feeling that they are authorized to speak about the effects dominant culture has had on them, however, can be substantially tougher. How might such speech be used against them? Can they trust the listener if the listener is not part of their community?

A story begun. A story still unfolding. I suppose that this is a story of my beginning to locate my own teaching and research within and amongst different linguistic allegiances, different practices - "not on the 'frontier' but on Indian land," to live and work not as a "pioneer" but as a "settler" (Lyons "Left" 126). This is not always an easy thing to do-and I do not always succeed. More and more I learn every day that there is a great deal that I do not know. I live near Indian land, but my students live on it. I live here on this land with some permanence, yet I have not yet settled. But I know that my students will teach me better how to do these things over time, if I listen. I know that the curriculum I have designed will continue to need to grow and change in very large ways because of their involvement. They will stretch me to consider other possibilities. And I am still learning.

\section{LOYOLA'S STORY: BETWEEN WORLDS-MOVING BETWEEN NATIVE CULTURE AND THE DESIGNATION “BASIC WRITER"}

My story offers an interesting addition to the stories provided by my co-authors. I write this story as a Native American student who was once designated as a "Basic Writer" myself. In referencing my own journey working "between worlds," I want to clarify one concern. The 
notion that Native students, or any other marginalized student group, can successfully move between two worlds without experiencing painful alienation (i.e., psychological, emotional, and intellectual) in both is very unrealistic. One can only likely hold such a perspective from a position of relative privilege. As we work with Native American students designated as Basic Writers, we need to encourage them to have facility in both worlds, and to understand that in certain contexts one world and set of values will be privileged above the other. The idea that a "conflict" or "contact zone" model which encourages borderland residency is politically viable, let alone helpful to every minority student, should be questioned. Instead, issues of context, linguistic expectations dictated by situation, and students' needs must determine how we understand what it means to move "between worlds."

As I have read the research in Basic Writing, like Laura and Judith, I have been struck by the lack of representations of Native students. And, I have been concerned by the number of students in the Southwestern universities and colleges who are too often tracked as Basic Writers whether they necessarily belong in such classes or not. I am a full-blooded Jicarilla Apache Indian. I was born in 1963, which makes me part of the "baby-boomer" generation. I cannot speak about my own literacy experiences without describing the historical and cultural backgrounds of my family/families. My biological lineage consists of both parents being of full Jicarilla Apache descent. Both were fluent in the Jicarilla language, and learned to speak English in boarding school. ${ }^{4}$ In the fall of 1963, I was officially invited into a new family structure which consisted of my adoptive parents - my mother, who was a fullblooded Jicarilla Apache, and my father, who is of English, Irish, and German descent. My father came to my hometown of Dulce, New Mexico, in the early 1950s, from Michigan. My parents were one of the first bi-racial couples to be married on the Jicarilla Apache Reservation. My father has lived on the reservation for over forty-five years, and considers Dulce home.

Like many Native American students who are classified as Basic Writers, I am a first generation college student (based on my biological lineage). In more recent years, two other members of my biological family have obtained Associate Degrees, with one planning to pursue a Bachelor's Degree soon. My adoptive parents' educational pursuits were varied as well. My adoptive mother attended Mesa Community College, in Grand Junction, Colorado, hoping to acquire credentials in journalism/business. She completed one year. My adoptive father completed up to the tenth grade in high school. My adoptive mother was a fluent speaker of her first language, Jicarilla. Her father spoke several languages including Jicarilla, Navajo, Spanish, and English. Her mother spoke only Jicarilla. My mother's siblings all conversed in Jicarilla while growing up. When exposed to the boarding school ex- 
perience, my adoptive mother's family - just like my biological parents - were forced to speak English instead of Jicarilla. This was the beginning of their experience of acculturation into the mainstream society. Punishment for uttering any word in Jicarilla was very severefor example, having one's mouth washed out with soap, being slapped on the hand with a wooden ruler, or being tied to a pole in the basement and whipped. These suspect moves toward "civilizing" signaled a shift away from the values and language of Jicarilla culture - an attempt to suppress and erase differences that might be threatening to white hegemonic discourses.

The historical background of my family is important in depicting my own linguistic and literacy background. Much as it pains me to write this, to this day I do not speak fluent Jicarilla. Did this contribute to my being classified as a Basic Writer in the early stages of my college career? I had not learned my native language first. I still have a chance to learn, but being discriminated against by being told that "you have an accent, and it's not Apache," continues to deter my willingness to learn. As the years go on, I still hope that I will learn my language. Learning to speak and write English as my first language was what my parents wanted. They felt that it would be the more important language to conquer, the language that would enable me to succeed in life. Caught between two worlds, the English-speaking world and the Jicarilla-speaking world, the fact that I could occupy neither space easily led many to classify me as a Basic Writer. Cultural differences, differences that were not understood by the instructors or the academic institutions in which they worked, were largely responsible for my placement there. The thinking process in the context of the Jicarilla language is entirely different from the writing process in English. Though teachers and administrators failed to consider this, many times ideas are turned around completely in the translation from one language to another. Something said in Jicarilla can mean its opposite when translated into English and vice versa. Many gatherings involve people telling jokes or stories in Jicarilla. A joke or a story would lose its meaning when translated into English. It would no longer be funny. As a result, complete fluency in both languages would require not only knowledge of both languages and their differences but the ability to feel at ease in both cultures. Though I might have struggled with not feeling completely comfortable in either context, I did not experience the even more difficult process of fully translating from fluent Jicarilla to non-fluent English. I found myself moving through both languages and cultures - even if a bit awkwardly at times.

To this day my greatest hope is that I may learn to speak and write Jicarilla fluently. I learned bits and pieces of the language from listening to conversations between my mother and grandparents. I grew up with over ninety-five percent of my peers consisting of Jicarilla 
Apache students. Though non-Native Americans are often not aware of this, today many Native students living on reservations do not speak or write their Native languages fluently. In my own case, I can say that less than half of the students with whom I attended school on the reservation spoke fluent Jicarilla. As a result, during the late 1960s and early 1970s acculturation was not a difficult issue for our tribe. Most of the students from my generation considered English our primary if not our only language. We had been taught that the English way was the only way. On the flip side, I also began primary education with no worries of being disciplined for uttering any word in Jicarilla.

Learning to speak Jicarilla was something I very much wanted to do, but my mother never taught me. I recognize now that I may not have pursued learning the language in part because I was never immediately surrounded by a full-fledged circle of Jicarilla speaking peers. While the white American communities may have found my writing and speaking to have overtones of "Native culture," on the reservation I was always told that I didn't have an "Indian" accent, that I was different, not "Native" enough. Other tribal members' perceptions and images created by my having a white father on a predominantly Indian populated reservation also contributed to my failure to learn to speak Jicarilla and my feeling of having one foot in each world, though neither firmly planted.

As a result, my individual focus in the reservation schools I attended was always geared toward the English language. I always received good scores on reading and writing assignments, although teachers would often comment on report cards that "my seatwork [the way I produced my work] was sloppy." I recall that my early interests were in reading and writing. I didn't like the third "R," Arithmetic. In those days, the older generation was concerned with incorporating and keeping the " $3 \mathrm{R}^{\prime} \mathrm{s}$ " in academic instruction, especially in primary education. I breezed through elementary English and reading classes. I moved on to junior high level English, and then high school English, achieving above average grades. I was placed in the higher academic level of English classes, and I graduated from Dulce High School, in 1981, as Salutatorian, with the goal of being the first college graduate in my family.

My college expectations were high. I applied to attend the University of Arizona, in Tucson. I had never been off the reservation or away from my family for more than two weeks in all of my eighteen years. Besides the enormous transition of leaving the "rez," my attempts to "fit in" academically would be shattered during the first semester at this university. To my surprise, I was placed into what was called a "remedial" English class, as well as a basic math class. Upon my first day walking into the classroom, I observed that the room was full of Natives. In one sense, I was happy. These were people who shared 
some of my experiences. Yet I began to question why we were the ones who were there and not other students from other kinds of cultural backgrounds as well. What assumptions were being made about our writing backgrounds and our tribal affiliations? Did we really belong there, or was this a faulty assumption perpetuated by a racist academic culture?

I was also disturbed by what being in a Basic Writing class meant in practical terms. The class was dull, boring, and slow moving. When I received my course textbook, it centered on grammatical structure alone. We spent our semester learning to differentiate between a noun and a pronoun, a verb and an adverb-eventually moving on to the construction of a paragraph and finally to a full-blown essay. I believe that we were given a list of choices to write about. I know one included writing about what we did during the summer. So I chose to write about my grandfather. I really enjoyed writing about my grandfather, who was a very interesting, loving man. But in another way the assignment was far too simplistic. I also recall that while working on this piece, I was required to re-draft the paper and incorporate my teacher's comments, with the assistance of my tutor. What was curious about this experience is that I conversed more with my tutor than I did with my teacher and together we struggled to decipher the meaning of the teacher's comments.

Something became palpably clear to me at that time. Perhaps this was what the "institution of higher learning" thought about me and my writing potential, that I was not fully capable of functioning in mainstream academia. The trouble is that I definitely began to feel this way as well, as I fought to maintain an interest in all of the aspects of grammar "again." I believed my high school experience had prepared me to be competitive in the university setting. I was completely wrong, and to this day, I have never forgotten the traumatizing effect of being placed in this remedial English class. I have often wondered how my peers were affected by this same placement. And I continue to wonder why so many Native American students are placed in and then stay in these classes in colleges and universities within the Southwestern United States.

In some important ways, I feel that the humiliating experience of being "lesser" in the area of English contributed to my overall decline at this university. Like many of the Native students who begin attending universities in the Southwest, I did not return the following year. Disillusioned with my academic experience, instead I chose to attend a smaller community college located closer to my home of Dulce. There I could be closer to family, find some success in my work, and rebuild my confidence. For both better and worse, I found the curriculum moved at a less demanding speed. But, most importantly, I was encouraged by my writing professor, and the fear of looking over my 
shoulder and seeing the "grammar patrol" was gone. Though it seems strange to say it, this non-attention made me feel better than all of the detailed attention that I received in that Basic Writing class ever could. With time and the patience of a new set of instructors, I became increasingly confident in my writing skills.

My next educational experience took place at a liberal arts institution, and by this time, I knew I wanted to major in English. Despite the earlier setbacks in this area of study, I still had a strong desire to accomplish and succeed. At that point I was more fully able to reflect on my educational experiences. During my formative years in high school, I was a well-rounded student. I participated in sports, made the honor-roll, and engaged in many extra-curricular activities. My senior year our English teacher asked us to do a research project which she said would help us prepare for the college experience. But, I don't recall having the support I needed to compose such a paper. I don't even recall having read various classic works of literature. Since I did not have the foundation in English that I needed from high school, I spent much of my time catching up and finally reading these "classics" while at Fort Lewis College. My exposure to these readings and various authors of color opened the doors to new dreams and expectations regarding my future in English. Reading finally became a welcome addition to my life. I was not concerned with what I read, just as long as I read. And the more I read, the more I learned what areas of literature were appealing to me. At the same time, I was learning to articulate my thoughts associated with reading in a comprehensible and confident writing style.

Maturity also played a great part in my completion of a Bachelor's Degree in English as I gained the confidence I needed to perform to expected academic standards. With the years, came the intense desire to accomplish what I had started years before. Though it has taken time, I now know that I have something to offer society and particularly my tribal people, and I hope to encourage the younger generations in their pursuit of higher learning. For five years I worked for the Department of the Interior, Bureau of Indian Affairs, as an Administrative Officer for the Jicarilla people in Dulce, New Mexico. I composed agency newsletters, and gained much satisfaction contributing to the welfare of my tribal people. Now I am completing a Master's degree in Rhetoric, Composition, and Professional Writing at Northern Arizona University - where I am also gaining a certificate in Professional Writing.

Through all of these experiences I have come to enjoy writing in several genres. I must admit that there are still those times when I sense that "old feeling" of not being able to express my ideas in as articulate a manner as many of my peers, people who have never been tracked as Basic Writers. I admit I will always be conscious of my choice of words and my use of structure. 
Being classified as a Basic Writer has been difficult. I came to understand this term, its history, and my own placement in such classes more fully by studying the literature in Basic Writing Studies. It is something I still feel a bit uncomfortable admitting now, even though I am completing a Master's degree and continue to consider doctoral work. It held a stigma for me as it does for many Native students who are tracked into these courses. I feel this way despite the fact that by all objective measures I have transcended the category. However, my experiences being labeled in this way still stick with me. I tell this story as one Native woman who hopes that she can help other Native American students to understand that they can resist this labeling and move beyond it. I tell this story to teachers and theorists who work with Native students in the Southwest as well as across the United States. It will become increasingly important for those who teach and do research in the field of Basic Writing to learn more about the diversity of contemporary Native peoples; to face the flaws in their own stereotypes and the metaphoric investments of Basic Writing Studies that have made it such an inhospitable place for Native students, teachers, and scholars; and to understand how to more fully support Native students designated as Basic Writers.

\section{JUDITH'S STORY: TUTORING NATIVE BASIC WRITERS IN A DORMITORY HIGH SCHOOL}

\section{Excerpt From My Tutoring Journal, October 21, 2002}

It was almost time for my 7:00 pm English tutoring session at the Kinlani (Flagstaff) Bordertown Dormitory High School. At ten minutes after 7:00, the students filed into the cafeteria that would serve as my classroom. They sat at tables fastened to the floor, surrounded by backpacks and Doritos. One of the cafeteria ladies, a Navajo woman, finished mopping the floor, wandered over, and watched me jotting notes in the margins of my paper. She asked me in halting English what I was writing.

I considered the possible tangles of language and settled on an explanation. "It's a paper on how to help Native American students succeed," I said." "Some of them seem to have a lot of trouble learning in school."

She nodded, then leaned toward me conspiratorially. "We know why. But it's not something we talk about."

"I think it needs to be talked about," I said.

"But it's not what you think," she said. "The real reason they can't learn." 
"Why can't they learn?" I asked.

"Witchcraft," she said.

"Witchcraft?"

Her face was serious. "The Witch on the reservation puts a curse on them and it makes them stupid," she said.

This was a possibility I had not considered.

I glanced around at the students nearby.

"Is this true?" I asked them. They nodded solemnly.

"Could you please explain this to me?" I asked. "Because this is something I don't know about."

A student at the next table spoke up. "The Witch doesn't want them to leave the reservation and go to school," he said. "So the Witch puts some stuff in a pipe and she blows it out the pipe and it makes like a rock that you can't see and it goes and sticks in the person's forehead and then he is stupid. They know when it happens to them. That's why they don't study. The curse makes them stupid. They know it won't do them no good."

"What can take the curse away?" I asked.

One student said, "The Medicine Man. He can do it." The other students agreed.

The dormitory school director, a Hopi woman, appeared out of nowhere. I wondered how long she had been listening.

"Well, no one can put a curse on the English tutor," she said briskly, "because she doesn't believe in the curse."

She looked to me for confirmation. I looked away. I wasn't sure. Actually, I was feeling a little stupid myself right at the moment, with a slight feeling of tenderness and discomfort in my forehead. And I could see that the curse, far from being a foolish superstition, was alive and well and hurting my students' chances for success. Still, I didn't come here to destroy traditional Native American beliefs. I was here to teach writing.

This excerpt from my journal reveals how oftentimes poorly understood cultural differences create barriers and misunderstandings that block our efforts to communicate effectively with our Native American students. Even our practice of taking attendance may alienate students. In Navajo culture, it is impolite and rude to directly ask a person's name. One learns a person's name by asking another nearby person, who introduces the unknown one. On many occasions I have seen Diné students respond to a teacher asking a student's name while taking attendance by blushing and turning away, or blanching and refusing to answer, or frequently by giving someone else's name. 
Since the "dumbing-witch" incident, I have come to understand how deeply Navajo traditional beliefs in adishgash, magic, may affect our schools (see Brenner; Kluckhohn). A practitioner of adishgash, or witchery, is called adilgaashii, or "Skinwalker," a person who is able to transform into a wolf, bear, or other flesh-eating creature and cause harm. Some Navajos consider these Skinwalkers to be so dangerous that they are worthy of death. In 1864, the Navajo conducted a formal witch hunt (comparable to the Salem witch trials but on a smaller scale) near Chinle, Arizona, directed at a group of Navajos who were disturbing hozho (the state of harmony and order) through their excessive prosperity (see Grant for further elaboration). Forty Navajo lives were claimed by Navajo witch hunters before the United States Army stepped in to stop the slaughter. The Navajos remember this event as Hweeldii, the Hardship (Blue). Native American students may internalize such stories, and their message is clear: Too much success is over-reaching, immoral, suspect. Whether or not students personally believe in adishgash, witchcraft, there still exists the cultural value of staying in one's proper place. What a contrast to our universities and colleges that encourage students to reach for the stars and achieve all they can. In Native culture, such achievement may be seen as a threat to students' hozho.

Navajo society places a high premium on maintaining hozho. As Navajo writer Andy Harvey writes, "To be out of harmony, even with one's own words, is devastating to a Navajo person's ability to be a successful learner" (5). Thus, the competitive, goal-oriented academic environment may be antithetical to more holistic Navajo ideologies. Similarly, members of other Native American tribes may find that the sometimes materialistic values of the academy oppose their own traditional philosophical ideals.

While each tribe has its own beliefs and traditions, and individuals within Native American society vary greatly, Native American students can face challenges that may stem from cultural beliefs and values that are incompatible with Western academic ideologies. When these beliefs and values collide, Native American students are often caught in the middle of two distinct and powerful traditions - their home cultures' and those of the academy. Therefore, if Native American students are to succeed, they must find harmony within these two distinct worlds. With this in mind, I believe it is our responsibility as academics to clear the way for Native American students to succeed in our colleges and universities by embracing a larger vision of diversity and imagining new practices and pedagogies that will welcome Native American students.

When I first began working with Navajo high school students, it was difficult for me to see them as individuals, whose lives and experiences varied greatly both from one another and from my own. These 
students have been my teachers, made themselves vulnerable so that I could begin to see them for who they really are. Some want to preserve their indigenous languages; others study French. Some students are greatly interested in holding to their native traditions, others want only to assimilate and escape their lives of desperate rural poverty on the reservations. Still other students practice some traditional ways while pursuing other Anglo ideals. Our Navajo Basic Writing students may or may not speak English as a second language. In the high school where I tutor, 50 percent of students speak Navajo, some fluently, others poorly. For some, English is their only language. These students may be fluent or illiterate in several languages: French, Hopi, Spanish, English, and Navajo. So diverse are these students that we can make few assumptions about them. Our only option is to know them and allow them to teach us. From them we can learn that there are many ways for our students to invent themselves in the world. Their necessary crossings and re-crossings between worlds should be encouraged, even if that means letting go of our fears and embracing the lifeways of another culture alongside our own. We should also understand that such crossings are difficult, painful, and oftentimes problematic.

But while teachers ought to accommodate students who are interested in preserving their traditional cultures, I wonder sometimes whether our concern with preserving Navajo traditions may be more a reflection of our desire to imagine Navajo students as relics of a quaint past, as static members of a fixed society, while we imagine white culture, academic culture, as a sort of creative motion. If we essentialize Navajo students as human time capsules, we do them a great disservice and contribute to their continued absence from Basic Writing literature and from the academy. When we see the university only in terms of archaic or modern, as insider or outsider, we miss other privileging hierarchies that are revealing.

Since the academy is at least in part an elitist institution, it is also an exclusive institution. In Lives on the Boundary, Mike Rose suggests that the academy is a secret society, that the novice is taken on a journey by his mystagogue and initiated into a select clique: "The student is being spiritually transported by the teacher and by an inspiring humanities program from the margins to the center. He is being brought into and invited into the club" (8). Later, Rose elaborates, referring to his own experience as a student who had grown up in a Los Angeles ghetto: "Nothing is more exclusive than the academic club: its language is highbrow, it has fancy badges, and it worships tradition. It limits itself to a few participants who prefer to talk to each other. What Father Albertson did was bring us inside the circle" (58). The exclusive and limiting aspects of higher education are problematic. Native American students, who already feel marginalized, are reminded daily that they stand outside the circle of ideal college students; hence, they 
may not possess the confidence to step over Father Albertson's line, to join those on the inside. These students, whose lives feature frequent feelings of powerlessness, may blanch at handing their locus of control to a teacher whom they may (rightly) perceive as a somewhat selfinterested elite. Indeed, the whole idea that they need to be included may further serve to reiterate for Native American students what they already feel: they are outlanders. Far from being inspired, these students may be discouraged, further peripheralized, and driven out by the very system of initiation designed to assimilate them.

This willingness on the part of academics to posit an "other" may be more than an aspect of the hierarchical nature of the academy. In her essay entitled "Intellectual Development and the Place of Narrative in 'Basic' and Freshman Composition," Kathleen G. Dixon also questions this approach, suggesting that fear underlies our desire to postulate an "other":

Why must human difference, otherness, (or "alterity" as literary critics are now fond of saying) be figured along these poles of adulation or denigration? Is the "other," as certain Lacanian psychoanalytic critics tell us, that which the dominant culture fears and represses? (7)

If college instructors are imagined to be the dominant culture in higher education, over and above students, perhaps predicating the student as "other" serves to create a safety zone for rising academics between students and themselves, positing a qualitative difference that raises professorial status and maintains the rigid institutional hierarchies on which academics are dependent and with which academics are complicit. If we are to aid Basic Writers who are Native American students, we must understand how their particular "otherness" is constructed culturally as well as by the academy.

I close with the forceful words of one of my current students who, struggling with the inadequate technological resources we encounter daily at the school, printed a copy of his college application letter for me to read. The computer room seemed strange and empty as I read his letter. I was stunned by the rhetorical power and beauty of his prose. I could not help but think once again that categorizing Native American students as Basic Writers too often fails to account for their actual experiences and lives.

My name is Tyler Johnson, and I am a Navajo. My home is on the Navajo Reservation, in a discrete place called Tonlea. To follow my traditional customs, I am of the Many Goats clan, born for the Towering House clan, and my paternal grandfather is of the Yucca Fruit clan. This is the story of my education and life. 
As a child, I have seen the hardships of life without a proper education. I have seen my parents struggle with the daily task of providing for their family. I have seen people live on the government, including my own family. I have seen my family struggle to live without it, and still see it today. I have vowed to myself that I will do everything in my power to get the education I need to survive on my own.

In the third grade I had taught myself to read, since then I have strived to be the best I could be. In the seventh grade, I was placed in Transitional Mathematics (a high school math class), and half way through my eighth grade year I was sent to Carmel, Indiana. I was sent there to further my schooling and broaden my view of the world. In my school I was the only Native American, and lived there with a white family. I had never been so far away from home, much less the reservation. I worked hard to adjust to an entirely different lifestyle and an education that exceeded my own. I received honor classes and received the best grades I could get. I returned home stronger than before, and became one of the few at the top of my class. Through the trials of life, I have accelerated above my peers, and have continued to take many challenging courses throughout high school.

Life on the reservation is not easy, life in general is not easy. I live in a Hogan (the traditional home of the Navajo) with no running water or electricity. My home is a dusty town with one gas station, no high school, and twenty miles from the nearest major town. Life for my family is hard considering my mom has to drive thirty miles to get to work and my father one hundred miles, each going in opposite directions. Money never seems to be in our hands, and we live day to day, never knowing what the sunrise brings. Every day is a challenge, which we gladly accept, never losing hope of a better day. Despite these circumstances, my family has survived and I continue my schooling.

My parents have taught me well from the experiences they have gone through, and that to get what I desire, I need an education. My mother has taught me to be a good person, and my father has taught me never to give up. They are my inspiration to do my best in everything I do, whether it is in school or in sports.

This is my story, and this is the life I live. Today I am still continually trying to advance my education, and I see that education is my key to the world. 


\section{CHALLENGING THE CONSTRUCTION OF BASIC WRITING'S OTHERS}

The accounts we present here supply small glimpses into a crucial area of research for Basic Writing Studies, one that needs to begin to receive more significant attention. While we have not provided ready answers, we hope that we have exposed some of the potential metaphoric problems in the history of Basic Writing scholarship, problems that have perhaps contributed in certain ways to (if not perpetuated) the invisibility of Native American Basic Writers. We also hope to have provided some thoughts about such students, what they can teach us as well as what and how they may want us to teach them. If we do not make this research a priority in the years to come, the tracking of $\mathrm{Na}-$ tive American students into Basic Writing programs across the country will continue with few questions asked. As a result, we may not begin to thoughtfully consider how best to aid these students as well as how to work with and between cultural differences. We might fail to determine whether Native American students are too often tracked as Basic Writers because of universities' lack of knowledge about such cultural differences. We might fail to understand the racist biases against Native Americans that remain too often unquestioned.

If we are to begin such scholarly work, however, we must recognize the significant hurdles that we face. And, by no means are we able to investigate them sufficiently here. If the terministic screen adopted by Basic Writing Studies has often relied upon the frontier myth and images of mapping and territorialization, particularly of Western landscapes, in the future we will need to understand and reconceive this phenomenon in radical ways. We will need to work against the negative potentials of this terminology from the inside out, to in fact throw away the maps we have used to understand the territory of Basic Writing-instead recognizing the critical presence of Native American students in this landscape. Studying the work of Native American Basic Writers in ways that allow them to speak to our research has the possibility of re-writing this history of colonization sometimes unwittingly embodied in the metaphors of our discipline. It also holds the potential to shift the troubling history in the United States of Anglo teaching that has forced Native students to assimilate and acculturate to a set of often rather arbitrary standards, frequently with little rationale offered.

However, in order for this to come about, we increasingly need to generate situations and research possibilities that allow our Native American students to talk back and through to the discipline, to challenge it from within. Likewise, we must encourage teachers of Basic Writing to learn from their Native American students - to study their lives, their homes, and their cultures. We must learn about the assumptions Native American students may have about college and univer- 
sity environments. Perhaps the new efforts of Basic Writing Studies might best be described as a kind of de-territorialization and de-colonization, encouraging Native students to rewrite the metaphors that have heretofore structured the very operations of this discipline. This will take Basic Writing Studies in crucial new directions, perhaps exposing trails that have always been there on the land, but ones we have overlooked in the past in favor of the frontier myth. The frontier myth has too long played a part in the language of Basic Writing Studies. Increasingly teachers of Basic Writing need to become settlers on Indian lands, much as Lyons encourages all Rhetoric and Composition scholars to do-challenging and disrupting the once comforting images of ourselves as pioneers.

\section{Authors' Acknowledgement}

We would like to thank the reviewers of this essay for their very thoughtful feedback and suggestions, which we have tried to consider here. One reviewer encouraged us to extend our research for a book chapter or even an entire volume. Since we are all continuing independent research in this vein to some degree, bringing together our various voices in a larger project is certainly something we will consider. We thank the reviewer for this suggestion.

\section{Notes}

1. Too often in Western culture "hauling water" has flavors of the unsanitary and suggests a deficit model. When we talk about "hauling water" we invoke images of menial chores and hardship, perhaps influenced by White frontier people who had wells and bucketed their own water. But this suggestion hides the richness of Native culture. For instance, Northern California's Wintu community includes a thousand-year-old ceremony held at a sacred spring in the meadow. Wintu religion focuses on healing through the use of natural resources, including the spring and the mountain there. Many springs, wells, and waterfalls are sacred places and the carrying of water from these places to the home is a sacred act. Also, it is important to note that desert dwelling people do not need as much water as some cultures, as they use water carefully and sparingly. Water is sacred, springs or other water holes are the sacred dwelling places of the ancestors (which is why many Navajo do not eat fish), and water is not freely wasted on lawns, daily showers of the whole body, the way Anglos waste this precious resource. Also, the preciousness of water can be seen in the tribal clan names of Navajo people, for instance. The word "Havasupai" means "People of the Blue Green Water." There are the other Navajo 
clans to whom water is especially sacred: "Near the Water Clan," "Deer Spring Clan," "Two Who Came to the Water Clan," "Big Water Clan," "Reed People," "Red Running into the Water Clan," and the "Light Water People," just to name some. We should be careful not to essentialize or minimize a huge part of Native culture since "doing without" may be a sacred act.

2. For the purposes of both Laura's and Judith's stories, it is important to offer a brief history of Navajo as a written language. In 1849 the first Navajo word list was created by Lt. James $\mathrm{H}$. Simpson, part of a journal of military reconnaissance, appearing in Navaho Expedition. In 1852 the first Navajo vocabulary, Vocabulary of the Language of the Navaho, was published by J. H. Eaton. In 1887 Washington Matthews began publishing information about Navajo ceremonies. In 1912 the first major dictionary, A Vocabulary of the Navaho Language, was published by the Franciscan Fathers. In 1926 the first grammar, A Manual of Navaho Grammar by Fr. Berard Haile, appeared. In 1939 the Harrington-LaFarge alphabet for the Navajo language was created. This was the alphabet used in ADAHOONHILIGHII, or Current Events, developed by educators as a tool for teaching Navajo language reading skills. It was a monthly newsletter distributed to reservations and posted on bulletin boards. It covered both local and national events. The first issue was published on August 2, 1943. In the late 1930s, author Oliver LaFarge and anthropologist John P. Harrington of the Smithsonian Institution devised a Navajo alphabet that was usable on an English typewriter. Until that time, a written language had not existed. In 1941 the first bilingual primer, Diné Yazhi Ba'alchini, was published by James Byron Enochs. By 1941 the first compilation of place names emerged in the book Diné Bikeyah by Richard F. Van Valkenburgh. However, the first modern dictionary, The Navaho Language, by Robert W. Young and William Morgan did not appear until 1943. In 1956 the Navajo translation of the New Testament was completed, becoming one of the central ways in which the Navajo people first saw their language in written form. In 1967 the first modern Navajo textbook, Navajo Made Easier, by Irvy W. Goossen, was published. It was not until 1985 that the Navajo translation of the Old Testament was completed. Since then, various references for modern Navajo have appeared, and in the midto-late 1990s, Navajo fonts became available on computer programs.

3. See Laura Tohe, "Within Dinétah, the People Remain Strong," presented at the Navajo Treaty Day Commemorative Program by the Friends of the Navajo Treaty Project at the Cline Library at Northern Arizona University, June 1, 1999. Other compelling texts that take up related concerns from an historical perspective include Sam Bingham and Janet Bingham, eds., Between Sacred Mountains: Navajo Stories and 
Lessons from the Land; Peter Iverson, Diné: A History of the Navajos; Klara Bonsack Kelley and Harris Francis, Navajo Sacred Places; Laurence D. Linford, Navajo Places: History, Legend, Landscape; and Robert S. McPherson, Sacred Land, Sacred View: Navajo Perceptions of the Four Corners Region.

4. Here we refer to the practice of forcibly removing Native American children from their homes, or what the Carlisle School in Pennsylvania, founded by Henry Pratt during the 1880s, referred to as the "kill the Indian, save the child" philosophy of education. For a useful overview of the schooling practices of Natives from the 1880s through the 1920s, see Carolynn Marr's work "Assimilation Through Education: Indian Boarding Schools in the Pacific Northwest." While she speaks to issues relevant within that geographical location, as she notes, her overviews of the structure of Indian Boarding Schools cut across such differences. Since all such schools were federally legislated, the set up of the schools, the subjects taught, the large focus on vocational training and knowledge of United States laws, and the school schedule were virtually identical across the nation. For several recent publications that examine the boarding school experience and its impacts upon Native American students today, see Margaret L. Archuleta, Brenda J. Child, and K. Tsianina Lomawaima's edited book Away From Home: American Indian Boarding School Experiences, 1879-2000 and John Bloom's To Show What an Indian Can Do: Sports at Native American Boarding Schools. For a comprehensive bibliographic overview of texts that take up this subject, see http://www.asu.edu/lib/archives/boardingschools.htm and http://www.asu.edu/lib/archives/labriola.htm.

\section{Works Cited}

Adler-Kassner, Linda, and Susanmarie Harrington. Basic Writing as a Political Act: Public Conversations About Writing and Literacies. Cresskill: Hampton Press, 2002.

Archuleta, Margaret L., Brenda J. Child, and K. Tsianina Lomawaima, eds. Away From Home: American Indian Boarding School Experiences, 1879-2000. Phoenix, AZ: Heard Museum ; Santa Fe/ Distributed by Museum of New Mexico Press, 2000.

Barlow, John. "Cyberhood Versus Neighborhood." Common Culture: Reading and Writing About American Popular Culture. Eds. Michael Petracca and Madeline Sorapure. 2nd ed. Upper Saddle River, NJ: Prentice Hall, 2001. 359-365.

Bingham, Sam, and Janet Bingham, eds. Between Sacred Mountains: Navajo Stories and Lessons from the Land. Tuscon: Sun Tracks and University of Arizona Press, 1984.

Bloom, John. To Show What an Indian Can Do: Sports at Native American 
Boarding Schools. Minneapolis: University of Minnesota Press, 2000. Blue, Martha. The Witch Purge of 1878: Oval and Documentary History in the Early Navajo Reservation Years. Tsaile, AZ: Navajo Community College P, 1988.

Brammer, Charlotte. "Linguistic Cultural Capital and Basic Writers." JBW 21.1 (2002): 16-36.

Brenner, Malcolm. "A Witch Among the Navajos." Gnosis 48 (Summer 1998): 36-43.

Bruffee, Kenneth. "On Not Listening in Order to Hear: Collaborative Learning and the Rewards of Classroom Research." JBW 7.1 (1988): 3-12.

Burke, Kenneth. Language as Symbolic Action: Essays on Life, Literature, and Method. Berkeley: U of California P, 1966.

Dixon, Kathleen G. "Intellectual Development and the Place of Narrative in 'Basic' and Freshman Composition." JBW8.1 (1989): 3-19.

Eaton, J. H.. "Vocabulary of the Language of the Navaho." Historical and Statistical Information Respecting the History, Condition, and Prospects of the Indian Tribes of the United States. Ed. H.R. Schoolcraft New York: Paladin Press, 1969 (orig. 1852).

Enoch, Jessica. "Resisting the Script of Indian Education: Zitkala Sa and the Carlisle Indian School." College English 65.2 (November 2002): 117-141.

Enochs, James Byron. Little Man's Family = Diné Yázhí Ba'átchini: Primer. Illustrated by Gerald Nailor. Washington, D.C.: U.S. Dept. of the Interior, Bureau of Indian Affairs, Division of Education; Lawrence, KA: Publications Service, Haskell Institute, 1950 (orig. 1941).

Fox, Tom. "Basic Writing as Cultural Conflict." Journal of Education 172(1990): 65-83.

-. Defending Access: A Critique of Standards in Higher Education. Portsmouth, NH: Boynton/Cook, 1999.

-. "Standards and Access." JBW 12.1 (1993): 37-45.

Franciscan Fathers. A Vocabulary of the Navaho Language. Saint Michaels, AZ: The Franciscan Fathers, 1912.

Gallego, Marg, and Sandra Hollingsworth, eds. What Counts as Literacy? Challenging the School Standard. New York: Teachers College Press, 2000.

Gay, Pamela. "Rereading Shaughnessy From a Postcolonial Perspective." JBW12.2 (1993): 29-40.

Goossen, Irvy W. Navajo Made Easier: A Course in Conversational Navajo. Flagstaff, AZ: Northland Press, 1967.

Grant, David. Hozho: A Navajo Cultural Concept for the Writing Classroom. Master's Thesis. Northern Arizona University, 1999.

Gray-Rosendale, Laura. Basic Writing's Others: History, Theory, and Silenced Voices from the Southwest. Project in progress.

-. Rethinking Basic Writing: Exploring Identity, Politics, and Community 
in Interaction. Foreword by Keith Gilyard. Mahwah, NJ: Lawrence Erlbaum, 2000.

Gunner, Jeanne. "Iconic Discourse: The Troubling Legacy of Mina Shaughnessy." JBW19.2 (1998): 25-42.

Haile, Father Berard. A Manual of Navaho Grammar. St. Michaels, AZ: The Franciscan Fathers, 1926.

Harris, Joseph. "Negotiating the Contact Zone." JBW14.1 (1995): 2742.

Harvey, Andy. "Speaking Navajo and Writing English First: Issues in Discovering Ways to Use English." Unpublished paper. Northern Arizona University, 2002.

Hester, Thurman Lee. Political Principles and Indian Sovereignty. New York: Routledge, 2001.

Horner, Bruce. "Discoursing Basic Writing." College Composition and Communication 42 (1996): 199-222.

-, and Min-Zhan Lu, eds. Representing the "Other": Basic Writers and the Teaching of Basic Writing. Urbana, IL: NCTE, 1999.

Hourigan, Maureen M. Literacy as Social Exchange: Intersections of Class, Gender, and Race. New York: SUNY P, 1994.

Hunter, Paul, and Nadine Pearce, Sue Lee, Shirley Goldsmith, Patricia Feldman, and Holly Weaver. "Competing Epistemologies and Female Basic Writers." JBW7.1 (1988): 73-81.

Hymes, Dell H. Ethnography, Linguistics, Narrative Inequality: Toward an Understanding of Voice. London: Taylor and Francis, 1996.

Iverson, Peter. Diné: A History of the Navajos. Albuquerque: University of New Mexico P, 2002.

Jaimes, M. Annette, ed.. The State of Native America: Genocide, Colonization, and Resistance. Boston: South End Press, 1992.

Kelley, Klara Bonsack, and Harris Francis. Navajo Sacred Places. Bloomington: Indiana UP, 1994.

Kluckhohn, Clyde. Navajo Witchcraft. Boston: Beacon Press, 1944 (reissued 1995).

LaDuke, Winona. All Our Relations: Native Struggles for Land and Life. Cambridge, MA: South End Press, 1999.

Larson, Sidner J. "Constituting and Preserving Self Through Writing." Telling Stories: Essays on American Indians and Literatures. Ed. Elizabeth Hoffman Nelson. New York: Peter Lang, 2001.

Laurence, Patricia, et. al. "Symposium on Basic Writing: Conflict and Struggle, and the Legacy of Mina Shaughnessy." College English 55 (1993): 879-903.

Lazere, Donald. "Orality, Literacy, and Standard English." JBW10.2 (1991): 87-98.

Linford, Laurence D. Navajo Places: History, Legend, Landscape. Salt Lake City: University of Utah P, 2000.

Lu, Min-Zhan. "Conflict and Struggle: The Enemies or Preconditions of Basic Writing?" College English 54 (1992): 887-913. 
Lyons, Scott. "A Captivity Narrative: Indians, Mixedbloods, and"'White' Academe." Outbursts in Academe: Multiculturalism and Other Sources of Conflict. Eds. Kathleen Dixon, William Archibald, and Jane Varley. Portsmouth, NH: Boynton Cook, 1996. 87-108.

-. "The Left Side of the Circle: American Indians and Progressive Politics." Radical Relevance: Toward A Scholarship of the "Whole Left." Eds. Laura Gray-Rosendale and Steven Rosendale. Albany: SUNY P, 2004 (in press). 119-143.

-. Rhetorical Sovereignty: American Indian Writing as Self-Determination. Dissertation Abstracts International Section A: The Humanities and Social Sciences. 61:10 (2001 April), 3980.

-. "Rhetorical Sovereignty: What Do American Indians Want from Writing?" College Composition and Communication 51:3 (February 2000): 447-468.

Marr, Carolynn. "Assimilation Through Education: Indian Boarding Schools in the Pacific Northwest." See http:// content.lib.washington.edu/aipnw/marr/marr.html.

Matthews, Washington. The Mountain Chant: A Navajo Ceremony. Foreword by Paul Zolbrod. Salt Lake City: University of Utah P, 1997.

McPherson, Robert S. Sacred Land, Sacred View: Navajo Perceptions of the Four Corners Region. Provo, UT: Brigham Young UP, 1992.

Means, Russell. "The Same Old Song." Marxism and Native Americans. Ed. Ward Churchill. Boston: South End Press, 1992. 19-33.

Mutnick, Deborah. Writing in An Alien World: Basic Writing and the Struggle for Equality in Higher Education. Portsmouth, NH: BoyntonCook, 1996.

Powell, Malea. "Rhetorics of Survivance: How American Indians Use Writing." College Composition and Communication 53.3 (February 2002): 396-434.

Rose, Mike. Lives on the Boundary: The Struggles and Achievements of America's Underprepared. New York: Macmillan, 1989.

Shaughnessy, Mina. Errors and Expectations: A Guide for the Teacher of Basic Writing. New York: Oxford UP, 1977.

Simpson, James H. Navajo Expedition: Journal of a Military Reconnaissance from Santa Fe, New Mexico to the Navajo Country Made in 1849 by Lieutenant James H. Simpson. Ed. Frank McNitt. Norman: University of Oklahoma P, 1964.

Slotkin, Richard. The Fatal Environment: The Myth of the Frontier in the Age of Industrialization, 1800-1890. New York: Atheneum, 1985.

-. Regeneration Through Violence: The Mythology of the American Frontier, 1600-1860. Middletown, CT: Wesleyan UP, 1973.

Smith, Deborah Deutsch. Introduction to Special Education: Teaching in an Age of Opportunity. $4^{\text {th }}$ ed. Boston: Allyn and Bacon, 2001.

Smith, Henry Nash. Virgin Land: The American West as Symbol and Myth. Cambridge, MA: Harvard UP, 1950.

Stygall, Gail. "Politics and Proof in Basic Writing." JBW7.2 (1988). 28- 
41.

-. "Resisting Privilege: Basic Writing and Foucault's Author Function." College Composition and Communication 45.3 (1994): 320-341.

Szasz, Margaret Connell. Education and the American Indian: The Road to Self-Determination Since 1928. $3^{\text {rd }}$ ed. Albuquerque: University of New Mexico P, 1999.

Tohe, Laura, "Within Dinétah, the People Remain Strong." Presented at the Navajo Treaty Day Commemorative Program by the Friends of the Navajo Treaty Project at the Cline Library at Northern Arizona University, June 1, 1999.

Turner, Frederick Jackson. The Frontier in American History. Foreword by R. A. Billington. Malabar, FL: R. E. Krieger, 1985.

Van Valkenburgh, Richard F. Diné Bikeyah. Eds. Lucy Wilcox Adams and John C. McPhee. Window Rock, AZ: Office of Indian Affairs, 1941.

Vizenor, Gerald. Manifest Manners: Narratives on Postindian Survivance. Lincoln: University of Nebraska P, 1994.

Warrior, Robert. Tribal Secrets: Recovering American Indian Intellectual Traditions. Minneapolis: University of Minnesota P, 1995.

Young, Robert W., and William Morgan. The Navaho Language: The Elements of Navaho Grammar with a Dictionary in Two Parts Containing Basic Vocabularies of Navaho and English. Phoenix, AZ: Education Division, United States Indian Service, 1943. 


\section{News and Announcements}

Conference on Basic Writing Invites Nominations for Innovation Award. The Conference on Basic Writing requests applications for its 2004-2005 Award for Innovation. This award recognizes basic writing programs for innovations that improve educational processes through creative approaches. Only innovations that have been implemented will be considered for the award. The winner will be presented with a plaque at the 2004 CCCC meeting in San Antonio, Texas. CBW wants to recognize those programs that are implementing new or unique ways to improve the success of their basic writing students. Is your program doing something especially useful and effective in terms of assessment, placement, pedagogy, curriculum, community outreach, etc.? If so, please nominate your program for the 2004-2005 CBW Award for Innovation. For complete application information, see <http:// www.asu.edu/clas/english/composition/cbw/Inny_1.html>, or contact Greg Glau (gglau@asu.edu).

Call for papers: The Journal of Teaching Academic Survival Skills (JTASS) is seeking articles for its next issue. JTASS is a multi-disciplinary, refereed journal that publishes articles focusing on the teaching of "at-risk" students - those who might fall between the cracks in colleges and universities without some intervention on our part. We seek critical work in areas such as instructional strategies, political considerations, incidents with students, promising practices, student services, program development, and more. We value studies that are pertinent to specialists yet accessible to non-specialists. We are pleased to consider articles that extend our definition of the at-risk population or that focus on how the condition of being "at-risk" undergoes variation and transformation in light of particular environments, class-based markers, or learning situations. To submit a manuscript or learn more about our journal, please contact: John Paul Tissoni, Editor, Journal of Teaching Academic Survival Skills, Department of English, Miami University Middletown, Middletown, $\mathrm{OH}$ 45042. Manuscripts should follow APA format. Please submit both in hard copy and disk form. Contributors can also submit electronically to tassonjp@muohio.edu. 


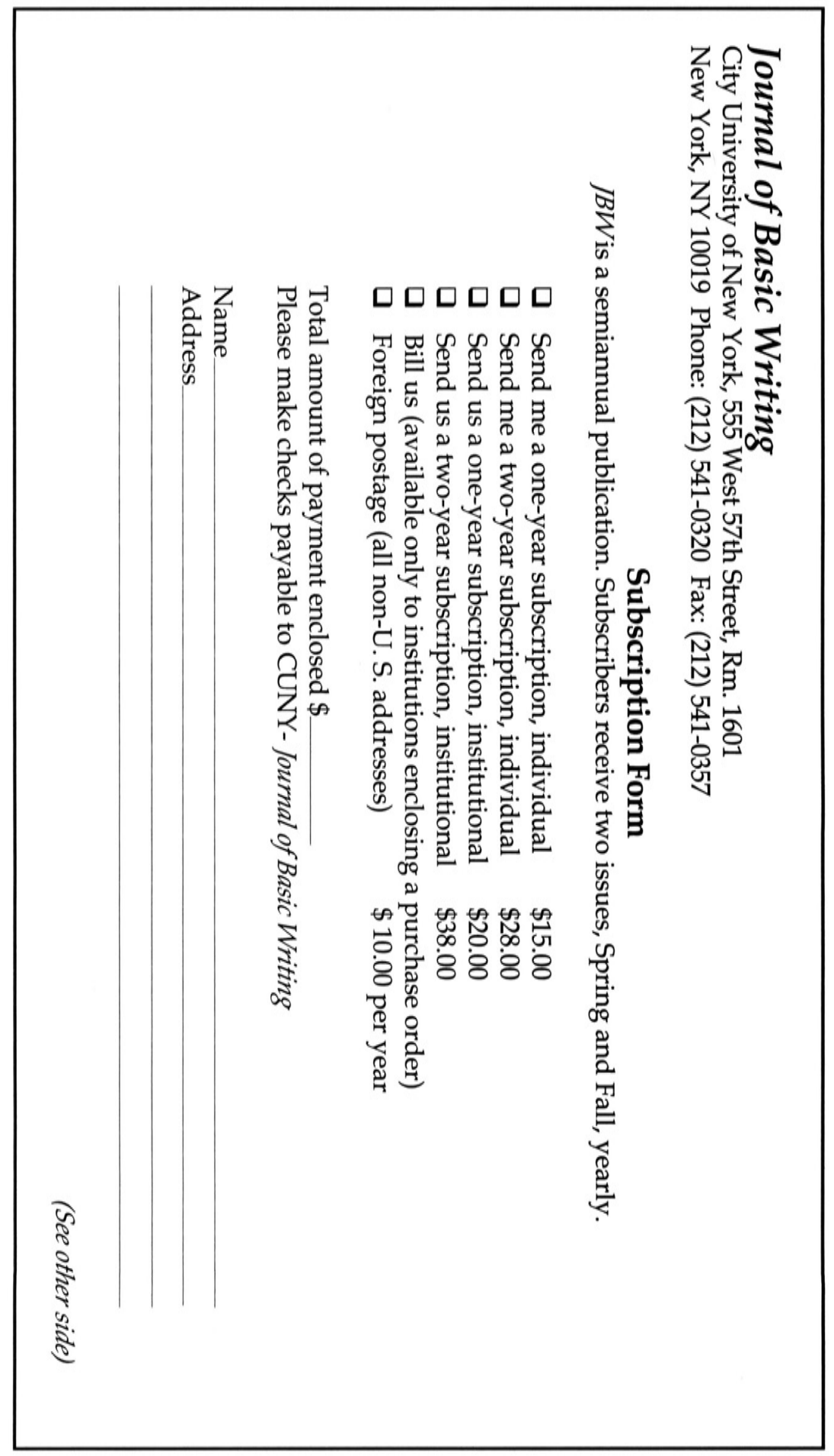




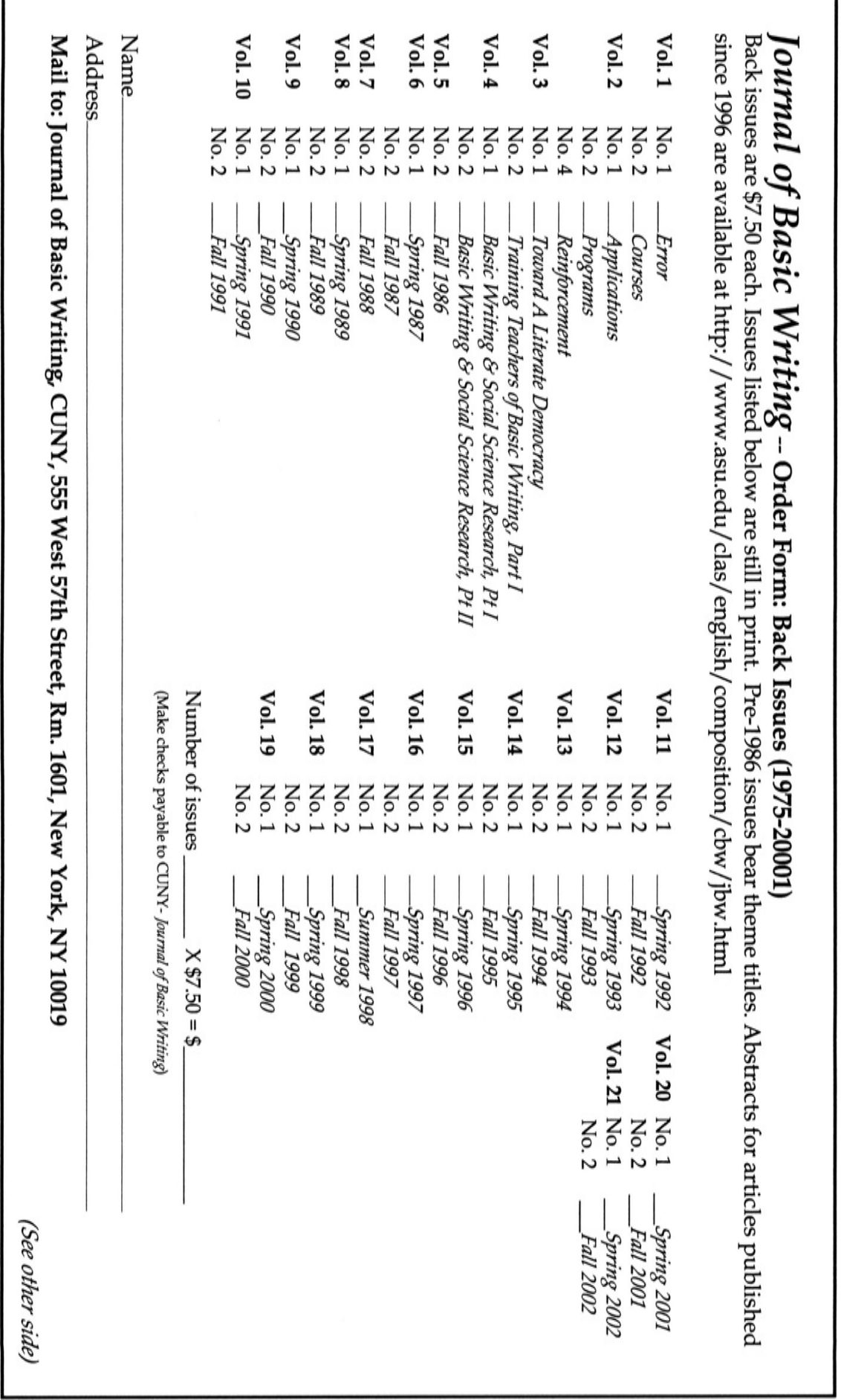





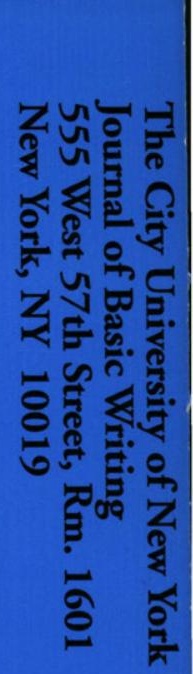

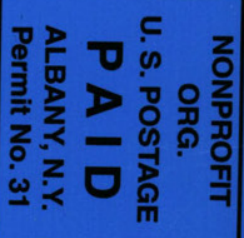

